\title{
The Gains from Input Trade with Heterogeneous Importers
}

\author{
Joaquin Blaum ${ }^{1}$, Claire Lelarge ${ }^{2} \&$ Michael Peters $^{3}$ \\ Working Paper \#612
}

December 2016

\begin{abstract}
Trade in intermediate inputs allows firms to reduce their costs of production and thus benefits consumers through lower prices of domestically produced goods. The extent to which firms participate in foreign input markets, however, varies substantially. We develop a methodology to measure how consumer prices are affected by input trade in environments that allow for such heterogeneity in import behavior. We provide a theoretical result that holds in a variety of settings: the firm-level data on value added and domestic expenditure shares in material spending are sufficient to compute changes in consumer prices. Approaches that abstract from firm level heterogeneity and rely on aggregate statistics give biased results. In an application to French data, we find that prices of manufacturing products would be $27 \%$ higher in the absence of input trade.
\end{abstract}

Keywords: Productivity, Imports, Gains from trade, Sufficient statistic approach.

JEL classification: F11, F12, F14, F62, D21, D22.

\footnotetext{
${ }^{1}$ Brown University. Email address: joaquin blaum@brown.edu

${ }^{2}$ Banque de France and CEPR. Email address: claire.lelarge@banque-france.fr

${ }^{3}$ Yale University and NBER. Email address: m.peters@yale.edu
} 


\section{NON-TECHNICAL SUMMARY ${ }^{4}$}

International trade benefits consumers by lowering the prices of the goods they consume. An important distinction is that between trade in final goods and trade in intermediate inputs. While the former benefits consumers directly (see Broda and Weinstein, 2006, for a quantification), the latter operates only indirectly. By allowing firms to access novel, cheaper or higher quality inputs, input trade reduces firms' production costs and thus the prices of locally produced goods. In this article, we quantify this indirect channel, which we refer to as the gains from input trade. In contrast to existing work which uses only aggregate information, we rely on firm-level data and show that doing so is quantitatively important.

A recent body of work has incorporated input trade into quantitative trade models - see e.g. Eaton, Kortum and Kramarz (2011), Caliendo and Parro (2015) and Costinot and Rodriguez-Clare (2014). These frameworks have the convenient implication that the welfare consequences of input trade are fully determined from aggregate data. This property, however, only holds when firms' import intensities are equalised - a feature that is at odds with the (French) data: While most firms spend less than $10 \%$ of their material spending in foreign inputs, some firms are heavy importers with shares exceeding $50 \%$. Does this micro-level heterogeneity affect our understanding of the aggregate gains from input trade? Our research shows that it does.

We focus on a widely used class of models of importing with heterogeneous firms, where firms' demand system between domestic and foreign inputs has a constant elasticity of substitution (CES) but we leave other aspects of the import environment unrestricted. This class includes recent contributions such as Gopinath and Neiman (2014), Antras, Fort and Tintelnot (2014) and Halpern, Koren and Szeidl (2015). In this context, we show that the effect of any shock to the input trading environment (e.g. a decline in trade costs or an improvement in foreign technology) on domestic consumer prices can be measured from firm-level data on import intensity and value added. In particular, knowledge of the joint distribution of firm size and the change in import intensities resulting from the shock is sufficient to measure the change in consumer prices of locally produced goods. While this result can be used to study any counterfactual, a focal point for the analysis is the case of a reversal to input autarky - a situation where firms are forced to buy their inputs domestically. Because in such case counterfactual import intensities are zero for all firms, the change in consumer prices between the observed equilibrium and input autarky can be directly measured from the observed micro data.

Why do the micro data matter? Import intensities are important because they summarize how production costs are affected by the use of imported inputs. A high material import share indicates that the firm benefits substantially from input trade - that is, it would see its unit cost increase substantially in the absence of trade. To aggregate these firm-level gains into the aggregate gains for local consumers, one needs to know each firm's importance in the economy. In particular, when

\footnotetext{
${ }^{4}$ We thank Costas Arkolakis, Arnaud Costinot, Dave Donaldson, Jonathan Eaton, Pablo Fajgelbaum, Lionel Fontagné, Penny Goldberg and Daniel Xu. We are grateful to seminar participants at Brown, Columbia, Dartmouth, LSE, Penn State, Princeton, Stanford, UCLA and Yale. A previous version of this paper circulated under the title "The Gains from Input Trade in Firm-Based Models of Importing". Blaum thanks the International Economics Section at Princeton for their support and hospitality.

This non-technical summary is also available from the VoxEu website: http://voxeu.org/article/measuringgains-input-trade
} 
relatively large firms tend to have high import shares, the aggregate gains from input trade will turn out to be large. Surprisingly, we find that in the French data, the relationship between import intensity and firm size is relatively flat and that there is substantial dispersion in import shares conditional on size. It is this data which crucially determines the magnitude of the gains from input trade.

Quantifying the gains from input trade. We apply our methodology to quantify the gains from input trade relative to autarky to the population of manufacturing firms in France. We allow for multiple sectors, with a rich structure of input-output linkages. We find that input trade reduces consumer prices of manufacturing products by $27.5 \%$. That is, the prices of manufacturing goods produced in France would be $27.5 \%$ higher if French firms were not allowed to source their inputs from abroad. Relying on aggregate data would result in a significantly different estimate. First, for given parameters, we find that ignoring the dispersion in firms' import intensities would result in overestimating the price index by $10 \%$. Second, an important parameter required by our methodology is the elasticity of substitution between domestic and foreign varieties. In our work, we identify it from firm-level data with a methodology akin to production function estimation. We find a value for this elasticity of 2.36 , which is substantially smaller than the estimates based on aggregate data (usually around 4). This effect leads to underestimating the price index gains by about $50 \%$. Hence, relying on aggregate data can lead to substantial biases in the estimates of the gains from input trade.

The effects of devaluations. Finally, we consider unobserved conterfactuals and focus on currency devaluations which makes imported inputs relatively more expensive. Because firms' import intensities after the shock are unobservable, we need to specify a full model of importing to predict them. We consider two types of models: one featuring firm level heterogeneity in both efficiency and fixed costs of importing, and the other featuring firm level heterogeneity in both efficiency and home bias in intermediate input usage. We calibrate them to salient features of the micro data and obtain that both models lead to very similar predictions in terms of prices: for example, a devaluation that decreases the aggregate trade share by $20 \%$ leads to an increase in the consumer price index of $7 \%$. Parametrizations of the models that are not disciplined by the micro data predict a change in consumer prices that are almost $20 \%$ higher. In contrast, we show that the predictions of the two models in terms of welfare are highly differentiated, mostly because they imply very different costs associated with the decision to import (the so-called "extensive margin"). 


\section{Résumé: Les gains liés au commerce de biens intermédiaires lorsque les importateurs sont hétérogènes}

Le commerce en biens intermédiaires permet aux entreprises de réduire leurs coûts de production. II bénéficie de ce fait au consommateur final par le biais des diminutions induites en termes de prix des biens produits domestiquement. Cependant, la participation des entreprises au commerce de biens intermédiaires est très hétérogène, de sorte que la quantification de ces effets est difficile. Nous développons une méthodologie de mesure de ces effets applicable à une large classe de cadres analytiques permettant de prendre en compte cette hétérogénéité des comportements et dérivons un résultat théorique valide dans cette classe de modèles: les distributions empiriques de valeur ajoutée et de part des dépenses intermédiaires réalisées en intrants domestiques sont des statistiques suffisantes pour évaluer les effets prix d'intérêt. Nous montrons qu'a contrario, les analyses qui reposent sur des quantités agrégées et font abstraction de ces deux dimensions d'hétérogénéité des entreprises conduisent à des évaluations biaisées. En appliquant notre méthodologie aux données françaises, nous obtenons que les prix des biens produits par l'industrie manufacturière seraient supérieurs de $27 \%$ en l'absence de commerce en biens intermédiaires.

Mots-clés : Productivité, Importations, Gains issus des échanges internationaux, Approche statistique suffisante. 


\section{Introduction}

International trade benefits consumers by lowering the prices of the goods they consume. An important distinction is that between trade in final goods and trade in intermediate inputs. While the former benefits consumers directly, the latter operates only indirectly : by allowing firms to access novel, cheaper or higher quality inputs from abroad, input trade reduces firms' production costs and thus the prices of locally produced goods. Because intermediate inputs account for about two thirds of the volume of world trade, understanding the normative consequences of input trade is important.

A recent body of work has incorporated input trade into quantitative trade models - see e.g. Eaton et al. (2011), Caliendo and Parro (2015) and Costinot and Rodríguez-Clare (2014). As in Arkolakis et al. (2012), these frameworks have the convenient implication that the change in consumer prices can be measured with aggregate data, and hence firm heterogeneity is irrelevant. This property, however, holds only when firms' import intensities are equalized - a feature that is at odds with the data. This is shown in Figure 1, which depicts the cross-sectional distribution of French manufacturing firms' domestic expenditure shares, i.e. the share of material spending allocated to domestic inputs. These differ markedly. While the majority of importers spend more than $90 \%$ of their material spending on domestic inputs, some firms are heavy importers with import shares exceeding $50 \%$. In this paper, we show that accounting for this heterogeneity in import behavior is crucial to quantify the aggregate effects of input trade.

[Figure 1 here]

We provide a methodology to measure the effect of input trade on consumer prices in environments with heterogeneous firms. Building on Feenstra (1994), we show that changes in consumer prices can be computed from firm-level data on domestic expenditure shares and value added and we provide a closed-form expression to do so. Importantly, this formula holds in a wide class of models of importing because it does not require specific assumptions on firms' import environment. By relying on firms' observable domestic shares, we circumvent the need to structurally estimate a particular model. We do not require information on the prices and qualities of the foreign inputs, nor how firms find their suppliers, e.g. whether importing is limited by fixed costs or a process of network formation. Therefore, many positive aspects of heterogenous import behavior across firms, such as the number of supplier countries or the distribution of spending across trading partners, are irrelevant for the link between input trade and consumer prices.

The intuition behind this result is simple. Consider the case of a reversal to input autarky, where firms can only use local inputs. Domestic consumers are affected by input trade solely through firms' unit costs. By inverting the demand system for intermediates, we can link each firm's unit cost to its spending pattern on domestic inputs. When such a demand system is CES, the unit cost reduction from importing can be recovered from the observable domestic expenditure share. In particular, a low domestic share indicates that the firm benefits substantially from input trade. In this sense, Figure 1 shows that the gains from input trade are heterogeneous at the micro-level. To correctly aggregate these firm-level gains, one needs to know each firm's relative importance in the economy. In a multi- 
sector general equilibrium trade model with intersectoral linkages, we show that the aggregate effect of input trade on the consumer price index is akin to a value-added weighted average of the firm-level gains. Hence, a key aspect of the data is how firm size and domestic shares correlate; if bigger firms feature lower domestic shares, the aggregate effects of input trade will turn out to be large.

The extent to which this is the case in France is depicted in Figure 2. In the left panel, we display the distribution of value added by import status. In the right panel, we focus on the population of importers and show the distribution of domestic shares for different value added quantiles. We see that importing and firm size are far from perfectly aligned. While importers are significantly larger than non-importers, there is ample overlap in their distribution of value added. Furthermore, conditional on importing, the relationship between import intensity and size is essentially flat and there is substantial dispersion in import shares conditional on size. We show that these patterns of heterogeneity are important : models that do not match the data displayed in Figure 2 yield biased estimates of the effects of input trade on consumer prices.

[Figure 2 here]

This logic can be extended to study shocks other than a reversal to input autarky. More precisely, we show that the effect of any shock to the import environment (e.g. a trade liberalization episode or an increase in foreign input prices) on the domestic consumer price index is fully determined from the joint distribution of value added and the changes in firms' domestic shares.

A key aspect of our methodology is that we can measure firms' unit cost changes independently of the macroeconomic environment. We show that in a wide class of models of importing the micro and macro parts of the model can be effectively separated and we exploit this property to easily handle rich macroeconomic settings. In particular, we can consider multi-sector general equilibrium environments with realistic input-output linkages and different assumptions about competition in output markets. We consider both a CES monopolistic competition model and a setting with variable markups in the spirit of Edmond et al. (2015) and Atkeson and Burstein (2008). ${ }^{1}$ We show that the micro data on firm size and domestic expenditure shares is sufficient to compute changes in consumer prices in these different settings and we provide closed-form expressions to do so.

We apply our methodology to data from the population of manufacturing firms in France. We first measure the change in consumer prices relative to autarky. We estimate the distribution of tradeinduced changes in unit costs across firms implied by the distribution of domestic expenditure shares displayed in Figure 1 above. While the median unit cost reduction is $11 \%$, it exceeds $80 \%$ for $10 \%$ of the firms. We then aggregate these firm-level gains to compute the consumer price gains by relying on the joint distribution of domestic shares and value added displayed in Figure 2 above. We find that consumer prices of manufacturing products would be $27 \%$ higher if French firms were not allowed

1. Our methodology can be applied to settings with variable markups other than the one of Atkeson and Burstein (2008). We only require that mark-ups can be expressed as a function of the distribution of firms' relative prices. 
to source intermediate inputs from abroad. ${ }^{2} 3$ There are three reasons why the consumer price gains exceed the median firm-level gains, which go back to the above-mentioned empirical patterns. First, the dispersion in firm-level gains, displayed in Figure 1, is valued by consumers given their elastic demand. Second, the weak but positive relation between import intensity and firm size, shown in Figure 2, is beneficial because the endogenous productivity gains from importing and firm efficiency are complements. Third, there are important linkages between firms whereby non-importers buy intermediates from importing firms. ${ }^{4}$

We then calculate these consumer price gains in the context of aggregate models. By relying on aggregate statistics, instead of the micro data in Figures 1 and 2, these models yield biased results. We first show theoretically that, while the magnitude of this bias depends on the underlying micro data, its sign only depends on a small set of parameters. In particular, aggregate models are upward biased whenever the elasticity of substitution between domestic and foreign inputs is small, or the elasticity of consumers' demand is large. In our application to the French data, we find that aggregate models overestimate the change in consumer prices relative to autarky by about $10 \%$.

Finally, we turn to counterfactuals other than autarky. In particular, we study shocks that make foreign inputs more expensive (e.g. a currency devaluation). To do so, we need to fully specify the import environment to predict firms' domestic shares after the shock. We consider a standard framework where importing is subject to fixed costs and evaluate quantitatively whether the micro data on size and domestic shares is important for the estimates of the effects. More precisely, we compare different parametrizations of the model which vary in the extent to which they match the data displayed in Figures 1 and 2. First, we find that versions of the model that do not match the data in Figures 1 and 2 tend to over-predict the increase in consumer prices by 13-18\%. For example, models where efficiency is the single source of heterogeneity imply a one-to-one, and hence counterfactual, relation between firm size and domestic shares and predict effects that are too large. Second, models that match the data in Figures 1 and 2 predict very similar effects of the shock. Conditional on the observable micro data, the details of the import environment, e.g. whether firms differ in fixed costs or in their efficiency as importers, are not crucial to predict consumer prices. These results suggest that the sufficiency of the data in Figures 1 and 2, which holds exactly for the case autarky, quantitatively extends to other counterfactuals.

An important parameter throughout the analysis is the elasticity of substitution between domestically sourced and imported inputs. Because firm-based models do not generate a standard gravity equation for aggregate trade flows, we devise a strategy to identify this elasticity from firm-level variation. By expressing firms' output in terms of material spending, the domestic share appears as

2. Using a related methodology, Amiti et al. (2016) also measure the change in a consumer price index resulting from a shock to firms' ability to source inputs from abroad. They focus on the decline in input tariffs in China after entry into the WTO. They find that the manufacturing price index in the US of goods sourced from China fell by $2 \%$ as a result of this shock.

3. Allowing for variable markups yields very similar estimates for the change in consumer prices.

4. When we include the non-manufacturing sector, the consumer price gains amount to $9 \%$ instead of $27 \%$. The reason is that manufacturing accounts for a relatively small share in aggregate consumer spending and that production links between the manufacturing and the non-manufacturing sector, which we assume to be closed to international trade, are limited. 
an additional input in the production function. Because the sensitivity of firm revenue to domestic spending depends on the elasticity of substitution, we can estimate this parameter with methods akin to production function estimation. To address the endogeneity concern that unobserved productivity shocks might lead to both lower domestic spending and higher revenue, we use changes in the world supply of particular varieties as an instrument for firms' domestic spending. Using the variation across firms is important as we obtain a value for the elasticity close to two. Estimation approaches that rely on aggregate data typically find values closer to five. Using such aggregate elasticity would lead to under-estimating the change in consumer prices relative to autarky by $65 \%$.

Related Literature. Our paper contributes to the literature that measures how consumer prices are affected by international trade - see Feenstra (1994), Broda and Weinstein (2006) and Arkolakis et al. (2012). This literature studies trade in final goods and uses observable expenditure shares to measure the change in the consumer price index. We apply a similar methodology to the context of firms importing intermediate inputs from abroad. ${ }^{5}$ In this environment, two important differences arise. First, we measure the distribution of firms' unit costs rather than final good prices directly. To do so, we exploit firm-level customs data which allows us to compute expenditure shares at the micro level. Second, to map the firms' units costs into the consumer price index, we specify a macroeconomic environment including the structure of product market competition and input-output linkages. We find that, when firms' import intensities are heterogeneous, the results in Arkolakis et al. (2012) do not apply : aggregate statistics are no longer sufficient to compute the change in consumer prices and the entire distribution of domestic shares and firm size is required. We provide a formula to map this distribution to the change in the consumer price index.

There is a recent literature that studies input trade in quantitative models with firm heterogeneity - see e.g. Halpern et al. (2015), Antràs et al. (2014) or Eslava et al. (2015). Halpern et al. (2015) is particularly related, because they study the relationship between input trade and firm productivity. However, while they analyze input trade by fully specifying and estimating a structural model of importing, we follow a different approach. We measure firms' unit cost changes directly from micro data on domestic expenditure shares. Our approach has two benefits. First, we can be agnostic about several components of the theory. Hence, our estimates do not rely on particular assumptions about firms' import environment, such as the qualities of foreign inputs or whether firms' extensive margin is limited by fixed costs. Second, our methodology is particularly useful to study the aggregate implications of input trade, because we can take general equilibrium effects into account and allow for input-output linkages across industries and variable mark-ups across firms. Incorporating these features into a structural estimation would entail substantial computational complexities. Using our methodology, we can incorporate these elements into the analysis easily. The limitation is that our formula can be directly applied only in situations where expenditure shares are observed, e.g. past policies or a reversal to autarky (see Costinot and Rodríguez-Clare (2014)).

5. The analogy with Feenstra (1994) is helpful. That paper shows that the expenditure share on continuing varieties is sufficient to measure the change in consumer prices. By treating domestic varieties as continuing varieties, we can link firms' domestic expenditure shares to their unit costs. 
Antràs et al. (2014) are mostly interested in explaining positive aspects of firms' sourcing behavior. They develop a static model of importing that can rationalize a number of empirical regularities of US importers, such as the relationship between firm size and the number of sourcing countries and the interdependence of firms' market entry decisions. In doing so, they provide a numerical algorithm to deal with the combinatorial problem associated with the extensive margin of importing in models with country-specific fixed costs. Other papers have studied import behavior in dynamic environments, e.g. Lu et al. (2016) who analyzes how firms accumulate their suppliers. In contrast to these contributions, we focus on the normative aspects of input trade. We characterize the effect of importing on consumer prices in a class of models which includes the above contributions and show that, to study observed policies or a reversal to autarky, the solution to the firms' extensive margin problem - static or dynamic - is not required.

In a recent paper, Amiti et al. (2016) use a related methodology to study the effect of China's WTO entry on the U.S. consumer price index. In particular, they focus on the reductions in Chinese input tariffs and their effect on Chinese exporters' productivity growth (see Amiti and Konings (2007)). They also express changes in firms' production costs as a function of changes in expenditure shares. However, they use data on the allocation of spending across imported inputs and therefore measure the efficiency gains from firms expanding their range of foreign varieties. In contrast, we focus on firms' substituting between domestic and foreign varieties.

Our paper is also related to Gopinath and Neiman (2014). They study the 2001 Argentine currency devaluation and present a set of empirical facts on the heterogeneous responses of importers. They uncover a novel margin of adjustment by which firms stop importing particular products from abroad while still remaining active in international markets. They also stress how heterogeneity in import behavior is important for the link between input trade and aggregate welfare. To quantify the aggregate consequences of the currency devaluation they calibrate a static model of importing. In contrast, we exploit the information in firms' domestic expenditure shares to measure changes in consumer prices directly from the data.

Finally, a number of empirically oriented papers study trade liberalization episodes to provide evidence on the link between imported inputs and firm productivity - see e.g. Amiti and Konings (2007), Goldberg et al. (2010) or Khandelwal and Topalova (2011). ${ }^{6}$ Our results are complementary to this literature. Our sufficiency result implies that in a wide class of models of importing the static productivity gains from the policy can be measured from changes in firms' domestic expenditure shares. Put differently, by focusing on the domestic expenditure share as the outcome of interest (instead of standard measures of firm productivity), one can disentangle the static from the dynamic effects of the policy. If micro data on value added is also available, our results can be used to gauge the full effect of the policy on consumer prices in general equilibrium.

The remainder of the paper is structured as follows. Section 2 lays out the theory that we consider to measure the effect of input trade on firms' unit costs and consumer prices. The application to

6. Kasahara and Rodrigue (2008) study the effect of imported intermediates on firm productivity through a production function estimation exercise. See also the recent survey in De Loecker and Goldberg (2013) for a more general empirical framework to study firm performance in international markets. 
France is contained in Sections 3. Section 4 concludes.

\section{Theory}

In this section, we lay out the theoretical framework of importing that we use to measure the effects of input trade. We show that the information contained in firms' domestic spending shares and size is sufficient to calculate the impact of shocks to the import environment on consumer prices. In particular, a wide class of models predicts the exact same change in consumer prices given the micro data. Models relying on aggregate data give biased answers. For the special case of autarky, we characterize this bias analytically and provide a simple parametric condition to determine its sign.

\subsection{The Environment}

Micro : Firms and Input Trade. Consider the problem of a firm, which we label as $i$, that uses local and foreign inputs according to the following production structure :

$$
\begin{aligned}
y & =\varphi_{i} f(l, x)=\varphi_{i} l^{1-\gamma} x^{\gamma} \\
x & =\left(\beta_{i}\left(q_{D} z_{D}\right)^{\frac{\varepsilon-1}{\varepsilon}}+\left(1-\beta_{i}\right) x_{I}^{\frac{\varepsilon-1}{\varepsilon}}\right)^{\frac{\varepsilon}{\varepsilon-1}} \\
x_{I} & =h_{i}\left(\left[q_{c i} z_{c}\right]_{c \in \Sigma_{i}}\right) .
\end{aligned}
$$

where $\gamma, \beta_{i} \in(0,1)$ and $\varepsilon>1 .{ }^{7}$ Hence, the firm combines intermediate inputs $x$ with primary factors $l$, which we for simplicity refer to as labor, in a Cobb-Douglas fashion with efficiency $\varphi_{i} .{ }^{8}$ Intermediate inputs are a CES composite of a domestic variety, with quantity $z_{D}$ and quality $q_{D}$, and a foreign input bundle $x_{I}$, with relative efficiency for domestic inputs given by $\beta_{i}$. We refer to $\beta_{i}$ as the firm's home-bias. The firm has access to foreign inputs from multiple countries, whose quantity is denoted by $\left[z_{c}\right]$, which may differ in their quality $\left[q_{c i}\right]$, where $c$ is a country index. ${ }^{9}$ Foreign inputs are aggregated according to a constant returns to scale, potentially firm-specific production function $h_{i}(\cdot) .{ }^{10}$ An important endogenous object in the production structure is the set of foreign countries the firm sources from, which we denote by $\Sigma_{i}$ and henceforth refer to as the sourcing strategy. We do not impose any restrictions on how $\Sigma_{i}$ is determined until Section 3.4. As far as the market

7. While the case of $\varepsilon \leq 1$ can also be accommodated by the theory, it implies that all firms are importers - a feature that is inconsistent with the data.

8. We consider a single primary factor for notational simplicity. It will be clear below that our results apply to $l=g\left(l_{1}, l_{2}, \ldots, l_{T}\right)$, where $g(\cdot)$ is a constant returns to scale production function and $l_{j}$ are primary factors of different types. In the empirical application of Section 3, we consider labor and capital.

9. We discuss below how to generalize the results of this section when the Cobb-Douglas and CES functional forms in (1)-(2) are not satisfied. In particular we consider the cases where (1) takes a CES form so that intermediate spending shares are not equalized, and a multi-product version of (2), where domestic and foreign inputs are closer substitutes within a product nest. We abstract from the product dimension in the main text because we do not observe firms' domestic spending at the product level.

10. Note that this setup nests the canonical Armington structure where all countries enter symmetrically in the production function. Additionally, this setup allows for an interaction between quality flows and the firm's efficiency, i.e. a form of non-homothetic import demand that is consistent with the findings in Kugler and Verhoogen (2011) and Blaum et al. (2013). 
structure is concerned, we assume that the firm takes prices of domestic and foreign inputs $\left(p_{D},\left[p_{c i}\right]\right)$ as parametric, i.e. it can buy any quantity at given prices. Note that $p_{c i}$ includes all variable trade costs. Similarly, we assume that labor can be hired frictionlessly at a given wage $w$.

This setup describes a class of models of importing that have been used in the literature. First, it nests aggregate quantitative trade models (Eaton et al., 2011; Costinot and Rodríguez-Clare, 2014; Caliendo and Parro, 2015). In these models, firms' import intensities are equalized. In the above setup, this corresponds to the case where firms' sourcing strategies are equalized, all firms face the same prices and qualities and there is no heterogeneity in the home-bias (i.e. $\Sigma_{i}=\Sigma,\left[p_{c i}, q_{c i}\right]=\left[p_{c}, q_{c}\right]$, $\left.\beta_{i}=\beta\right) .{ }^{11}$ Second, it nests a variety of recent examples of firm-based import models, e.g. Halpern et al. (2015), Gopinath and Neiman (2014), Antràs et al. (2014), Kasahara and Rodrigue (2008), Lu et al. (2016), Amiti et al. (2014) and Goldberg et al. (2010). ${ }^{12}$ A unifying feature of these models is that firms engage in input trade because it lowers their unit cost of production via love of variety and quality channels. Additionally, these contributions generate heterogeneity in firms' import intensities through variation in the sourcing strategies $\Sigma_{i}$. Characterizing firms' optimal sourcing strategy $\Sigma_{i}$ in economies with fixed costs can be non-trivial and requires stringent assumptions - see Antràs et al. (2014). One of the main results of this paper is that, to measure the effect of input trade on consumer prices, the solution to this problem is not required.

The assumptions made above, most importantly parametric input prices and constant returns to scale, guarantee that the unit cost is constant given the sourcing strategy $\Sigma$. This separability between the intensive and extensive margin allows us to characterize the unit cost at the firm level without solving for the optimal sourcing set nor specifying the demand the firm faces. Formally, the unit cost is given by

$$
u\left(\Sigma_{i} ; \varphi_{i}, \beta_{i},\left[q_{c i}\right],\left[p_{c i}\right], h_{i}\right) \equiv \min _{z, l}\left\{w l+p_{D} z_{D}+\sum_{c \in \Sigma_{i}} p_{c i} z_{c} \text { s.t. } \varphi_{i} l^{1-\gamma} x^{\gamma} \geq 1\right\}
$$

subject to (2)-(3). For simplicity, we refer to the unit cost as $u_{i}$. Standard calculations imply that there is an import price index given by

$$
A\left(\Sigma_{i},\left[q_{c i}\right],\left[p_{c i}\right], h_{i}\right) \equiv m_{I} / x_{I}
$$

where $m_{I}$ denotes import spending and $x_{I}$ is the foreign import bundle defined in (3). Importantly, conditional on $\Sigma_{i}$, this price-index is exogenous from the point of view of the firm and we henceforth denote it by $A_{i}\left(\Sigma_{i}\right)$. Next, given the CES production structure between domestic and foreign inputs,

11. Under these conditions, our setup implies an aggregate import demand system that is equivalent to the one generated by the quantitative trade models mentioned above.

12. To nest the contributions that allow for multiple products (see e.g. Halpern et al. (2015) or Goldberg et al. (2010)), our production function needs to be extended. In particular, the intermediate input bundle $x$ would be given by $x=\prod_{k} x_{k}^{\eta_{k}}$. Here $x_{k}$ denotes the intermediate input bundle for product $k$, which is given by equation (2). In Section 6.1 in the Appendix, we extend the theoretical results of this section to this case. Regarding Antràs et al. (2014), note that they consider a model of importing in the spirit of Eaton and Kortum (2002) instead of a variety-type model. Their Fréchet assumption implies that these models are isomorphic. 
the price index for intermediate inputs is given by the familiar expression

$$
Q_{i}\left(\Sigma_{i}\right)=\left(\beta_{i}^{\varepsilon}\left(p_{D} / q_{D}\right)^{1-\varepsilon}+\left(1-\beta_{i}\right)^{\varepsilon} A_{i}\left(\Sigma_{i}\right)^{1-\varepsilon}\right)^{\frac{1}{1-\varepsilon}}
$$

Because $A_{i}\left(\Sigma_{i}\right)$ is decreasing in the size of $\Sigma_{i}{ }^{13}$, firms with more trading opportunities abroad benefit from lower input prices. Additionally, this price index depends on a number of unobserved parameters related to the trading environment, e.g. the prices and qualities of the foreign inputs $\left[q_{c i}, p_{c i}\right]$ and firms' import technology $h_{i}$. Instead of imposing sufficient structure to be able to estimate $A_{i}\left(\Sigma_{i}\right)$ and $Q_{i}\left(\Sigma_{i}\right)$, we use the fact that the unobserved price index $Q_{i}\left(\Sigma_{i}\right)$ is related to the observed expenditure share on domestic inputs $s_{D i}$ via

$$
s_{D i}=\left(Q_{i}\left(\Sigma_{i}\right)\right)^{\varepsilon-1} \beta_{i}^{\varepsilon}\left(\frac{q_{D}}{p_{D}}\right)^{\varepsilon-1} .
$$

It then follows that the firm's unit cost is given by ${ }^{14}$

$$
u_{i}=\frac{1}{\varphi_{i}} w^{1-\gamma}\left(Q_{i}\left(\Sigma_{i}\right)\right)^{\gamma}=\frac{1}{\tilde{\varphi}_{i}} \times\left(s_{D i}\right)^{\frac{\gamma}{\varepsilon-1}} \times\left(\frac{p_{D}}{q_{D}}\right)^{\gamma} w^{1-\gamma}
$$

where $\tilde{\varphi}_{i} \equiv \varphi_{i} \beta_{i}^{\frac{\varepsilon \gamma}{\varepsilon-1}}$. Equation (6) is a sufficiency result : conditional on the firm's domestic expenditure share $s_{D i}$, no aspects of the import environment, including the sourcing strategy $\Sigma_{i}$, the prices $p_{c i}$, the qualities $q_{c i}$ or the technology $h_{i}$, affect the unit cost. The domestic expenditure share conveniently encapsulates all the information from the import environment that is relevant for the unit cost.

This equation allows us to express trade-induced changes in firms' unit costs in terms of observables. To see this, consider an arbitrary shock to the import environment, i.e. a change in foreign prices, qualities, trade-costs or the sourcing strategy. The change in the firm's unit cost resulting from the shock, holding prices $\left(p_{D}, w\right)$ constant, is given by

$$
\left.\ln \left(\frac{u_{i}^{\prime}}{u_{i}}\right)\right|_{p_{D}, w}=\frac{\gamma}{1-\varepsilon} \times \ln \left(\frac{s_{D i}}{s_{D i}^{\prime}}\right),
$$

where $u_{i}^{\prime}$ and $s_{D i}^{\prime}$ denote the unit cost and the domestic expenditure share after the shock. Intuitively, an adverse trade shock, such as an increase in foreign prices or a reduction in the set of trading partners, hurts the firm by increasing the price index of intermediate inputs $Q_{i}$. Conditional on an import demand system, we can invert the change in this price index from the change in the domestic expenditure share. ${ }^{15}$ Hence, the effect of input trade on firm productivity can be directly measured

13. Formally, $A_{i}\left(\Sigma_{i}\right) \leq A_{i}\left(\Sigma_{i}^{\prime}\right)$ whenever $\Sigma_{i} \supseteq \Sigma_{i}^{\prime}$.

14. With a slight abuse of notation we suppress the constant $\left(\frac{1}{1-\gamma}\right)^{1-\gamma}\left(\frac{1}{\gamma}\right)^{\gamma}$ in the definition of (6).

15. Equation (7) is akin to a firm-level analogue of Arkolakis et al. (2012). In the same vein as consumers gain purchasing power by sourcing cheaper or complementary products abroad, firms can lower the effective price of material services by tapping into foreign input markets. While this analogy works at the firm-level (in the sense that the change in a home share is a sufficient statistic for a given outcome), we note that it breaks at the aggregate level. We show below, in the context of a macro model, that there is no aggregate statistic that is sufficient to measure changes in 
from the data, without having to fully specify and estimate a structural model of importing.

While (7) is a partial equilibrium result, we note that it identifies the dispersion in unit cost changes across firms in general equilibrium and hence the distributional effects of input trade. ${ }^{16}$ Importantly, (7) implies that all models in our class predict the exact same change in unit costs given the change in the firm's spending pattern and parameters. In the Appendix, we show how the result in (7) can be extended to a more general production function than (1)-(3). In particular, we consider the cases where (i) domestic and foreign inputs are not combined in a CES fashion, (ii) the output elasticity of material inputs is not constant, and (iii) firms source multiple products from different countries. ${ }^{17}$

This result implies that domestic expenditure shares are the crucial empirical object to learn about the relationship between input trade and production costs. Other micro moments such as characteristics of the set of sourcing partners, the distribution of expenditure across sourcing countries, or whether or not international sourcing is hierarchical, while potentially interesting per se, are not important for the relationship between input trade and unit costs. One special case of (7) where this is especially apparent is input autarky. In that case, $s_{D i}^{\prime}=1$ and (7) reduces to $\frac{\gamma}{1-\varepsilon} \times \ln \left(s_{D i}\right)$. Hence, Figure 1 fully summarizes how each importer's unit cost (relative to a domestic producer) would change if forced to source its input only domestically. ${ }^{18}$

Macro : Consumer Prices in General Equilibrium. We now embed the above model of firm behavior in a macroeconomic environment to link input trade to consumer prices. The micro result in (7) above is crucial as it allows us to measure the firm-level unit cost reductions directly from the micro data, albeit in partial equilibrium. To aggregate these firm-level gains taking general equilibrium effects into account, we need to take a stand on two aspects of the macroeconomic environment : (i) the nature of input-output linkages across firms and (ii) the degree of pass-through, which depends on consumers' demand system and the output market structure. While the former determines the effect of trade on the price of domestic inputs $p_{D}$, the latter determines how much of the trade-induced cost reductions actually benefit consumers. ${ }^{19}$

As a baseline case, we consider a multi-sector CES monopolistic competition environment. Below

consumer prices. Instead the entire distribution of firms' domestic shares is required.

16. To see this, note that (6) implies that $u_{i} / u_{j}$ does not depend on $p_{D}, w$.

17. See Section 6.1 of the Appendix for details. There we also discuss what additional data, relative to the result in (7), is required to perform counterfactual analysis in these cases. For the multi-product version of our model, (7) generalizes to $\left.\ln \left(u_{i}^{\prime} / u_{i}\right)\right|_{p_{D}, w}=\frac{\gamma}{1-\varepsilon} \sum_{k=1}^{K} \eta_{k} \ln \left(s_{D i}^{k} / s_{D i}^{k^{\prime}}\right)$, where $\eta_{k}$ are the Cobb-Douglas weights in the intermediate input production (see footnote 12). In our application, we consider the setup in (1)-(3) because we do not observe firms' domestic shares at the product level.

18. The result in (7) can be useful for applied empirical work, e.g. to study the effect of trade liberalizations on firm productivity (e.g. Pavcnik (2002), Amiti and Konings (2007), or De Loecker et al. (2016)). According to (7), the causal effect of the policy on firms' unit costs can be measured from the change in firms' domestic shares which are due to the policy. See also footnote 22. We also note that opening up to trade might induce firms to engage in productivity enhancing activities that directly increase efficiency $\varphi$, such as R\&D - see e.g. Eslava et al. (2015). Such increases in complementary investments are not encapsulated in (7), which only measures the static gains from trade holding efficiency fixed.

19. To isolate the effect of input trade, we abstract from trade in final goods. Domestic consumers therefore benefit from trade openness only indirectly through firms' cost reductions. 
we generalize our results to a setting with variable mark-ups. There are $S$ sectors, each comprised of a measure $N_{s}$ of firms which we treat as fixed. There is a unit measure of consumers who supply $L$ units of labor inelastically and whose preferences are given by

$$
U=\prod_{s=1}^{S} C_{s}^{\alpha_{s}} \text { and } C_{s}=\left(\int_{0}^{N_{s}} c_{i s}^{\frac{\sigma_{s}-1}{\sigma_{s}}} d i\right)^{\frac{\sigma_{s}}{\sigma_{s}-1}}
$$

where $\alpha_{s} \in(0,1), \sum_{s} \alpha_{s}=1$ and $\sigma_{s}>1$. Firm $i$ in sector $s=1, \ldots, S-1$ produces according to the production technology given by (1)-(3) above, where the structural parameters $\varepsilon$ and $\gamma$ are allowed to be sector-specific. As before, we do not assume any particular mechanism of how the extensive margin of trade is determined nor impose any restrictions on $\left[p_{c i}, q_{c i}, h_{i}, \beta_{i}\right]$. That is, the distribution of prices and qualities across countries and the aggregator of foreign inputs can take any form. Additionally, these parameters can vary across firms in any way. We assume sector $S$ to be comprised of firms that do not trade inputs and refer to it as the non-manufacturing sector. ${ }^{20}$

We assume the following structure of roundabout production, which is also used in Caliendo and Parro (2015). Firms use a sector-specific domestic input that is produced using the output of all other firms in the economy according to

$$
z_{D s}=\prod_{j=1}^{S} Y_{j s}^{\zeta_{j}^{s}} \text { and } Y_{j s}=\left(\int_{0}^{N_{j}} \frac{\sigma_{j}-1}{\sigma_{j}} d \nu\right)^{\frac{\sigma_{j}}{\sigma_{j}-1}}
$$

where $z_{D s}$ denotes the bundle of domestic inputs, $\zeta_{j}^{s}$ is a matrix of input-output linkages with $\zeta_{j}^{s} \in[0,1]$ for all $s$ and $j$ and $\sum_{j=1}^{S} \zeta_{j}^{s}=1$ for all $s$, and $y_{\nu j s}$ is the output of firm $\nu$ in sector $j$ demanded by a firm in sector $s$. In this setting, the price of the domestic input $p_{D s}$ is endogenous so that domestic firms are affected by trade policy via their purchases of intermediate inputs from importers.

Building on our result from above, we can express the effect of input trade on the consumer price index associated with (8) in terms of observables. Given the expression for firms' unit costs (7), the CES demand and monopolistic competition structure, the consumer price index for sector $s$ is given by

$$
P_{s}=\mu_{s}\left(\int_{0}^{N_{s}} u_{i}^{1-\sigma_{s}} d i\right)^{\frac{1}{1-\sigma_{s}}}=\mu_{s}\left(\frac{p_{D s}}{q_{D s}}\right)^{\gamma_{s}} \times\left(\int_{0}^{N_{s}}\left(\frac{1}{\tilde{\varphi}_{i}}\left(s_{D i}\right)^{\gamma_{s} /\left(\varepsilon_{s}-1\right)}\right)^{1-\sigma_{s}} d i\right)^{\frac{1}{1-\sigma_{s}}}
$$

where $\mu_{s} \equiv \sigma_{s} /\left(\sigma_{s}-1\right)$ is the mark-up in sector $s$ and we treat labor as the numeraire. Equation (10) shows that, holding domestic input prices fixed, the effect of input trade on consumers' purchasing power is an efficiency-weighted average of the firm-level gains. While firm efficiency $\tilde{\varphi}_{i}$ is not observed,

20. We introduce this sector for empirical reasons. In the next section, we consider an application to France where we do not have data on firm-level imports outside of the manufacturing sector. To make aggregate statements about input trade, we take the non-manufacturing sector into account. See Section 3 for details. 
it can be recovered up so scale from data on value added and domestic spending as ${ }^{21}$

$$
v a_{i} \propto\left(\tilde{\varphi}_{i}\left(s_{D i}\right)^{\gamma_{s} /\left(1-\varepsilon_{s}\right)}\right)^{\sigma_{s}-1} .
$$

Consider again any shock to the import environment, i.e. a change in foreign prices, qualities, tradecosts or the sourcing strategies. Combining (10) and (11), the change in the sectoral consumer price index due to the shock is given by

$$
\ln \left(P_{s}^{\prime} / P_{s}\right)=\gamma_{s} \ln \left(p_{D s}^{\prime} / p_{D s}\right)+\frac{1}{1-\sigma_{s}} \ln \left(\int_{0}^{N_{s}} \omega_{i}\left(\frac{s_{D i}}{s_{D i}^{\prime}}\right)^{\frac{\gamma_{s}}{1-\varepsilon_{s}}\left(1-\sigma_{s}\right)} d i\right)
$$

where $\omega_{i}$ denotes firm i's share in sectoral value added. Equation (12) shows that shocks to firms' ability to source inputs from abroad affect consumer prices through two channels. First, there is a direct effect stemming from firms in sector $s$ changing their intensity to source inputs internationally - this is the last term in (12). Importantly, this term can be directly computed from the micro data. Second, there is an indirect effect as the price of domestic inputs changes because of input-output linkages, $p_{D s}^{\prime} / p_{D s}$. Because of the structure of roundabout production in (9), this indirect effect can be computed from the system of equations in (12). This is the content of our main proposition.

Proposition 1. Consider a shock to firms' import environment and let $P$ and $P^{\prime}$ be the consumer price indices before and after the shock. Define the direct cost reduction of input trade in sector $s$ as

$$
\Lambda_{s}=\frac{1}{1-\sigma_{s}} \ln \left(\int_{0}^{N_{s}} \omega_{i}\left(\frac{s_{D i}}{s_{D i}^{\prime}}\right)^{\frac{\gamma_{s}}{1-\varepsilon_{s}}\left(1-\sigma_{s}\right)} d i\right)
$$

The change in consumer prices is then given by

$$
\ln \left(\frac{P^{\prime}}{P}\right)=\alpha^{\prime}\left(\Gamma(\mathcal{I}-\Xi \times \Gamma)^{-1} \Xi+\mathcal{I}\right) \times \Lambda
$$

where $\Lambda=\left[\Lambda_{1}, \Lambda_{2}, \ldots, \Lambda_{S}\right], \Lambda_{s}$ is given in (13), $\Xi=\left[\zeta_{j}^{s}\right]$ is the $S \times S$ matrix of production interlinkages, $\alpha$ is the $S \times 1$ vector of demand coefficients, $\mathcal{I}$ is an identity matrix and $\Gamma=$ diag $(\gamma)$, where $\gamma$ is the $S \times 1$ vector of input intensities.

In the special case of a reversal to input autarky, the increase in consumer prices is given by (14), where $\Lambda_{s}$ is given by

$$
\Lambda_{s}^{A u t}=\frac{1}{1-\sigma_{s}} \ln \left(\int_{0}^{N_{s}} \omega_{i} s_{D i}^{\frac{\gamma_{s}}{1-\varepsilon_{s}}\left(1-\sigma_{s}\right)} d i\right) \geq 0 .
$$

Démonstration. See Section 6.2 in the Appendix.

Proposition 1 shows that the micro data on value added and changes in domestic shares is sufficient to fully characterize the consumer price consequences of trade-induced shocks in the class

21. This assumes that the data on value added does not record firms' expenses to attain their sourcing strategies. If it did, one could express (11) in terms of sales or employment. 
of models considered in this section. In particular, the change in consumer prices can be directly computed by using (13) and (14) given parameters for consumer demand and production. Moreover, these equations highlight that the micro data is required only to compute the direct cost reductions of input trade, i.e. $\Lambda_{s}$. The other terms in (14) reflect the general equilibrium effect of input-output linkages across firms, by which changes in importers' unit costs diffuse through the economy. To see this, note that in the case of a single sector economy (14) simplifies to

$$
\ln \left(\frac{P^{\prime}}{P}\right)=\frac{\Lambda}{1-\gamma}
$$

that is, the change in the consumer price index is simply given by the direct cost reduction $\Lambda$, inflated by $1 /(1-\gamma)$ to capture the presence of roundabout production.

A key aspect of Proposition 1 is that it allows us to measure changes in consumer prices without specifying many details of the micro part of the model. In particular, we do not have to parametrize (and estimate) the import environment $\left[p_{c i}, q_{c i}, h_{i}, \beta_{i}\right]$ or characterize firms' sourcing strategy $\Sigma_{i}$. Hence, we do not need to take a stand on whether firms' extensive margin is shaped by the presence of fixed costs or a process of search or network formation. These aspects are irrelevant for consumer prices conditional on the data on size and domestic spending. Moreover, any estimated model in our class will arrive at the exact same number as long as it is successfully calibrated to the observable micro data.

A further advantage of our methodology relative to approaches that estimate an entire model of import behavior is related to computational complexity. The macroeconomic environment in our framework allows for multiple sectors with a rich input-output structure and takes general equilibrium interactions into account. Antràs et al. (2014) for example assume that wages are not affected by input trade but determined in an outside sector. Halpern et al. (2015) use a single sector partial equilibrium framework. Estimating these models in full general equilibrium with sectoral interlinkages would entail substantial computational difficulty. The reason is that the solution to firms' optimal sourcing problem, which is already challenging in models with fixed costs (see Antràs et al. (2014)), interacts with finding the equilibrium market clearing prices. Moreover, we show below that our methodology can also allow for strategic pricing behavior so that firms' markups respond to the trade shock.

Proposition 1 can be applied to the analysis of observed policies, i.e. in situations where the researcher has access to both $s_{D i}$ and $s_{D i}^{\prime}$. To the extent that the change in domestic shares can be attributed to the policy, the effect of the policy on consumer prices can be readily calculated from equation (14). ${ }^{22}$ A special case of interest is a reversal to input autarky. Because firms' counterfactual domestic shares are given by unity, the change in domestic spending between the current trade equilibrium and autarky is simply given by their level in the observed equilibrium. Input autarky is therefore a policy which is trivially observable in any firm-level dataset that contains information on firms' domestic spending patterns. The data contained in Figures 1 and 2 is therefore sufficient to

22. In practice, one needs to use changes in firms' domestic shares that are only due to the policy. In the context of a trade liberalization episode, one can for example use the change in policy to construct instruments, e.g. by exploiting cross-sectional differences in firms' exposure to the policy. See also Section 3, where we use a related identification strategy. See also footnote 18. 
calculate the gains from input trade. We measure these gains for the French economy in Section 3 below.

A limitation of our methodology is that it cannot be directly applied when firms' domestic shares after the shock are not observed. In this case, the entire import environment $\left[p_{c i}, q_{c i}, h_{i}, \beta_{i}\right]$ and the extensive margin mechanism need to be spelled out in the context of a particular model. Our methodology is therefore complementary to contributions that estimate a fully specified model of importing - e.g. Halpern et al. (2015), Gopinath and Neiman (2014) or Antràs et al. (2014). While this approach is necessary to perform counterfactual analysis, in the case of observed policies our methodology does not require a structural estimation and can handle richer macroeconomic settings. ${ }^{23}$

Prices vs. Welfare. As in Feenstra (1994) and Broda and Weinstein (2006), our results focus on changes in consumer prices and therefore may not capture the full welfare effects of input trade. In particular, this may be the case when firms need to spend resources to find their trading partners. ${ }^{24}$ If the shock to the import environment results in changes in firms' sourcing strategies, the shock may affect the share of aggregate profits in income, making changes in welfare not proportional to changes in prices. This feature is not specific to theories of importing but also arises in models of exporting. For example, the welfare formula of Arkolakis et al. (2012) precisely relies on the condition that profits are a constant share of aggregate income, which is one of their three macro level restrictions. Whether or not this condition is satisfied depends on details of the environment which we did not have to specify to derive Proposition 1. In Section 3.4 below, we explore this distinction in more detail. While the change in consumer prices characterized in Proposition 1 provides an upper bound for the change in welfare in all models in our class, we provide examples of fully-specified models of importing where this bound is tight or where consumer prices and welfare are substantially different (despite the fact that the models are calibrated to the exact same data).

\subsection{Extension : Variable Markups.}

Proposition 1 was derived in the familiar CES monopolistic competition setting. While this is a convenient starting point, the result in Proposition 1 extends directly to more general settings where competition among firms, and hence the distribution of mark-ups, endogenously responds to changes in the trading environment. Specifically, we follow Edmond et al. (2015) and consider an extension of the above economy to allow for variable markups as in Atkeson and Burstein (2008). ${ }^{25}$ Demand

23. While Proposition 1 requires changes in firms' domestic shares that are due to the policy, a similar identification challenge arises in structural exercises that study past policies. Gopinath and Neiman (2014) for example quantify the productivity losses of Argentine firms during the 2001 crisis and assume that the entire decline in aggregate manufacturing import spending is due to an increase in foreign import prices caused by the devaluation. Antràs et al. (2014) study the import behavior of US firms and assume that the entire increase in US imports from China between 1997 and 2007 was due to an increase in China's sourcing potential.

24. Because such resource loss is not observed in the data, welfare has to be quantified in the context of a fully-specified model.

25. Section 6.3 of the Appendix contains all derivations. 
is given by (8) above, together with

$$
C_{s}=\left(\int_{0}^{N_{s}} c_{j s}^{\frac{\sigma_{s}-1}{\sigma_{s}}} d j\right)^{\frac{\sigma_{s}}{\sigma_{s}-1}} \text { and } c_{j s}=\left(\sum_{i=1}^{N_{j s}} \frac{\theta_{s}-1}{c_{i j s}}\right)^{\frac{\theta_{s}}{\theta_{s}-1}}
$$

where $\theta_{s} \geq \sigma_{s}{ }^{26}$ Instead of each variety $j \in\left[0, N_{s}\right]$ being produced by a monopolistic firm, it is now given by another CES composite produced by a set of $N_{j s}$ firms. As in Atkeson and Burstein (2008), we assume that firms behave strategically vis a vis other firms producing their variety $j$, but take all other prices as given. In particular, we assume that firms compete a la Cournot. In this context, the change in consumer prices resulting from a shock to the import environment is given by Proposition 1 where $\Lambda_{s}$ is now

$$
\Lambda_{s}^{V M}=\frac{1}{1-\sigma_{s}} \ln \left(\int_{0}^{N_{s}}\left(\sum_{i=1}^{N_{j s}} \omega_{i}\left(\frac{s_{D i}}{s_{D i}^{\prime}}\right)^{\frac{\gamma_{s}}{1-\varepsilon_{s}}\left(1-\theta_{s}\right)}\left(\frac{\mu_{i}^{\prime}\left(\left[\omega_{i}, s_{D i} / s_{D i}^{\prime}\right]\right)}{\mu_{i}\left(\omega_{i}\right)}\right)^{1-\theta_{s}}\right)^{\frac{1-\sigma_{s}}{1-\theta_{s}}} \omega_{j s} d j\right) .
$$

Here, $\omega_{j s}$ denotes variety $j s$ 's share in total spending, $\omega_{i}$ denotes firm i's share in variety spending, and $\mu_{i}, \mu_{i}^{\prime}$ denote firm $i$ 's markup in the current and counterfactual equilibria. Note first that $\Lambda_{s}^{V M}$ reduces to $\Lambda_{s}$ in the constant markup case when $\theta_{s}=\sigma_{s}$ as mark-ups do not respond to the trade shock (i.e. $\mu_{i}=\mu_{i}^{\prime}$ ).

Importantly, the notation in (17) makes explicit that firms' counterfactual mark-ups $\mu_{i}^{\prime}$ are again fully determined from firms' domestic shares and size. To see how (17) is calculated, note that current markups $\mu_{i}$ can be obtained from firms' observed revenue market shares via

$$
\mu_{i}=\frac{1}{1-\left(\frac{1}{\sigma} \omega_{i}+\frac{1}{\theta}\left(1-\omega_{i}\right)\right)} .
$$

The distribution of counterfactual markups $\mu_{i}^{\prime}$ can then be obtained from the following system of non-linear equations

$$
\frac{1}{\frac{1}{\sigma_{s}}-\frac{1}{\theta_{s}}}\left(\left(\frac{\theta_{s}-1}{\theta_{s}}\right)-\frac{1}{\mu_{i}^{\prime}}\right)=\frac{\left(\mu_{i}^{\prime}\right)^{1-\theta_{s}} a_{i}}{\sum_{\nu}\left(\mu_{\nu}^{\prime}\right)^{1-\theta_{s}} a_{\nu}}
$$

where

$$
a_{i} \equiv \mu_{i}^{-\left(1-\theta_{s}\right)} \omega_{i}\left(s_{D i} / s_{D i}^{\prime}\right)^{\frac{\gamma_{s}}{1-\varepsilon_{s}}\left(1-\theta_{s}\right)} .
$$

As $\left[a_{i}\right]$ in (20) are a function of observables in the micro data (and parameters), so are firms' counterfactual mark-ups $\left[\mu_{i}^{\prime}\right]$ stemming from (19). Once again, the micro data on firms' revenue and domestic expenditure shares $\left[\omega_{i}, s_{D i} / s_{D i}^{\prime}\right]$ is sufficient to compute the change in consumer prices. ${ }^{27}$

26. As before, we assume that the domestic input aggregator in (9) takes the same form as consumer demand in (8) and (16), where the Cobb-Douglas weights in (8) are given by $\left[\zeta_{k}^{s}\right]$.

27. The sufficiency of the data on domestic expenditure shares and firm size extends beyond the particular structure of the Atkeson and Burstein (2008) model. We show in Section 6.3 in the Appendix that such data is sufficient in any model where markups are only a function of relative prices. 


\subsection{The Importance of Firm Heterogeneity}

The analysis so far established that size and the domestic expenditure share are the only two relevant dimensions of firm heterogeneity as far as consumer prices are concerned. ${ }^{28}$ Existing approaches in the literature either abstract from firm heterogeneity altogether and rely on aggregate statistics, or do not explicitly target the joint distribution of domestic expenditure shares and size, e.g. Gopinath and Neiman (2014), Antràs et al. (2014) or Ramanarayanan (2014). ${ }^{29}$ In this section, we use Proposition 1 to assess to what extent this is consequential.

The Bias of Aggregate Models. Consider first aggregate approaches where firms' domestic expenditure shares are (by construction) equalized - see Eaton et al. (2011), Caliendo and Parro (2015) and Costinot and Rodríguez-Clare (2014). In these models, the gains from input trade relative to autarky are given by Proposition 1 where the direct price reductions $\Lambda_{s}^{\text {Aut }}$ are given by

$$
\Lambda_{A g g, s}^{A u t}=\frac{\gamma_{s}}{1-\varepsilon_{s}} \ln \left(s_{D s}^{A g g}\right)=\frac{\gamma_{s}}{1-\varepsilon_{s}} \ln \left(\int_{0}^{N_{s}} \omega_{i} s_{D i} d i\right),
$$

where $s_{D s}^{A g g}$ is the aggregate domestic expenditure share in sector $s$. Hence, as in Arkolakis et al. (2012), these frameworks have the benefit of only requiring aggregate data. Figure 1, however, shows that their implication of equalized domestic shares is rejected in the micro data and Proposition 1 shows that such deviation has aggregate consequences. In particular, (15) and (21) imply that the bias from measuring the price reduction in sector $s$ through the lens of an aggregate model is given by

$$
\operatorname{Bias}_{s} \equiv \Lambda_{A g g, s}^{A u t}-\Lambda_{s}^{A u t}=\frac{\gamma_{s}}{\varepsilon_{s}-1} \times \ln \left[\frac{\left(\int_{0}^{N_{s}} \omega_{i} s_{D i}^{\chi_{s}} d i\right)^{1 / \chi_{s}}}{\int_{0}^{N_{s}} \omega_{i} s_{D i} d i}\right]
$$

where $\chi_{s}=\frac{\gamma_{s}\left(\sigma_{s}-1\right)}{\varepsilon_{s}-1}$. Heterogeneity in import shares induces a bias in the estimates of the gains from trade of aggregate models, as long as $\chi_{s} \neq 1$. The magnitude of the bias depends on the underlying dispersion in domestic shares and their correlation with firm size - we quantify it in our empirical application below. The sign of the bias, however, depends only on parameters and not on the underlying micro-data. In particular, (22) together with Jensen's inequality directly imply that

28. Naturally, this statement relies on our assumption of constant material shares. With non-constant material shares, firms' unit costs would be determined from the micro data on domestic shares and material shares, and the counterfactual change in unit costs would be determined from the changes in these shares. We discuss this case in more detail in Section 6.1 of the Appendix. Empirically, the dispersion in domestic shares exceeds the one of material shares. Focusing on the sample of importing firms, the average interquartile range of material spending shares (domestic expenditure shares) within 2-digit industries is $0.25(0.42)$. The average difference between the 90 th and 10 th percentile is $0.46(0.71)$. In this paper, we focused on the heterogeneity in import shares.

29. There are instances where this information is not available. For example, in Argentina, which is the focus of the Gopinath and Neiman (2014) study, it is currently not possible to construct domestic expenditure shares at the firm level, as customs and fiscal data cannot be matched. 


$$
\text { Bias }_{s}>0 \text { if and only if } \chi_{s}=\frac{\gamma_{s}\left(\sigma_{s}-1\right)}{\varepsilon_{s}-1}>1
$$

Hence, as long as $\chi_{s}>1$, which is the case if consumer demand is elastic ( $\sigma_{s}$ is large) and the elasticity of unit costs with respect to the domestic share is large $\left(\frac{\gamma}{\varepsilon-1}\right.$ is high), an analysis based on aggregate data would imply consumer gains that are too large. The economic intuition of this result is as follows. Because the current trade equilibrium is observed in the data, quantifying the gains from trade boils down to predicting consumer prices in the counterfactual autarky allocation. Such prices are fully determined from producers' efficiencies, i.e. $\tilde{\varphi}_{i}^{\sigma-1}$. As these are unobserved, they are inferred from data on value added and domestic shares. More specifically, given the data on value added, (11) shows that $\tilde{\varphi}_{i}^{\sigma-1}$ is proportional to $s_{D i}^{\chi}$. In the same vain as dispersion in prices is valued by consumers whenever demand is elastic, dispersion in domestic shares is valued as long as $\chi>1$. In this case, the autarky price index inferred by an aggregate model is too high, making the gains from trade upward biased. ${ }^{30}$

Note also that $\Lambda_{A g g, s}^{A u t}$ provides a bound for the change in consumer prices resulting from tradeinduced shocks. More specifically, (22) and (23) directly imply that if $\chi>1(\chi<1)$ an aggregate model provides an upper (lower) bound for the effect of input trade on consumer prices for any model that is calibrated to the aggregate domestic share. Thus, aggregate approaches in the spirit of Arkolakis et al. (2012) can be used to derive a bound in cases where the micro data is not available. In the quantitative analysis in Section 3.4, we explicitly show that this intuition carries over to counterfactuals beyond autarky.

The Bias of Firm-based Models. On the other side of the spectrum are firm-based models of importing. These models generate heterogeneity in firms' import shares, typically via sorting into different import markets, thereby inducing a non-degenerate joint distribution of import intensity and size. Gopinath and Neiman (2014) and Ramanarayanan (2014) for example assume that firms differ only in their efficiency and thus generate a perfect negative correlation between domestic shares and value added conditional on importing. They also imply that all importers are larger than domestic firms. By assigning the largest unit cost reductions to the most efficient firms, this tends to magnify the aggregate gains from trade. Figure 2, however, shows that the correlation between firm size and domestic spending is negative but far from perfect, and that many importers are small. Because models with a single source of firm heterogeneity cannot match these features of the data, they will yield biased estimates of the gains from trade by construction. ${ }^{31}$ Antràs et al. (2014) and Halpern et al. (2015) allow for heterogeneity in efficiency and fixed costs and thus generate a non-

30. The following example might be instructive. Consider an economy where firms differ in their domestic shares but value added is equalized across producers. Looking at the data through the lens of an aggregate model, one would conclude that innate efficiency is also equalized across firms. This, however, cannot be the case as the dispersion in domestic shares implies that efficiency has to vary given a common level of value added - see (11). Whether or not consumers prefer the autarky allocation with equalized efficiency depends on $\chi$. If $\chi>1$, the absence of productivity dispersion will imply higher consumer prices and therefore higher gains from trade in an aggregative framework.

31. In our quantitative analysis in Section 3.4 we indeed find that models with a single source of heterogeneity give results that are upward biased. 
trivial distribution of value added and domestic spending. Whether or not the model-implied joint distribution of domestic shares and firm size looks like the one in the data depends on the calibration. In Section 3.4, we show quantitatively that failing to match such data can lead to substantial biases both for the case of autarky and general counterfactuals.

\section{Empirical Application}

We now take the framework laid out above to data on French firms to measure the effect of input trade on consumer prices. We start by focusing on the case of a reversal to input autarky. We rely on Proposition 1 to compute the resulting change in consumer prices directly from the observed micro data and a set of parameters (which we estimate using both micro and aggregate data). We then study shocks to the price of foreign inputs. To do so, we specify additional theoretical structure.

\subsection{Data}

The main source of information we use is a firm-level dataset from France. ${ }^{32}$ A detailed description of how the data is constructed is contained in Section 6.4 of the Appendix. We observe import flows for every manufacturing firm in France from the official custom files. ${ }^{33}$ Manufacturing firms account for $30 \%$ of the population of French importing firms and $53 \%$ of total import value in 2004. Import flows are classified at the country-product level, where products are measured at the 8-digit (NC8) level of aggregation. Using unique firm identifiers, we can match this dataset to fiscal files which contain detailed information on firm characteristics. Most importantly, we retrieve the total input expenditures from these files, which allow us to compute domestic shares as the difference between total input expenditures and total imports. ${ }^{34}$ The final sample consists of an unbalanced panel of roughly 170,000 firms which are active between 2002 and 2006, 38,000 of which are importers. Table 6 in the Appendix contains some basic descriptive statistics. We augment this data with two additional data sources. First, we employ data on input-output linkages in France from the STAN database of the OECD. Second, we use global trade flows from the UN Comtrade Database to measure aggregate export supplies which we use to construct an instrument to estimate the elasticity of substitution $\varepsilon$ below.

\subsection{Estimation of Parameters}

Our approach relies on both micro and aggregate data. We use the micro data to estimate the production function parameters, i.e. the material elasticities $\left[\gamma_{s}\right]$ and the elasticities of substitution

32. Similar data is available for many countries, among other Hungary (Halpern et al., 2015), Belgium (De Loecker, 2011), Slovenia (De Loecker and Warzynski, 2012), Indonesia (Amiti and Konings, 2007) and Chile (Kasahara and Rodrigue, 2008).

33. While we also observe imports for non-manufacturing firms, we do not directly observe to whom they resell. Hence, we cannot measure the indirect purchases of foreign inputs via resellers at the firm-level. At the aggregate level we therefore use the aggregate input-output table to take interlinkages between domestic firms and importers into account.

34. As in Halpern et al. (2015), domestic shares are therefore observed at the firm but not at the product level. 
$\left[\varepsilon_{s}\right]$, as well as the sector-specific demand elasticities $\left[\sigma_{s}\right]$. We identify the input-output structure on the production side $\left[\zeta_{j}^{s}\right]$ and the aggregate demand parameters $\left[\alpha_{s}\right]$ from the input-output tables. This allows us to account for the non-manufacturing sector and doing so is quantitatively important.

\section{Identification of $\alpha$ and $\zeta$}

We compute the demand parameters $\alpha_{s}$ and the matrix of input-output linkages $\left[\zeta_{j}^{s}\right]$ using data from the French input-output tables on the distribution of firms' intermediate spending and consumers' expenditure by sector. ${ }^{35}$ Sectors are classified at the 2 -digit level. Letting $Z_{j}^{s}$ denote total spending on intermediate goods from sector $j$ by firms in sector $s$ and $E_{s}$ total consumption spending in sector $s$, our theory implies

$$
\zeta_{j}^{s}=\frac{Z_{j}^{s}}{\sum_{j=1}^{S} Z_{j}^{s}} \text { and } \alpha_{s}=\frac{E_{s}}{\sum_{j=1}^{S} E_{j}} .
$$

We aggregate all non-manufacturing sectors into one residual sector, which we denote by $S$, and construct its consumption share $\alpha_{S}$ and input-output matrix $\zeta_{j}^{S}$ directly from the Input-Output Tables. The results for the consumption shares $\alpha_{s}$ for each sector are contained in column one of Table 1 below. The non-manufacturing sector is important as it accounts for a large share of the budget of consumers. For brevity, we report the input-output matrix $\zeta_{j}^{s}$ in the Online Appendix.

[Table 1 here]

\section{Estimation of $\varepsilon, \sigma$ and $\gamma$}

To identify the elasticity of substitution $\varepsilon$, the intermediate input share $\gamma$ and the demand elasticity $\sigma$, we turn to the French micro data. We follow Oberfield and Raval (2014) to measure the demand elasticities $\sigma_{s}$ from firms' profit margins, i.e. the ratio of revenue to total costs,

$$
\frac{p_{i} y_{i}}{\text { Cost }_{i}}=\frac{\sigma-1}{\sigma}
$$

where $p_{i} y_{i}$ is firm revenue and Cost $_{i}$ denotes production costs. ${ }^{36}$ We compute averages at the sector level to obtain $\sigma_{s}$. Column two of Table 1 contains the estimates which, consistent with the literature, are around 3 . To identify $\varepsilon$, note that firm output can be written as

$$
y_{i}=\tilde{\varphi}_{i} s_{D i}^{-\frac{\gamma_{s}}{\varepsilon_{s}-1}} l_{i}^{1-\gamma_{s}} m_{i}^{\gamma_{s}} \times B
$$

where $m_{i}$ is total material spending by firm $i$ and $B$ collects all general equilibrium variables, which are constant across firms within an industry. By expressing output in terms of spending in materials

35. See the Online Appendix for a detailed description of how we construct the input-output matrix.

36. We acknowledge that this measure is subject to the critique by Bresnahan (1989) that accounting costs do not represent accurately variable costs (and also encompass fixed costs). See Appendices 6.5 and A.6 for discussions of alternative assumptions about mark-ups and alternative IO methods. 
instead of quantities, (26) shows that we can identify $\varepsilon_{s}$ from variation in domestic expenditure shares holding material spending fixed. Intuitively, the domestic share is akin to a productivity shifter. We implement this idea with two complementary approaches. Our first method relies on simple accounting identities using firms' factor shares. It has the benefit that it is straightforward to implement and maps directly into our theory. Our second approach follows the recent literature on production function estimation, in particular De Loecker (2011). We describe both procedures in turn.

Approach 1 : Factor Shares. Consider first the approach based on observed factor shares, which is a simple and easy-to-implement benchmark (see e.g. Syverson (2011) and Oberfield and Raval (2014)). According to our theory, we can identify $\gamma$ directly from firms' spending shares, i.e.

$$
\frac{m_{i}}{p_{i} y_{i}}=\gamma \frac{\sigma-1}{\sigma}
$$

To estimate $\varepsilon$, we express $(26)$ in terms of firm revenue ${ }^{37}$ :

$$
\ln \left(p_{i} y_{i}\right)=\Phi+\tilde{\rho} \ln \left(l_{i}\right)+\tilde{\gamma} \ln \left(m_{i}\right)+\ln \left(\vartheta_{i}\right)
$$

where $\Phi$ contains general equilibrium variables, $\tilde{\rho}=\frac{\sigma-1}{\sigma}(1-\gamma), \tilde{\gamma}=\frac{\sigma-1}{\sigma} \gamma$ and

$$
\ln \left(\vartheta_{i}\right)=\frac{1}{1-\varepsilon} \tilde{\gamma} \ln \left(s_{D i}\right)+\frac{\sigma-1}{\sigma} \ln \left(\tilde{\varphi}_{i}\right) .
$$

Given estimates for $\gamma$ and $\sigma$, we can use (28) to recover the productivity residual $\ln \left(\vartheta_{i}\right)$ up to a constant. We can then use (29) to estimate $\varepsilon$ from the variation in changes in firms' domestic expenditure shares. Clearly, we cannot estimate (29) via OLS as the required orthogonality restriction fails : most models of import behavior predict that changes in firms' domestic share are correlated with changes in firm efficiency. Hence, we employ an instrumental variable strategy. In particular, we follow Hummels et al. (2011) and instrument $s_{D}$ with shocks to world export supplies, which we construct from the Comtrade data. More precisely, we construct the instrument

$$
z_{i t}=\Delta \ln \left(\sum_{c k} W E S_{c k t} \times s_{c k i}^{p r e}\right),
$$

where $W E S_{c k t}$ denotes aggregate exports of product $k$ from country $c$ in year $t$ to the entire world excluding France, $s_{c k i}^{p r e}$ is firm $i$ 's import share on product $k$ from country c prior to our sample, and $\Delta$ denotes the change between year $t-1$ and year $t$. Hence, $z_{i t}$ can be viewed as a firm-specific index of shocks to the supply of the firm's input bundle. Movements in this index induce exogenous variation in firms' domestic shares as long as changes in firm efficiency $\tilde{\varphi}$ are uncorrelated with changes in aggregate exports of the countries in the firm's initial sourcing set. Intuitively, if we see China's global exports of product $k$ increasing in year $t$, French importers that used to source product $k$ from

37. We work with revenue as we do not observe firm-specific prices. 
China will be relatively more affected by this positive supply shock and should increase their import activities. Hence, we estimate $\varepsilon$ from the second stage regression

$$
\Delta \ln \left(\hat{\vartheta}_{i s t}\right)=\delta_{s}+\delta_{t}+\frac{1}{1-\varepsilon} \times \Delta \tilde{\gamma}_{s} \widehat{\ln \left(s_{i s t}^{D}\right)}+u_{i s t},
$$

where $\delta$ are sector and year fixed effects, $o_{i s t}$ is a vector of firm-level controls, $\Delta \ln \left(\hat{\vartheta}_{i s t}\right)$ is the change in firm residual productivity, and $\Delta \tilde{\gamma}_{s} \ln \widehat{\left(s_{\text {Dist }}\right)}$ is the change in domestic shares, which is instrumented by (30).

We implement this procedure in the following way. First, we augment the production function to include capital, i.e. we consider $y_{i s}=\varphi_{i} l^{\phi_{l s}} x^{\gamma_{s}} k^{1-\phi_{l s}-\gamma_{s}} .{ }^{38}$ Second, we measure all parameters $\phi_{l s}, \gamma_{s}$ and $\sigma_{s}$ at the two digit sectoral level. To construct our instrument (30), we define products at the 6-digit level and take firms' respective first year as an importer to calculate the pre-sample expenditure shares $s_{c k i}^{p r e}$. Finally, to increase the power of the estimation, we estimate (31) by pooling all firms from all sectors and estimate a single $\varepsilon$.

Table 1 reports the estimated material elasticities $\gamma_{s}$ (column three) and also the sectoral share in aggregate value added (column four). The estimation results for $\varepsilon$ based on (31) are contained in Table 2. In the first column, we show the first stage relationship between changes in world export supply $z_{i t}$ and firms' changes in domestic spending. Reassuringly, there is a negative relationship that is statistically significant, i.e. firms whose trading partners see an increase in their total world exports reduce their domestic spending. Columns two and three show the reduced form results of regressing performance measures such as changes in productivity or log value added on the export supply shock $z_{i t}$. As expected, there is a positive correlation. Column four then contains the results for $\varepsilon$. In our preferred specification, which does not condition on import status and where we calculate firms' initial expenditure shares $s_{c k i}^{p r e}$ from the year before they start importing, we estimate this elasticity to be 2.38. If we keep the year used for the pre-sample weights $s_{c k i}^{p r e}$ fixed for all firms, the implied elasticity is lower. When we restrict our sample to continuing importers, these point estimates are essentially unchanged. Note, however, that the standard errors increase substantially as we lose a large amount of data by conditioning on import status. ${ }^{39}$

Approach 2 : Production Function Estimation. As a complementary approach to identify $\gamma$ and $\varepsilon$, we also estimate these parameters using methods to structurally estimate production functions - see e.g. Levinsohn and Petrin (2003), De Loecker (2011) and Ackerberg et al. (2015), who build on

38. Naturally, we include capital in our measure of total costs in (25) and calculate $\operatorname{Costs}_{i}=w l_{i}+m_{i}+R k_{i}$, where we assume a rental rate of $20 \%$. We redid our analysis for a rental rate of $10 \%$ with quantitatively very similar results. These are available upon request. Similarly, we augment (28) to include capital and infer the labor elasticity $\phi_{l}$ from the optimality condition $\frac{m_{i}}{w l_{i}}=\frac{\gamma}{\phi_{l}}$.

39. Our estimates are close to the ones of Antràs et al. (2014) who rely on cross-country variation. Kasahara and Rodrigue (2008) find estimates of the elasticity of substitution in the range of 3.1 to 4.4 using a related approach for Chilean data. However, they do not use an external instrument for firms' imported intermediates. Halpern et al. (2015) use Hungarian data and derive a production function equation analog to (28), as well as an import demand equation. They also find an elasticity of substitution of 4 . The main difference with our approach is that they obtain the parameters of their structural model by simultaneously estimating the production function and import demand equations. In contrast, we identify $\varepsilon$ mainly by using exogenous variation in input supplies. 
the seminal work by Olley and Pakes (1996). Our implementation and identification strategy closely follows De Loecker (2011). We describe the main idea here and leave the details to Section 6.5 of the Appendix. In particular, we again augment firms' production function to include capital and express revenue as

$$
\ln \left(p_{i} y_{i}\right)=\Phi+\tilde{\phi}_{k s} \ln \left(k_{i}\right)+\tilde{\phi}_{l s} \ln \left(l_{i}\right)+\tilde{\gamma}_{s} \ln \left(m_{i}\right)+\frac{1}{1-\varepsilon_{s}} \tilde{\gamma}_{s} \ln \left(s_{D i}\right)+\frac{\sigma_{s}-1}{\sigma_{s}} \ln \left(\tilde{\varphi}_{i}\right)+u_{i},
$$

where $\tilde{\gamma_{s}}=\frac{\sigma_{s}-1}{\sigma_{s}} \gamma_{s}$ (with $\tilde{\phi_{k s}}$ and $\tilde{\phi_{l s}}$ defined accordingly) and $u_{i}$ contains variables that are unknown to the firm at the time decisions are made as well as measurement error. Importantly, by using material inputs in terms of spending instead of quantities, (32) shows that we can estimate $\varepsilon_{s}$ by treating the domestic share as an additional input in a production function estimation exercise. ${ }^{40}$ Hence, in contrast to our first approach, we now estimate the parameters $\left(\tilde{\gamma}, \tilde{\phi}_{k}, \tilde{\phi}_{l}, \varepsilon\right)$ simultaneously and also allow $\varepsilon$ to vary by sector.

To do so, we make the following assumptions. First, we assume that capital, labor and the firm's international sourcing strategy are dynamic inputs. We allow productivity $\varphi_{i}$ to be a flexible $\operatorname{AR}(1)$ process and employ the methodology developed by Wooldridge (2009) to estimate the parameters via GMM. We identify the four parameters as follows. The parameters $\left(\tilde{\gamma}, \tilde{\phi}_{k}, \tilde{\phi}_{l}\right)$ are identified in the usual way, i.e. we use lagged values of capital, labor and materials to proxy for $\varphi$, and two-year lagged values of intermediate inputs as an instrument for current intermediate inputs. As for the novel parameter $\varepsilon$, we use the trade instrument discussed above in (30) to account for the endogeneity of firms' domestic shares. This is a valid instrument under our timing assumptions - see Section 6.5 in the Appendix for details. In addition to the baseline Cobb-Douglas specification embedded in (32), we consider a more flexible translog specification where we continue to assume a constant output elasticity for intermediate inputs but allow for second-order terms in capital and labor. For brevity, we report the full estimation results for the production function parameters in Table 7 in the Appendix. Our results for $\varepsilon$ are contained in Figure 3. We report the estimates for both the Cobb-Douglas and the Translog specification and also display the confidence intervals based on two standard deviations. We see that for the majority of industries the point estimates are precisely estimated and in the same ballpark as the pooled estimate from the factor shares approach. ${ }^{41}$ For a few other industries, we lack precision and we cannot reject that $\varepsilon$ is below one. The existence of non-importers, however, implies that $\varepsilon$ has to exceed unity. We therefore take the estimate stemming from the factor shares approach, i.e. $\varepsilon=2.38$, as the benchmark for the remainder of the paper. While we lock in to this particular point estimate, we report confidence intervals for all quantitative results which take the sampling variation in this benchmark estimate into account. Because the estimated elasticities from

40. Note that we assume that the input measures $(k, l, m)$ observed in the data are used for production and not required for overhead or for firms to attain their sourcing strategies. This allows us to estimate the parameters of the model needed to compute the consumer price gains without taking a stand on the extensive margin. Note also that one could have estimated $\varepsilon$ from firms' relative import demand system (see (4)-(5)). Because our data does not contain a reliable measure of quality-adjusted input prices with variation at the firm-level, we prefer our approach based on (32).

41. This suggests that the relatively low value for $\varepsilon$ found in the pooled factor shares approach is not a result of the sectoral pooling of our data. This is in contrast to estimations on aggregate data, which find a downward bias (Imbs and Mejean, 2015). 
the production function approach are within the sampling variation of the factor share estimate, our quantitative results will also be informative for these estimates.

\subsection{A Reversal to Autarky}

With the structural parameters at hand, we now quantify the gains from input trade in France using Proposition 1. For the case of observed shocks, i.e. situations where data on the changes in firms' domestic spending patterns induced by the shock is available, one can simply use Proposition 1 to measure the change in consumer prices for all models in our class. We focus on one particular observed shock - a hypothetical reversal to input autarky, which can be directly analyzed using the cross-sectional data on firm-size and domestic shares displayed in Figures 1 and 2.

The crucial ingredient to quantify the aggregate gains from input trade is the distribution of unit cost changes in the population of firms, which are simply given by $\frac{\gamma_{s}}{1-\varepsilon} \ln \left(s_{D}\right)$ (see $(7)$ ). We depict this distribution in Figure 4 and summarize it in Table 3. We see that there is substantial heterogeneity across firms. While the median firm would see its unit cost increase by $11.2 \%$ if moved to autarky, firms above the 90 th percentile of the distribution would experience losses of $85 \%$ or more. Moreover, this heterogeneity is partly systematic in that bigger firms and exporters see higher gains. When we condition on import status, the positive relation between firm size and the firm-level gains essentially disappears. ${ }^{42}$ This is consistent with the pattern documented in Figure 2.

We now turn to Proposition 1 to aggregate these firm-level cost-changes to the change in aggregate consumer prices. Panel A in Table 4 contains the results. We find that the price level in the manufacturing sector would be $27.5 \%$ higher if French producers were forced to source their inputs domestically. When the non-manufacturing sector is taken into account, the consumer price gains amount to $9 \% .{ }^{43}$ The reason why these economy-wide gains are substantially smaller is that the non-manufacturing sector (which in our setting is assumed to be closed to trade) experiences only a $3 \%$ reduction in prices, but accounts for $70 \%$ of consumers' budget - see Table 1 .

To quantify the importance of firm heterogeneity, we also report the consumer price gains predicted by an aggregate approach that only uses data on domestic spending at the sector level. This aggregate approach implies gains of $31.4 \%$ and $9.9 \%$ in the manufacturing sector and the entire economy, respectively. Ignoring the heterogeneity in firms' import behavior within sectors therefore results in an over-estimation of the consumer price gains by 3.4 and 1 percentage points for the manufacturing sector and the entire economy, respectively. The aggregate approach is upward biased because the estimated parameters imply that, for most sectors, $\Lambda_{s}$ is a convex aggregator of firms' domestic shares - see (22)-(23).

[Table 4 here]

To assess our confidence in these estimates, we calculate 90-10 confidence intervals of the bootstrap

42. See Section A.3 of the Online Appendix for details.

43. Formally, the economy-wide gains $P^{A u t} / P$ are related to the gains in the manufacturing sector $P_{M}^{A u t} / P_{M}$ via $P^{A u t} / P=\left(P_{M}^{A u t} / P_{M}\right)^{1-\alpha_{S}}\left(P_{S}^{A u t} / P_{S}\right)^{\alpha_{S}}$, where $\alpha_{S}$ is the expenditure share in the non-manufacturing sector. 
distribution. ${ }^{44}$ These are reported in italics in Table 4 . Note that the uncertainty in the point estimates stems from two sources. First, because we base our analysis on a large but finite sample, there is uncertainty in our aggregate statistics for given parameters. Second, the structural parameters $\varepsilon, \gamma_{s}$ and $\sigma_{s}$ are estimated with error. These two forces induce quite a bit of variation in the estimates (with the majority of the variation stemming from the second source). With $80 \%$ probability, the consumer price gains in the manufacturing sector lie between $21 \%$ and $36 \%$ and the gains for the entire economy lie between $7 \%$ and $12 \%$. We also find that the aggregate approach yields more uncertain estimates (second row) and leads to an over-estimation of the gains with $80 \%$ probability (third row).

In Panel B of Table 4, we provide additional details of the gains from input trade. More specifically, we report the gains by sector and provide a decomposition to isolate the importance of production linkages across sectors. We first report the sectoral consumer price gains, $P_{s}^{A u t} / P_{s}$, which measure the change in the price of the output bundle of sector $s$. We find substantial heterogeneity in the effect of input trade across sectors : e.g. while prices for textile products would be $56 \%$ higher if producers were not allowed to source their inputs from abroad, this effect is only $18 \%$ for metal products. We then decompose these price changes into the direct price reduction from firms in sector $s$ sourcing internationally, $\Lambda_{s}$, and the indirect gains stemming from firms in sector $s$ buying domestic inputs from other firms who in turn may engage in trade, $p_{D s}^{A u t} / p_{D s} .{ }^{45}$ We find that interlinkages are important as they account for roughly $50 \%$ of the sectoral price gains. Note also that the importance of interlinkages varies substantially across industries as a result of the underlying heterogeneity in the input-output matrix : sectors that rely on relatively open sectors more intensively benefit more from input trade as their upstream suppliers experience larger unit cost reductions. To assess the importance of such heterogeneous interconnections, consider the case without cross-industry inputoutput linkages, where each sector uses only its own products as inputs. ${ }^{46}$ In this case, we find a point estimate for the consumer prices gains from trade of $12 \% .{ }^{47}$ Compared to the actual gains of $9 \%$, the economy without interlinkages over-estimates the aggregate gains by about a third. The reason is that the non-manufacturing sector is not only important for final consumers but also as a provider of inputs to other manufacturing firms. As this sector is not a direct beneficiary of foreign sourcing in the model, such linkages actually dampen the aggregate effect of input trade.

Finally, Panel B of Table 4 also contains the direct price reductions that arise from an aggregate model, $\Lambda_{s}^{A g g}$, at the sectoral level. ${ }^{48}$ In 12 of the 18 manufacturing sectors the gains based on aggregate data are upward biased. The reason for this pattern goes back to the condition in (23)

44. We explain the details of the bootstrap procedure in Section A.4 of the Online Appendix. A sketch of the procedure is as follows. For each bootstrap iteration, we construct a new sample of the French manufacturing sector by drawing firms from the empirical distribution with replacement. We then redo the analysis of Section 3.2 and obtain new estimates for the structural parameters. Finally, for each iteration, we recalculate the consumer price gains and the other statistics of interest.

45. Formally, $p_{D s}$ is the sector-specific price index of a unit of the bundle of domestic inputs, which is an aggregator of all the goods produced locally, see (9).

46. In this case, the matrix of input-output linkages is given by $\zeta_{j}^{s}=0$ for $j \neq s$ and $\zeta_{j}^{j}=1$.

47. This number is calculated as $\sum_{s} \alpha_{s} \Lambda_{s} /\left(1-\gamma_{s}\right)$.

48. See also the last column of Table 1 , where we report the aggregate domestic expenditure share at the sector level. 
which characterizes the sign of the bias as a function of parameters encapsulated in $\chi_{s}$. It turns out that for most sectors our estimated parameters imply that $\chi_{s}>1$ (see last column) so that the aggregate models are upward biased. Note also that the bias can be quite substantial. Consider for example the office and computing machinery sector. While the aggregate approach would imply a direct price reduction of $37 \%$, the exact firm-based formula tells us that this number should be only $20 \%$. Taken together, our results suggest that the heterogeneity in firms' domestic expenditure shares is important to credibly quantify the gains from input trade. ${ }^{49}$

Elasticity Bias. Importantly, there is a second source of bias that arises when using an aggregate approach which pertains to the "correct" elasticity of substitution $\varepsilon$. While we treat $\varepsilon$ as a production function parameter and estimate it from micro-data, aggregate models often estimate $\varepsilon$ from a gravity equation using aggregate trade flows. While there is a large literature concerning this particular parameter, most aggregate approaches find estimates that are larger than our preferred estimate of 2.38. ${ }^{5051}$ Costinot and Rodríguez-Clare (2014) for example use a trade elasticity of 5 as their benchmark value. See also Simonovska and Waugh (2013) and Simonovska and Waugh (2014) who report estimates between 3 and $4 .{ }^{52}$ As the implied gains from trade are decreasing in the elasticity of substitution, such choice would lead to substantially smaller gains from trade. In Section 6.6 of the Appendix, we redo the analysis of Table 4 for a range of values of $\varepsilon$ spanning the estimates from the literature. The elasticity bias can be substantial. Moving to $\varepsilon=5$, for example, reduces the consumer price gains from trade of the aggregate approach by $65 \%$.

Variable Mark-ups. We now gauge the sensitivity of our results with respect to the assumption of constant mark-ups. Building on our theoretical results from above, we follow Edmond et al. (2015) and allow for variable mark-ups in the context of the Atkeson and Burstein (2008) model. Because this case is conceptually similar to the CES benchmark, our analysis here is brief - an extensive analysis is contained in Section A.6 of the Online Appendix. According to (17)-(20), we require only two additional pieces of information : first we need to make a choice regarding the level of aggregation of the "lower" market segment of the CES demand structure and second we need to estimate the additional demand elasticity $\theta_{s}$. We then simply solve for the counterfactual distribution of mark-ups from (19) and calculate the change in consumer prices according to (17) and Proposition 1.

We follow Gaubert and Itskhoki (2016) and model the lower segment of demand as a 3-digit industry. In our data, this leaves us with 106 subsectors. To discipline the two elasticities $\left(\theta_{s}, \sigma_{s}\right)$,

49. We note that the results of Table are robust to using different weighting schemes. We re did the analysis weighting firms by employment and sales, instead of value added, and found very similar results. These are available upon request.

50. Antràs et al. (2014) also discuss the discrepancy between firm-level and aggregate estimates for this parameter. They show theoretically that estimates from an aggregate gravity equation are likely to be upward biased and present empirical evidence, which shows that firm-level estimates are indeed lower. See also Goldberg et al. (2010) for indirect evidence on the low substitutability between domestic and imported inputs for Indian manufacturing firms.

51. Recall that our benchmark is at the upper end of our estimates, as all other estimates of $\varepsilon$ in Table 2 are smaller.

52. These contributions also stress the importance of the trade elasticity to quantify the aggregate gains from trade. In particular, Simonovska and Waugh (2014) show that, conditional on the same trade-share data, models with different micro-structures require different trade-elasticity parameters to match the same moments from the distribution of relative prices. 
we require the variable mark-up economy to be consistent with the same moment as the constant markup economy, namely the aggregate revenue-cost ratio. ${ }^{53}$ The model implies that:

$$
\frac{1}{R C R_{s}}=1-\frac{1}{\theta_{s}}\left(1-\Omega_{s}\right)-\frac{1}{\sigma_{s}} \Omega_{s},
$$

where $R C R_{s}$ denotes the aggregate revenue cost ratio in sector $s, \Omega_{s}=\sum_{j \in s} \omega_{j s} H_{j s}$, where $\omega_{j s}$ is the share of subsector $j$ in sector $s$ and $H_{j s}$ is the Herfindahl index of firms' market shares in subsector $j$. Equation (33) defines a schedule of $\left(\theta_{s}, \sigma_{s}\right)$ that are consistent with $R C R$. To select among them, we consider two examples : in our first case, $\theta_{s}$ is large relative to $\sigma_{s}$ (we take $\theta_{s}=2 \times \sigma_{s}$ ); in our second case, $\theta_{s}$ is small (we take $\theta_{s}=1.1 \times \sigma_{s}$ ). ${ }^{54}$ The changes in consumer prices are very similar in the two cases : in the high $\theta_{s}$ case, consumer prices would be $28.9 \%$ higher in autarky; in the low $\theta_{s}$ case, the corresponding number is $28.7 \%$. Moreover, these estimates are quantitatively very similar to our earlier estimate of $27.5 \%$ in the constant markup economy. ${ }^{55}$

\subsection{A Shock to Import Prices}

We now extend the analysis to shocks that make all foreign varieties more expensive without leading the economy into autarky, as is for example the case under a currency devaluation (see e.g. Gopinath and Neiman (2014)). While the effect of the shock on consumer prices is still fully determined from the changes in firms' domestic shares, such changes are no longer observed and one needs a model to predict them. Hence, we now specify additional components of the theory. Doing so also allows us to quantify the effect of input trade on welfare, taking into account the resources (if any) spent by firms to attain their sourcing strategies. The goal of this section is to assess whether the observable micro data is important to quantify the effects of counterfactuals, which - by construction - are unobserved. To do so, we consider different models of importing which vary in the extent to which they match the micro data and compare their counterfactual implications.

53. The aggregate revenue-cost ratio is computed as the sector level average of firms' profit margins - see (25).

54. In principle, we could identify $\left(\theta_{s}, \sigma_{s}\right)$ from an additional moment. It is natural to exploit the information about the dispersion in markups. The model for example implies that :

$$
q_{1 / \mu, s}^{p}-q_{1 / \mu, s}^{q}=\left(\frac{1}{\sigma_{s}}-\frac{1}{\theta_{s}}\right) \times\left(q_{\omega, s}^{1-p}-q_{\omega, s}^{1-q}\right),
$$

where $q_{1 / \mu, s}^{\tau}\left(q_{\omega, s}^{\tau}\right)$ denotes the $\tau$ quantile of the distribution of the inverse of mark-ups $\mu^{-1}$ (the within subsegment market shares $\left.\omega_{i j}\right)$. (33) and (34) are sufficient to identify the parameters $\left(\theta_{s}, \sigma_{s}\right)$. In our application, it turns out that the model is unable to rationalize the observed dispersion in mark-ups for parameters $\left(\theta_{s}, \sigma_{s}\right)$ that are consistent with (33) and satisfy the theoretical restriction $1 \leq \sigma_{s} \leq \theta_{s}$. The French data therefore seems to ask for a richer model of pricing than the Atkeson and Burstein (2008) model. While we do find that mark-ups are increasing in sub-sector market shares, the relationship is quite noisy, i.e. there is ample cross-firm dispersion in mark-ups that is not explained by the variation in market-shares. Addressing this issue is beyond the scope of this paper and we thus focus on the two examples mentioned in the text. An extensive discussion is contained in Section A.6 in the Online Appendix. There we also compare our parameter estimates to the ones of Edmond et al. (2015).

55. We note, however, that the importance of the mark-up channel varies substantially across sectors and, in particular, that input trade is pro-competitive in some industries and anti-competitive in others - see Section A.6 of the Online Appendix. 


\section{Modeling Domestic Shares}

To construct a model of firms' domestic shares, we start from the general framework laid out in Section 2 and impose restrictions. ${ }^{56}$ For brevity, we provide all derivations in Section 6.7 of the Appendix. We consider settings where firms' extensive margin is limited through the presence of fixed costs so that firms choose their sourcing strategy by trading off the import-induced reduction in unit costs vs the payment of fixed costs. While this seems a natural starting point, one could extend the analysis to other models of the extensive margin.

We assume that the fixed cost of sourcing from a given country varies across firms but is constant across countries, i.e. $f_{c i}=f_{i}$. In this case, the firm selects its sourcing countries based purely on their price-adjusted qualities and the sourcing strategy reduces from a set $\Sigma$ to a scalar, a price-adjusted quality cutoff. ${ }^{57}$ We also impose the following functional form assumptions : (i) the import bundle $x_{I}$ takes a CES form with elasticity of substitution $\kappa$ and (ii) country quality $q_{c}$ is Pareto distributed, i.e. $\operatorname{Pr}\left(q_{c} \leq q\right)=1-\left(q_{\min } / q\right)^{\theta}$, where where $\theta>\min [1, \kappa-1] .{ }^{58}$ These assumptions imply that the import price index depends only on the mass of countries sourced from and takes a convenient power form :

$$
A(\Sigma)=\left(\int_{c \in \Sigma} q_{c}^{-(1-\kappa)} d c\right)^{\frac{1}{1-\kappa}}=\frac{1}{q_{\min }}\left(\frac{\theta}{\theta-(\kappa-1)}\right)^{\frac{1}{1-\kappa}} n^{-\left(\frac{1}{\kappa-1}\right)} \equiv z n^{-\eta}=A(n) .
$$

Here $n$ is the share of countries the firm sources foreign inputs from and $z$ and $\eta$ are "auxiliary" parameters which depend on the parameters governing the distribution of quality $\left(q_{\text {min }}, \theta\right)$ and the elasticity of substitution across foreign varieties $\kappa$. In particular, $z$ parametrizes the average qualityadjusted price of foreign inputs. We will consider changes in $z$ as our counterfactual shock. While the reversal to autarky considered above corresponds to $z \rightarrow \infty$, we are now able to study finite increases in $z$.

Under the above assumptions, the firm's profit maximization problem is given by

$$
\pi=\max _{n}\left\{u(n)^{1-\sigma} \times B-w\left(n f+f_{I} \mathbb{I}(n>0)\right)\right\},
$$

where $f$ denotes the fixed cost per country, $f_{I}$ is an additional fixed cost to start importing, $\mathbb{I}(\cdot)$ is an

indicator of import status and $B \equiv \frac{1}{\sigma}\left(\frac{\sigma}{\sigma-1}\right)^{1-\sigma} P^{\sigma-1} S$, with $P$ and $S$ denoting the consumer price index and aggregate spending, which are determined in general equilibrium. The unit cost function $u$ is given by the analogues of equations (5) and (6), which we replicate here for convenience :

56. For expositional simplicity, we consider a one-sector version of the model. See the Online Appendix for the analysis with multiple sectors.

57. More precisely, as long as fixed costs are constant across countries, if country $c$ with price-adjusted quality $q_{c} / p_{c}$ is an element of $\Sigma$ so are all countries $c^{\prime}$ with $q_{c^{\prime}} / p_{c^{\prime}}>q_{c} / p_{c}$. Computing firms' optimal sourcing strategies can be challenging when prices, qualities and fixed costs vary by country in an arbitrary way - see Antràs et al. (2014). Allowing for country-specific fixed costs will only matter for normative questions as long as it translates into a different predicted distribution of domestic shares.

58. For simplicity, we assume a continuum of countries so that firms' extensive margin can be characterized by a first order condition. It is straight-forward to work with a discrete number of countries. 


$$
\begin{aligned}
u(n) & \equiv \frac{1}{\tilde{\varphi}} w^{1-\gamma}\left(\frac{p_{D}}{q_{D}}\right)^{\gamma} s_{D}(n)^{\frac{\gamma}{\varepsilon-1}} \\
s_{D}(n) & =\left(1+\left(\frac{1-\beta}{\beta}\right)^{\varepsilon}\left(\left(\frac{p_{D}}{q_{D}}\right) \frac{1}{z} n^{\eta}\right)^{\varepsilon-1}\right)^{-1} .
\end{aligned}
$$

While (37) shows that the effect of input trade on firms' unit costs is fully summarized by the domestic share, (38) now contains a theory of domestic shares : these can be small either because the firm sources from many countries ( $n$ is large) or because of a technological bias towards foreign inputs ( $\beta$ is low).

Equations (36)-(38) fully describe firms' optimal import behavior. ${ }^{59}$ To close the model in general equilibrium, we impose equilibrium in the labor market and balanced trade between the domestic economy and the rest of the world. ${ }^{60}$ We assume that foreigners demand the output of local firms with the same CES demand structure as domestic consumers and producers ${ }^{61}$ and that the supply of foreign inputs from country $c$ is perfectly elastic. Letting $y_{i}^{R O W}$ be the foreign demand for firm $i$ 's production, balanced trade requires that

$$
\int_{i} p_{i} y_{i}^{R O W} d i=\int_{i}\left(1-s_{D i}\right) m_{i} d i
$$

where $m_{i}$ denotes material spending of firm $i$, so that $\left(1-s_{D i}\right) m_{i}$ is firm $i$ 's spending on imported varieties, and $p_{i}$ is firm $i$ 's price. An equilibrium is attained when firms maximize profits, consumers maximize utility, trade is balanced and labor and good markets clear.

In this context, it can be shown that the equilibrium change in consumer welfare relative to autarky is given by

$$
\frac{W}{W^{A u t}}=\frac{P^{A u t}}{P} \times\left(\frac{L-\int_{i} l_{\Sigma_{i}} d i}{L}\right),
$$

where $W$ denotes consumer welfare and $\int_{i} l_{\Sigma_{i}} d i$ denotes the aggregate resource loss due to fixed costs. Hence, the welfare gains from input trade consist of two components. First, there is the reduction in consumer prices associated with input trade. This is the main focus of our paper. Second, there is the resource loss due to fixed costs, which results in (weakly) fewer workers left for production. Because this second term in (40) is weakly smaller than unity, the change in the consumer price index provides an upper bound for the change in welfare in the class of models of Section 2. While we calculate $\int_{i} l_{\Sigma_{i}} d i$ within a model of fixed costs, we note that (40) is consistent with any extensive margin mechanism. For example, if importers found their trading partners through a process of

59. In Section 6.7 in the Appendix, we fully characterize the solution to this problem. There we also show that, conditional on importing, the optimal mass of sourcing countries $n$ is increasing in $\varphi$ and decreasing in $f$.

60. We abstract from trade in final goods. In this single sector economy with roundabout production, domestic inputs and final goods are equivalent. This is no longer the case with multiple sectors - see Section A.7 of the Online Appendix.

61. This simplifies the problem of local producers as the demand of their different customers (consumers, local firms and foreigners) can be aggregated into a single iso-elastic demand function. The term $B$ in (36) incorporates the sum of spending across the three types of customers. 
network formation, (40) would still hold but the environment to calculate $\int_{i} l_{\Sigma_{i}} d i$ would be different.

\section{Calibration and Results}

We now calibrate this model to the French micro data. In order to generate the rich distribution of domestic shares and value added shown in Figures 1 and 2, we have to allow for (at least) two sources of firm heterogeneity. As is standard, we allow firms to differ in efficiency $\tilde{\varphi}_{i}$. For the second source of heterogeneity, we consider two options. Our first option is a model with heterogeneous fixed costs, where firms differ in their $f_{i}{ }^{62}$ For simplicity, we assume that the fixed cost to start importing $f_{I}$ is constant across firms. Second, we consider a model with heterogenous home bias, where firms differ in their $\beta_{i}$. In this model, we assume there are no fixed costs of importing per country $(f=0)$, but we still assume a positive fixed cost to start importing $\left(f_{I}>0\right)$ to be able to match the existence of non-importing firms.

As $\tilde{\varphi}_{i}$ and the endogenous unit costs reduction through input trade are complements, there is a firm-specific efficiency cutoff, either $\bar{\varphi}\left(f_{i}\right)$ or $\bar{\varphi}\left(\beta_{i}\right)$, above which firms select into importing. This sorting generates overlap in the size distribution of importers and non-importers as seen in Figure 2. Furthermore, both models generate variation in import intensity conditional on size. While the heterogenous fixed cost model generates dispersion in import shares fully via variation in the extensive margin $n_{i}$, the bias-model is the polar opposite in that firms gain differentially from international trade because of variation in $\beta_{i}$.

In order to calibrate these parametrizations of the model to the data, we adopt the following strategy. First, we use the estimates of $\varepsilon, \gamma$ and $\sigma$ from Section 3.2 above. ${ }^{63}$ Next, for the model with heterogeneous fixed costs we need to estimate $\eta$, which determines the price index of the import bundle - see (35) - and hence the demand for foreign varieties. We estimate $\eta$ directly from the micro data : we identify it from the cross-sectional relationship between firms' extensive margin of trade and their domestic shares. ${ }^{64}$ Without loss of generality, we can normalize the quality of the domestic variety $\left(q_{D}\right)$ to unity. ${ }^{65}$

Finally, we parametrize the distributions for firm heterogeneity. For efficiency, we take a lognormal distribution with variance $\sigma_{\varphi}^{2}$. We normalize mean efficiency to unity. For the heterogeneous fixed cost model, we parametrize the conditional distribution of fixed costs also as log-normal, i.e. we parametrize the distribution of $(\log )$ fixed costs by its mean $\left(\mu_{f}\right)$, its variance $\left(\sigma_{f}^{2}\right)$ and the correlation with efficiency $\left(\rho_{f \varphi}\right)$. Similarly, we assume that the degree of home-bias, $\tilde{\beta} \equiv \frac{\beta}{1-\beta} \in[0, \infty]$,

62. This model is similar to the one in Halpern et al. (2015). They, however, do not target explicitly the joint distribution of firm size and domestic expenditure shares.

63. Section 3.2 provides estimates of $\sigma$ and $\gamma$ by sector. In this section, we use value-added weighted averages of these sectoral estimates, which yield $\sigma=3.83$ and $\gamma=0.61$.

64. In particular, (38) predicts a log-linear relation between $n$ and $\left(1-s_{D}\right) / s_{D}$, with a slope given by $\eta$. See Section 6.8 in the Appendix for details and results. Our preferred specification yields a value of $\eta$ of 0.382 that is precisely estimated. This implies that the elasticity of substitution between foreign varieties $\kappa$ is given by $\kappa=1+\eta^{-1}=3.63$. Note also that we do not require $\eta$ for the heterogeneous bias model as all firms decide to source from all countries (conditional on importing), i.e. $n=1$, see (38).

65. See Section A.8 of the Online Appendix. 
is conditionally $\log$-normally distributed with mean $\mu_{\tilde{\beta}}$, variance $\sigma_{\tilde{\beta}}^{2}$ and correlation $\rho_{\tilde{\beta} \varphi}{ }^{66}$

Calibration. Our calibration strategy is as follows. ${ }^{67}$ The distributions of firm heterogeneity are parametrized by four parameters. For the model with heterogenous fixed costs (resp. home bias), such parameters control the dispersion in efficiency, the dispersion in fixed costs (resp. home bias), the average fixed cost (resp. home bias) and the correlation of fixed costs (resp. home bias) with efficiency. For each model, we calibrate these parameters by targeting salient features of the joint distribution of value added and domestic shares displayed in Figures 1 and 2. In particular, we match the aggregate domestic share, the dispersion in value added, the dispersion in domestic shares and their correlation with value added. Finally, we also need to calibrate the fixed cost to start importing $f_{I}$ and to do so we target the share of non-importing firms.

To assess the value of the micro data, we also calibrate the above models without targeting the moments associated with the heterogeneity in domestic shares, i.e. their dispersion and correlation with firm size. As we drop these two moments, we also drop two parameters in each model. In the heterogeneous fixed costs model, we set $\sigma_{f}=\rho_{f \varphi}=0$, which corresponds to assuming constant fixed costs across firms. We call this parametrization the homogeneous fixed cost model. ${ }^{68}$ In the heterogeneous home bias model, we set $\sigma_{\beta}=\rho_{\beta \varphi}=0$, which corresponds to a homogeneous home bias model. Finally, we consider a model with no fixed costs of any kind, $f_{i}=f_{I}=0$ and a constant home bias. This version of the model implies that firms' import intensities are equalized and aggregate statistics are sufficient. We therefore refer to it as the aggregate model. ${ }^{69}$

Table 5 summarizes the five parametrizations of the model we consider and contains the calibration results. In Panel A, we report the calibrated parameters. Panel B contains the model-generated moments, as well as the targeted ones in bold letters. We first note that all versions of the model match the targeted moments exactly. As expected, the aggregate model (column 5) generates full participation in import markets and equalized domestic shares. The homogeneous fixed cost and home bias models (columns 3 and 4) improve on these counterfactual implications by allowing for fixed costs. However, because they feature efficiency as the single source of firm heterogeneity, these models predict too strong a correlation between firm-size and domestic shares relative to the data, as well as no overlap in the size distribution of importers and domestic firms (see Figure 2). By allowing for an additional dimension of heterogeneity, the heterogenous fixed costs or home-bias models (columns 1 and 2) improve the fit along these dimensions. First, they increase the dispersion in domestic shares by introducing variation in import demand conditional on efficiency. Second, they reduce the correlation between size and domestic shares. Intuitively, to be consistent with the low correlation of size and import intensity both parametrizations require that some efficient firms have

66. Formally, we assume that $\ln (\tilde{\varphi}) \sim \mathcal{N}\left(-\frac{1}{2} \sigma_{\varphi}^{2}, \sigma_{\varphi}^{2}\right)$ and parametrize the conditional distribution of fixed costs and home bias as $\left.\ln (f)\right|_{\ln (\tilde{\varphi})} \sim \mathcal{N}\left(a_{0}+a_{\varphi} \ln (\tilde{\varphi}), \sigma_{f \mid \varphi}^{2}\right)$ and $\left.\ln (\tilde{\beta})\right|_{\ln (\tilde{\varphi})} \sim \mathcal{N}\left(b_{0}+b_{\varphi} \ln (\tilde{\varphi}), \sigma_{\tilde{\beta} \mid \varphi}^{2}\right)$. We then get that $\mu_{f}=a_{0}-\frac{a_{\varphi}}{2} \sigma_{\varphi}^{2}, \sigma_{f}^{2}=a_{\varphi}^{2} \sigma_{\varphi}^{2}+\sigma_{f \mid \varphi}^{2}$ and $\rho_{f \varphi}=a_{\varphi} \frac{\sigma_{\varphi}}{\sigma_{f}}$ (and for the case of the home bias analogously).

67. We describe the algorithm used to calibrate the model in Section A.8 of the Online Appendix.

68. This model is similar to the ones used in Gopinath and Neiman (2014) and Ramanarayanan (2014).

69. This model is parametrized by two parameters : the dispersion of efficiency and the home-bias $\tilde{\beta}$, which is constant across firms. We calibrate these parameters to match the dispersion in value added and the aggregate domestic share. 
a lower incentive to import compared to a model with a single source heterogeneity. This is achieved by having a positive correlation between firm efficiency and fixed costs (resp. home bias).

[Table 5 here]

Results. With the calibrated models at hand, we can now study the effect of any shock to the trading environment on both consumer prices and welfare. We focus on two counterfactuals : (i) a reversal to input autarky $(z \rightarrow \infty)$ and (ii) an increase in the relative price of all foreign inputs. More precisely, the latter exercise corresponds to increasing $z$ to attain a decrease in the aggregate import share of $5 \%, 10 \%$ or $20 \%$. Table 5 contains the results, from which we draw three main conclusions.

First, we find that the two models that match the micro data on size and domestic shares predict the same counterfactual change in consumer prices. To see this, consider the two models in columns 1 and 2. While both models perfectly match the four moments of the joint distribution of value added and domestic shares, their underlying microstructure is very different. They nevertheless give very similar predictions for the change in consumer prices across the different counterfactuals. That this result is exact for a reversal to input autarky (Panel C) is the content of Proposition 1 : both models predict an increase in consumer prices of $38 \% .{ }^{70}$ Panel D shows that this is also the case for the non-autarky counterfactuals : the difference in the implied changes in consumer prices between the two models is less than $1 \%$.

Second, the models that do not match the data on domestic shares and value added (columns 3- 5) yield quantitatively meaningful biases. In panel $\mathrm{C}$, we report the change in consumer prices relative to autarky : the three models predict changes that are $14-18 \%$ too high. That such biases are not confined to the autarky-counterfactual is seen in Panel D. The estimated effects of the three devaluations are also upward biased by similar magnitudes. To understand why these biases are positive it is helpful to go back to our theoretical results. That the aggregate model in column 5 predicts the largest change in consumer prices in the autarky counterfactual follows from our characterization of the bias in $(23)$ : because $\gamma(\sigma-1) /(\varepsilon-1)>1$, the aggregate model provides an upper bound for any model of importing. It is also intuitive that the models with homogeneous fixed costs and home-bias are upward biased viz-a-viz the models that match the microdata on firm-size and domestic shares. By relying on efficiency as the single source of firm heterogeneity, the models in column 3 and 4 generate a perfectly negative correlation between efficiency and the domestic share. This means that more efficient firms experience a larger reduction in their unit cost, a feature that tends to make input trade more attractive. Given the estimated parameters, this result is further reinforced by the lower dispersion in domestic shares generated by these models.

Finally, we also calculate the change in welfare taking the resource loss of fixed costs into account. We report the results for the reversal to autarky in the last row of Panel C. In contrast to the results for consumer prices, the implications for welfare can vary substantially across models, even conditional on fully matching the micro data. Specifically, columns 1 and 2 in Panel $\mathrm{C}$ show that the

70. This number does not coincide with that reported for the Manufacturing sector in Table 4 above, i.e. $27.5 \%$. The reason is that we calibrated a one-sector version of the model of Section 2 to moments obtained from pooling all industries. Additionally, we targeted only five moments of the joint distribution of size and domestic shares. 
heterogeneous fixed cost and home bias models predict very different changes in welfare relative to input autarky. While the former predicts an increase of $17 \%$ in welfare, the latter predicts an increase of $36 \% .{ }^{71}$ Thus, the share of the consumer price gains that is lost by firms' attaining their sourcing strategies crucially depends on how domestic shares are modeled.

\section{Conclusion}

Firms around the world routinely engage in input trade to reduce their costs of production, thereby benefiting domestic consumers through lower prices. Moreover, firms differ vastly in the intensity with which they participate in international markets. In this paper, we develop a methodology to measure how consumer prices are affected by input trade in environments which explicitly take the heterogeneity in import behavior into account.

Our main theoretical result is a sufficiency result that shows that the change in consumer prices due to changes in the import environment (e.g. a change in trade costs or a change in foreign prices) is fully determined from the joint distribution of firm size and changes in domestic expenditure shares. Importantly, a wide class of models used in the literature features the same predictions for consumer prices as long as they are calibrated to the same micro data. Approaches that abstract from firm heterogeneity altogether and rely on aggregate statistics give biased results. A focal point of our analysis is the case of a reversal to input autarky. As firms' counterfactual domestic shares in autarky are equal to unity, the gains from input trade are fully determined from firms' value added and domestic shares. In our application to France, we find that consumers would face $27 \%$ higher prices for manufacturing products under input autarky.

We then show quantitatively that this result extends to non-autarky counterfactuals such as an increase in the price of foreign inputs. In the context of a model with fixed costs, we find that parametrizations of the model that are calibrated to the micro data on firm size and domestic shares imply similar changes in consumer prices. Conversely, models that do not match this data give biased predictions. We conclude that the information contained in the joint distribution of firm-level domestic shares and size is crucial to quantify the effect of input trade on consumer prices in settings with heterogeneous importers.

71. Note that this difference is not due to the fact that the home bias model does not feature any fixed cost per sourcing country. The homogenous home bias model of column 4 does not feature any fixed costs per country either, but implies that the fixed costs to start importing account for about $40 \%$ of the consumer price gains. The reason why heterogeneity in the efficiency of using imported inputs generates a tighter bound between welfare and consumer prices is the discrepancy between the marginal importer, whose cost reductions determine the calibrated value of fixed costs, and the set of inframarginal firms, who might benefit from input trade substantially. 


\section{Références}

Ackerberg, Daniel, Kevin Caves, and Garth Frazer (2015), "Identification properties of recent production function estimators." Econometrica, 83, 2411-2451.

Amiti, Mary, Mi Dai, Robert C. Feenstra, and John Romalis (2016), "How did china's wto entry benefit u.s. consumers?" Working Paper.

Amiti, Mary, Oleg Itskhoki, and Jozef Konings (2014), "Importers, exporters, and exchange rate disconnect." American Economic Review, 104, 1942-1978.

Amiti, Mary and Jozef Konings (2007), "Trade liberalization, intermediate inputs and productivity." American Economic Review, 97, 1611-1638.

Antràs, Pol, Teresa C. Fort, and Felix Tintelnot (2014), "The margins of global sourcing : Theory and evidence from u.s. firms." Working Paper.

Arkolakis, Costas, Arnaud Costinot, and Andres Rodriguez-Clare (2012), "New trade models, same old gains?" American Economic Review, 102(1), 94-130.

Atkeson, Andrew and Ariel Burstein (2008), "Pricing-to-market, trade costs, and international relative prices." American Economic Review, 98, 1998-2031.

Bernard, Andrew B., J. Bradford Jensen, Stephen J. Redding, and Peter K. Schott (2012), "The empirics of firm heterogeneity and international trade." Annual Review of Economics, 4, 283-313.

Blaum, Joaquin, Claire Lelarge, and Michael Peters (2013), "Non-homothetic import demand : Firm productivity and quality bias." Working Paper.

Bresnahan, Timothy (1989), "Empirical studies of industries with market power." In Handbook of Industrial Organization, volume 2, 1011-1057, Elsevier.

Broda, Christian and David E. Weinstein (2006), "Globalization and the gains from varieties." Quarterly Journal of Economics, 121, 541-585.

Caliendo, Lorenzo and Fernando Parro (2015), "Estimates of the trade and welfare effects of nafta." The Review of Economic Studies, 82, 1-44.

Costinot, Arnaud and Andres Rodríguez-Clare (2014), "Trade theory with numbers : Quantifying the consequences of globalization." In Handbook of International Economics.

De Loecker, Jan (2011), "Product differentiation, multiproduct firms, and estimating the impact of trade liberalization on productivity." Econometrica, 79, 1407-1451.

De Loecker, Jan and Pinelopi Goldberg (2013), "Firm performance in a global market." The Annual Review of Economics, 6, 201-227. 
De Loecker, Jan, Pinelopi K. Goldberg, Amit K. Khandelwal, and Nina Pavcnik (2016), "Prices, markups and trade reform." Econometrica, 84, 445-510.

De Loecker, Jan and Frederic Warzynski (2012), "Markups and firm-level export status." American Economic Review, 102, 445-510.

Eaton, Jonathan and Samuel Kortum (2002), "Technology, geography, and trade." Econometrica, 70, 1741-1779.

Eaton, Jonathan, Samuel Kortum, and Francis Kramarz (2011), "An anatomy of international trade : Evidence from french firms." Econometrica, 79, 1453-1498.

Edmond, Chris, Virgiliu Midrigan, and Daniel Yi Xu (2015), "Competition, markups and the gains from international trade." American Economic Review, 105, 3183-3221.

Eslava, Marcela, Ana Cecilia Fieler, and Daniel Yi Xu (2015), "Trade, skills, and quality upgrading : A theory with evidence from colombia." Working Paper.

Feenstra, Robert C. (1994), "New product varieties and the measurement of international prices." American Economic Review, 84, 157-177.

Gaubert, Cecile and Oleg Itskhoki (2016), "Granular comparative advantage." Working Paper.

Goldberg, Pinelopi, Amit Khandelwal, Nina Pavcnik, and Petia Topalova (2010), "Imported intermediate inputs and domestic product growth : Evidence from india." Quarterly Journal of Economics, $125,1727-1767$.

Gopinath, Gita and Brent Neiman (2014), "Trade adjustment and productivity in large crises." American Economic Review, 104, 793-831.

Griliches, Zvi and Jerry A. Hausman (1986), "Errors in variables in panel data." Journal of Econometrics, 31, 93-118.

Halpern, Laszlo, Miklos Koren, and Adam Szeidl (2015), "Imported inputs and productivity." The American Economic Review, 105, 3660-3703.

Hummels, David, Rasmus Jorgenson, Jakob R. Munch, and Chong Xiang (2011), "The wage effect of offshoring : Evidence from danish matched worker-firm data." Working Paper.

Imbs, Jean and Isabelle Mejean (2015), "Elasticity optimism." American Economic Journal : Macroeconomics, 7, 43-83.

Kasahara, Hiroyuki and Joel Rodrigue (2008), "Does the use of imported intermediates increase productivity? plant-level evidence." Journal of Development Economics, 87, 106-118.

Khandelwal, Amit and Petia Topalova (2011), "Trade liberalization and firm productivity : The case of india." The Review of Economics and Statistics, 93, 995-1009. 
Kugler, Maurice and Eric Verhoogen (2011), "Prices, plant size, and product quality." Review of Economic Studies, 1-33.

Levinsohn, James and Amil Petrin (2003), "Estimating production functions using inputs to control for unobservables." Review of Economic Studies, 70, 317-341.

Levinsohn, James and Amil Petrin (2012), "Measuring aggregate productivity growth using plantlevel data." The RAND Journal of Economics, 43, 705-725.

Lu, Dan, Asier Mariscal, and Luis-Fernando Mejia (2016), "How firms accumulate inputs : Evidence from import switching." Working Paper.

Oberfield, Ezra and Devash Raval (2014), "Micro data and macro technology." Working Paper.

Olley, Steven and Ariel Pakes (1996), "The dynamics of productivity in the telecommunications equipment industry." Econometrica, 64, 1263-97.

Pavcnik, Nina (2002), "Trade liberalization, exit and productivity improvements : Evidence from chilean plants." Review of Economic Studies, 69, 245-276.

Ramanarayanan, Ananth (2014), "Imported inputs and the gains from trade." Working Paper.

Simonovska, Ina and Michael E. Waugh (2013), "The elasticity of trade : Estimates and evidence." Journal of International Economics, 92, 34-50.

Simonovska, Ina and Michael E. Waugh (2014), "Trade models, trade elasticities, and the gains from trade." Working Paper.

Syverson, Chad (2011), "What determines productivity?" Journal of Economic Literature, 49, 326365.

Wooldridge, Jeffrey (2009), "On estimating firm-level production functions using proxy variables to control for unobservables." Economics Letters, 104, 112-114. 


\section{$5 \quad$ Tables and Figures}

TABLE 1 - Structural Parameters by Industry

\begin{tabular}{|l|c|c|c|c|c|c|}
\hline Industry & ISIC & $\alpha_{s}$ & $\sigma_{s}$ & $\gamma_{s}$ & VA share & $s_{D s}^{A g g}$ \\
\hline \hline Mining & $10-14$ & $0.02 \%$ & 2.58 & 0.33 & $1.28 \%$ & 0.90 \\
Food, tobacco, beverages & $15-16$ & $9.90 \%$ & 3.85 & 0.73 & $15.24 \%$ & 0.80 \\
Textiles and leather & $17-19$ & $3.20 \%$ & 3.35 & 0.63 & $3.96 \%$ & 0.54 \\
Wood and wood products & 20 & $0.13 \%$ & 4.65 & 0.60 & $1.67 \%$ & 0.81 \\
Paper, printing, publishing & $21-22$ & $1.37 \%$ & 2.77 & 0.50 & $7.96 \%$ & 0.75 \\
Chemicals & 24 & $2.04 \%$ & 3.29 & 0.67 & $12.91 \%$ & 0.60 \\
Rubber and plastics products & 25 & $0.44 \%$ & 4.05 & 0.59 & $5.88 \%$ & 0.63 \\
Non-metallic mineral products & 26 & $0.24 \%$ & 3.48 & 0.53 & $4.54 \%$ & 0.72 \\
Basic metals & 27 & $0.01 \%$ & 5.95 & 0.67 & $2.07 \%$ & 0.60 \\
Metal products (ex machinery and equipment) & 28 & $0.26 \%$ & 3.27 & 0.48 & $9.27 \%$ & 0.81 \\
Machinery and equipment & 29 & $0.66 \%$ & 3.52 & 0.62 & $7.00 \%$ & 0.69 \\
Office and computing machinery & 30 & $0.43 \%$ & 7.39 & 0.81 & $0.35 \%$ & 0.59 \\
Electrical machinery & 31 & $0.47 \%$ & 4.49 & 0.60 & $3.99 \%$ & 0.64 \\
Radio and communication & 32 & $0.63 \%$ & 3.46 & 0.62 & $1.92 \%$ & 0.64 \\
Medical and optical instruments & 33 & $0.35 \%$ & 2.95 & 0.49 & $3.83 \%$ & 0.66 \\
Motor vehicles, trailers & 34 & $4.31 \%$ & 6.86 & 0.76 & $9.99 \%$ & 0.82 \\
Transport equipment & 35 & $0.37 \%$ & 1.87 & 0.35 & $4.72 \%$ & 0.64 \\
Manufacturing, recycling & $36-37$ & $1.79 \%$ & 3.94 & 0.63 & $3.42 \%$ & 0.75 \\
\hline Non-manufacturing & & $73.39 \%$ & na & 0.41 & & 1 \\
\hline
\end{tabular}

Notes : $\sigma_{s}$ denotes the demand elasticity, which is measured with industry-specific average markups. Markups are constructed as the ratio of firm revenues to total costs, which are computed as the sum of material spending, labor payments and the costs of capital. The costs of capital are measured as $R k$ where $k$ denotes the firm's capital stock and $R$ is the gross interest rate, which we take to be 0.20. $\alpha_{s}$ denotes the sectoral share in consumer expenditure, which is taken from the Input-Output Tables according to (24). $\gamma_{s}$ denotes the sectoral share of material spending in total costs, which is measured at the firm level and then averaged at the sector level. "VA share" is the sectoral share of value added in manufacturing, computed from the firm-level data. $s_{D s}^{A g g}$ are the sectoral aggregate domestic shares, computed as $s_{D s}^{A g g}=\sum_{i=1}^{n} s_{D i s} \times \omega_{i s}$, where $\omega_{i s}$ is the firm share in sectoral value added. See Appendix for the details. 


\section{TABLE 2 - Estimating the Elasticity of Substitution}

\begin{tabular}{|c|c|c|c|c|c|c|}
\hline & & \multirow[b]{2}{*}{ First stage } & \multicolumn{2}{|c|}{ Reduced form estimates : } & \multirow[b]{2}{*}{$\epsilon$} & \multirow[b]{2}{*}{$\mathrm{N}$} \\
\hline & & & $\Delta \ln$ productivity & $\Delta \ln \mathrm{VA}$ & & \\
\hline \multirow[t]{2}{*}{ Full sample } & All weights & $\begin{array}{c}-0.019 * * * \\
(0.003)\end{array}$ & $\begin{array}{c}0.014^{* * *} \\
(0.004)\end{array}$ & $\begin{array}{c}0.050^{* * *} \\
(0.005)\end{array}$ & $\begin{array}{c}2.378^{* * *} \\
(0.523)\end{array}$ & 526,687 \\
\hline & $\begin{array}{l}\text { Pre-sample } \\
\text { weights }\end{array}$ & $\begin{array}{c}-0.017^{* * *} \\
(0.004)\end{array}$ & $\begin{array}{c}0.024^{* * *} \\
(0.004)\end{array}$ & $\begin{array}{c}0.068^{* * *} \\
(0.006)\end{array}$ & $\begin{array}{c}1.711 * * * \\
(0.166)\end{array}$ & 443,954 \\
\hline \multirow[t]{2}{*}{ Importers } & All weights & $\begin{array}{c}-0.010 * * * \\
(0.004)\end{array}$ & $\begin{array}{c}0.005 \\
(0.004)\end{array}$ & $\begin{array}{c}0.030 * * * \\
(0.006)\end{array}$ & $\begin{array}{c}2.322^{* *} \\
(1.014)\end{array}$ & 65,799 \\
\hline & $\begin{array}{l}\text { Pre-sample } \\
\text { weights }\end{array}$ & $\begin{array}{c}-0.010^{* *} \\
(0.005)\end{array}$ & $\begin{array}{c}0.009 * * \\
(0.004)\end{array}$ & $\begin{array}{c}0.033^{* * *} \\
(0.006)\end{array}$ & $\begin{array}{c}1.892^{* * *} \\
(0.541)\end{array}$ & 54,604 \\
\hline
\end{tabular}

Notes : Robust standard errors in parentheses with ***, **, and $*$ respectively denoting significance at the $1 \%$, $5 \%$ and $10 \%$ levels. The table contains the results of estimating (31) with the instrument given in (30). We employ estimates of $\gamma_{s}$ and $\sigma_{s}$ based on (27) and (25), which are contained in Table 1.We use data for the years 2002-2006. The pre-sample period is 2001. In column 1 we report the first stage relationship between our instrument and the changes in firms' domestic expenditure shares. The F-statistic for the main specification is 10.5. Columns 2 and 3 show that the instrument is correlated with two measures of firm performance, productivity and value added. Column 4 reports the implied value of $\varepsilon$ as per (31). In the top panel we include all firm, in the bottom panel we only focus on the set of importing firms. In rows 1 and 3 we exploit the entire panel and calculate firms' pre-sample import shares from their expenditure pattern from the first year they appear as importers in the data. In rows 2 and 4 we take the first year in our data as the pre-sample period and hence only include firm, who were already active in that year. We retrieve $\hat{\varepsilon}$ from (31) using the standard delta-method. The obtained estimator is convergent and asymptotically Gaussian. However, in our setting, $\hat{\gamma}_{s}$ and $1 / \widehat{(1-\varepsilon)}$ are estimated in two separate regressions. We therefore rely on a bootstrap procedure with 200 replications to estimate the standard error associated with $\hat{\varepsilon}$.

TABle 3 - Moments of the Distribution of Producer Gains in France

\begin{tabular}{c|c|c|c|c|c}
\hline Mean & \multicolumn{5}{|c}{ Quantile } \\
& 10 & 25 & 50 & 70 & 90 \\
\hline \hline 24.87 & 0.64 & 2.79 & 11.18 & 33.74 & 85.73 \\
\hline
\end{tabular}

Notes : The table reports quantiles of the empirical distribution of the firm-level gains from input trade relative to autarky, i.e. $\left(s_{D i}^{\gamma_{s} /(1-\varepsilon)}-1\right) \times 100-$ see $(7)$. The data for the domestic expenditure share corresponds to the cross-section of importing firms in 2004. For $\varepsilon$ and $\gamma_{s}$, the estimates from the factor shares approach contained in Tables 1 and 2 are used. 


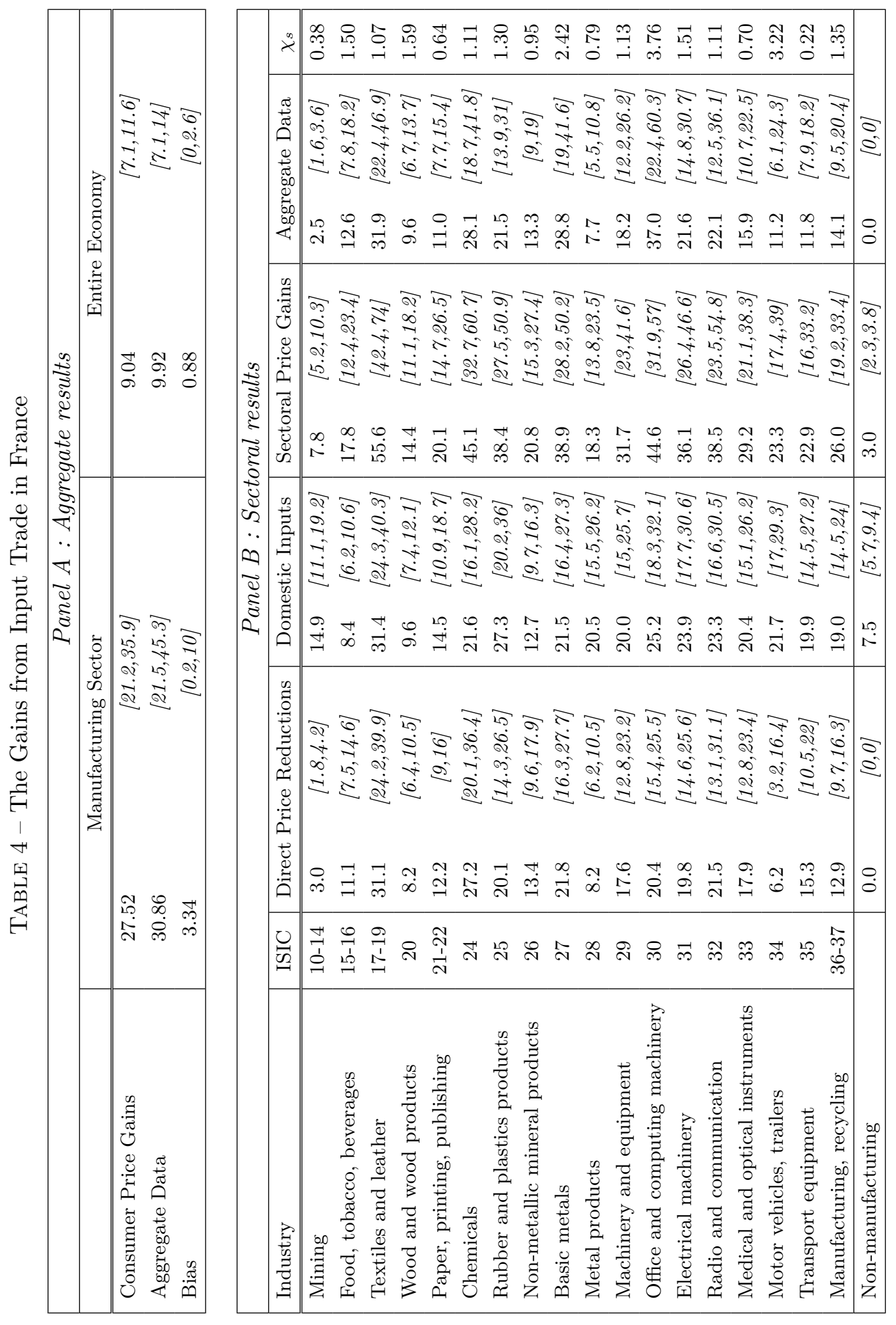

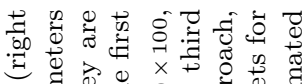

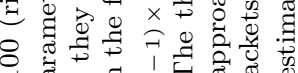
政击

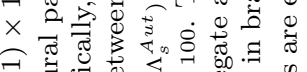

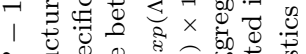

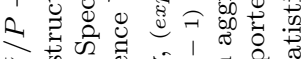

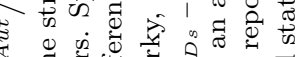

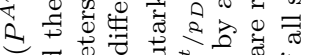

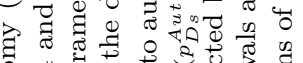

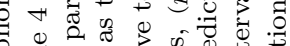

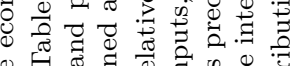

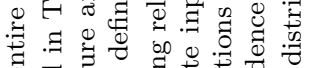
व क

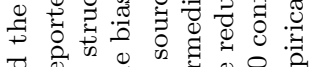

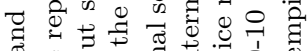

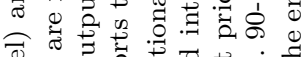

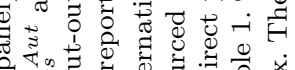

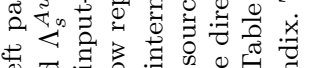

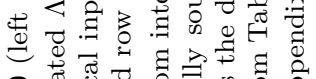

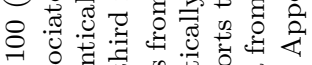

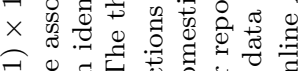
7 o 7 B

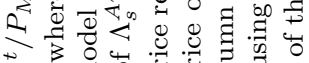
춘

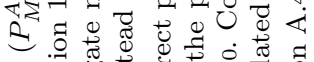

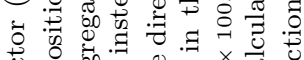

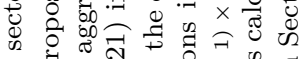
on 0 .

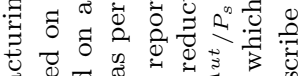

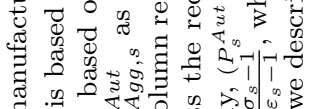

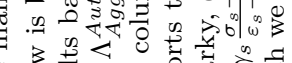
을

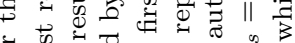

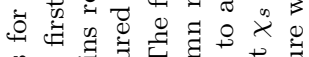
造 进.

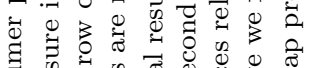

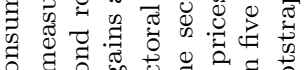
8.

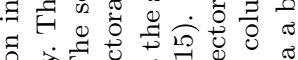
웅

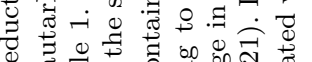

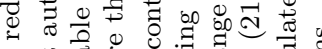

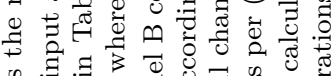

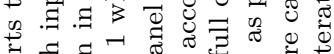
क人

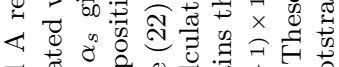

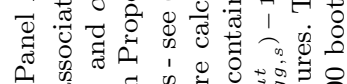

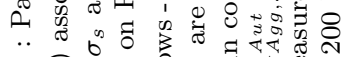

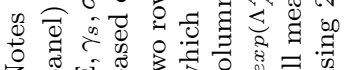




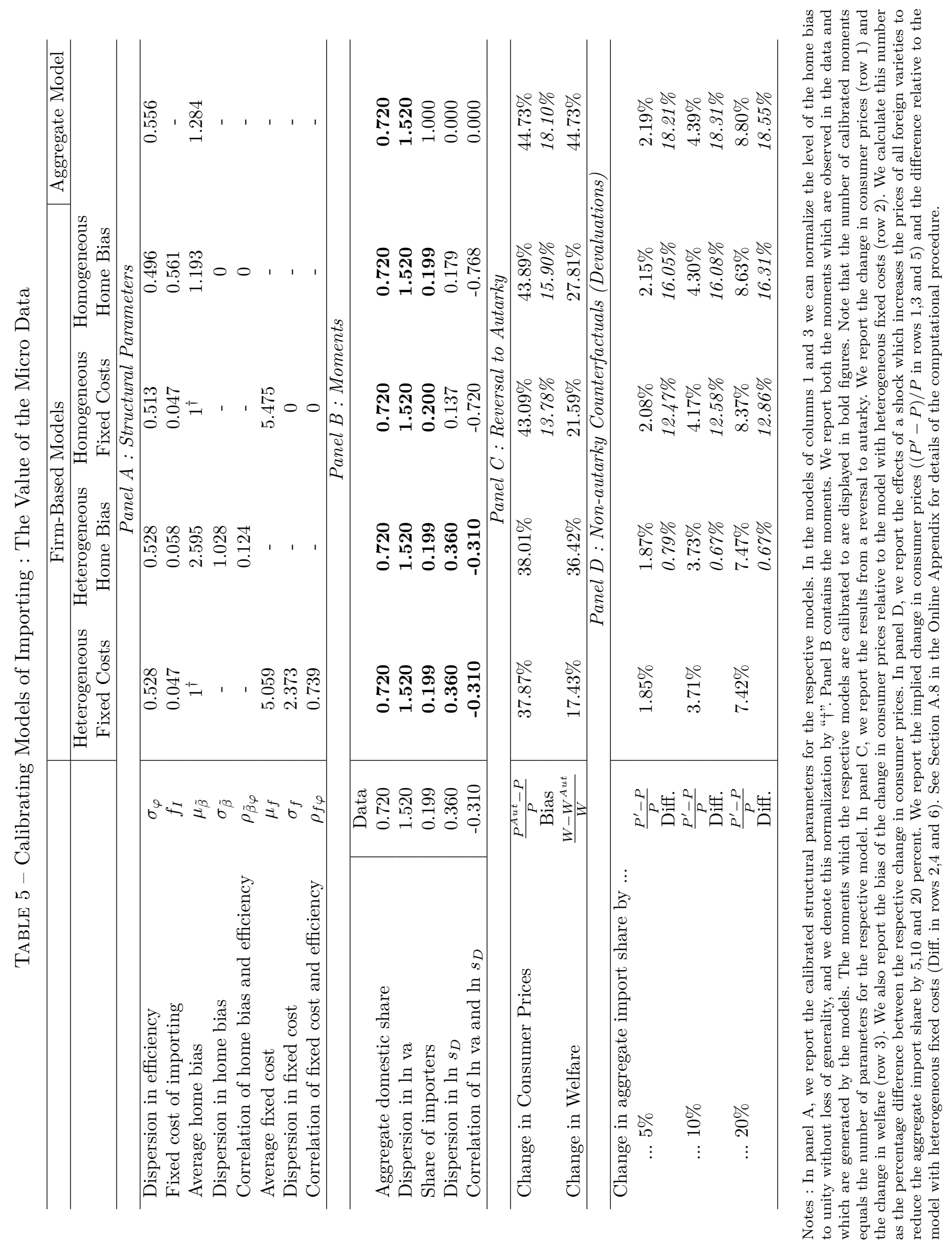


Figure 1 - The Dispersion in Domestic Shares

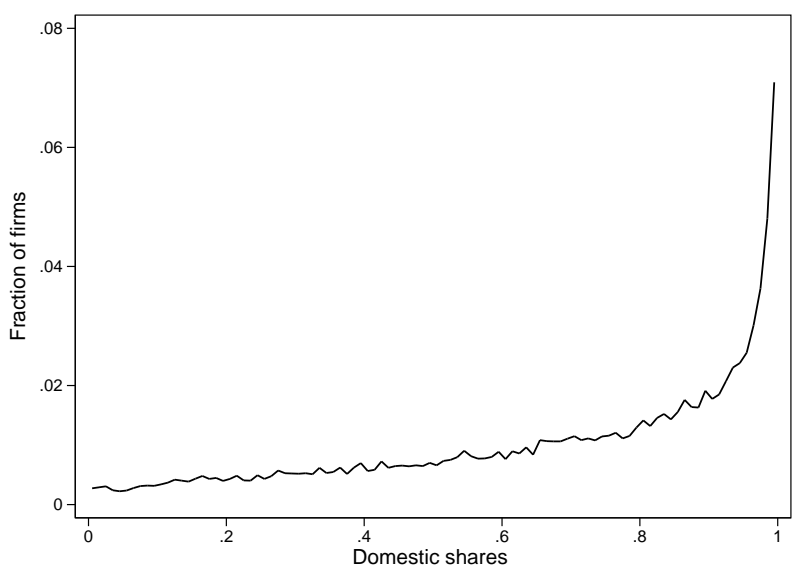

Notes : The figure shows the cross-sectional distribution of domestic expenditure shares, i.e. the share of material spending allocated to domestic inputs, for the population of importing manufacturing firms in France in 2004.

\section{Figure 2 - Domestic Shares and Firm Size}
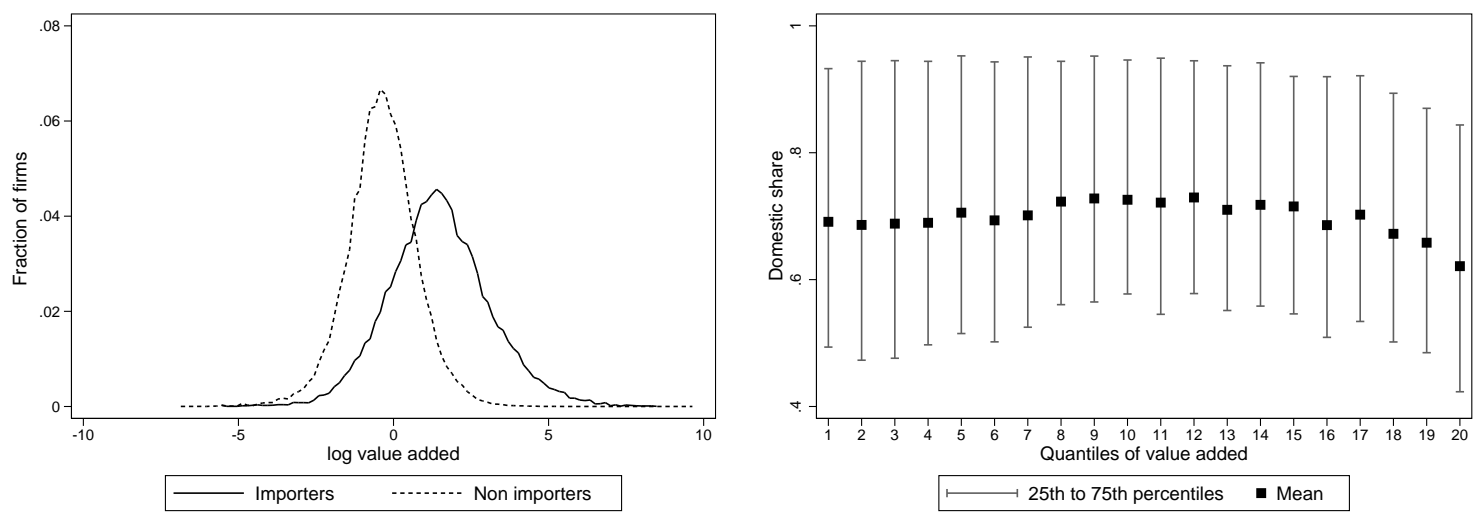

Notes : The left panel displays the distribution of log value added by import status. The right panel shows the mean and the 25th and $75 \mathrm{~h}$ percentiles of domestic shares for twenty quantiles of value added for importers. The data corresponds to the population of manufacturing firms in France in 2004. 
FIGURE 3 - Estimates of $\varepsilon_{s}$ from estimated production functions

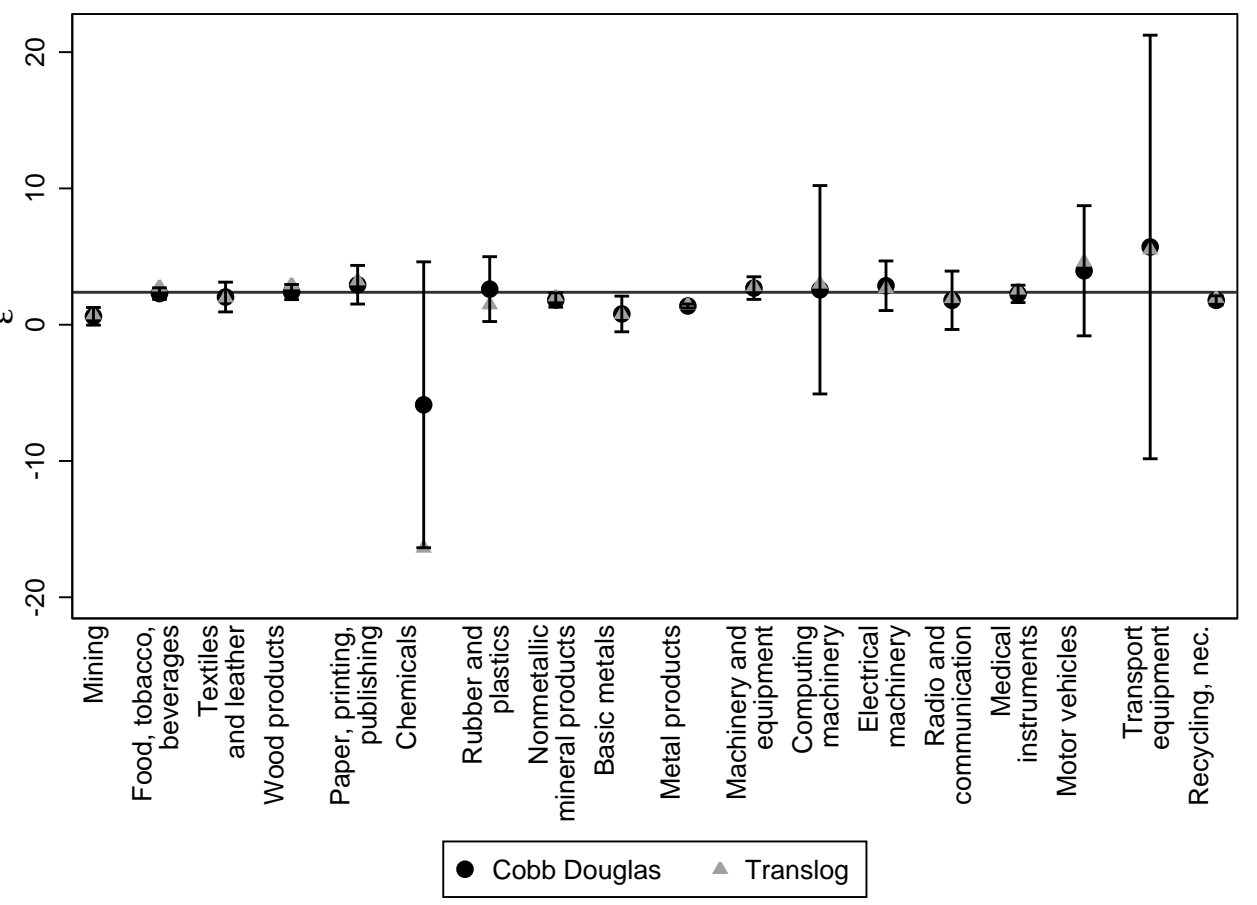

Notes : This figure displays the sector-specific estimates of $\varepsilon$ from (32). We show both the baseline Cobb-Douglas specification, including the confidence intervals, and an alternative specification, which allows for a translog production function in $k$ and $l$. See section 6.5 in the Appendix for more details and the full results. For comparison, we also display the benchmark estimate from the factor share approach $(\varepsilon=2.38)$

Figure 4 - The Firm-Level Gains from Input Trade in France

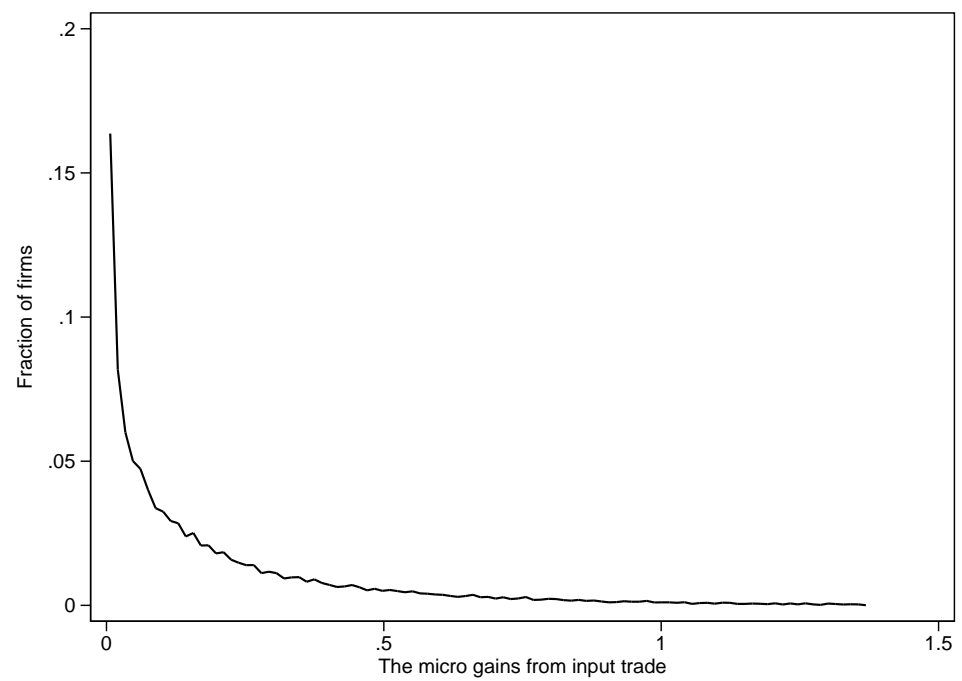

Notes : The figure reports the empirical distribution of the firm-level gains from input trade relative to autarky, i.e. $\left(s_{D i}^{\gamma_{s} /(1-\varepsilon)}-\right.$ 1) $\times 100$ - see (7). The data for the domestic expenditure shares corresponds to the cross-section of French importing firms in 2004 . The values for $\varepsilon$ and $\gamma_{s}$ are taken from Tables 1 and 2 . 


\section{Appendix}

\subsection{Generalizations of Equation (7)}

In this section, we consider three generalizations of equation (7), which states that the firm's unit costs is given by

$$
u_{i}=\frac{1}{\tilde{\varphi}_{i}} \times\left(s_{D i}\right)^{\frac{\gamma}{\varepsilon-1}} \times\left(\frac{p_{D}}{q_{D}}\right)^{\gamma} w^{1-\gamma} .
$$

(41) was derived under the restrictions : (i) the production function has a constant elasticity of materials $\gamma$, (ii) domestic and foreign inputs are combined in a CES fashion with elasticity of substitution $\varepsilon$ and (iii) foreign inputs are differentiated at the country, but not at the product level. We now relax these assumptions and derive expressions akin to (41).

Extension 1 : CES Upper Tier. Suppose that the production function between materials $x$ and primary factors $l$ is CES instead of Cobb-Douglas, i.e.

$$
y=\varphi\left((1-\gamma) l^{\frac{\zeta-1}{\zeta}}+\gamma x^{\frac{\zeta-1}{\zeta}}\right)^{\frac{\zeta}{\zeta-1}} .
$$

The rest of the environment is exactly as in Section 2. Let $Q$ denote again the price index of materials $x$ and $w$ denote the price of primary factors $l$. In this case, the firm's unit cost is given by

$$
u=\frac{1}{\varphi}\left(\gamma^{\zeta} Q^{1-\zeta}+(1-\gamma)^{\zeta} w^{1-\zeta}\right)^{\frac{1}{1-\zeta}}
$$

Noting that the optimal expenditure share on materials is given by

$$
s_{M}=\frac{\gamma^{\zeta} Q^{1-\zeta}}{\gamma^{\zeta} Q^{1-\zeta}+(1-\gamma)^{\zeta} w^{1-\zeta}},
$$

we can write the firm's unit cost as

$$
u=\frac{1}{\varphi} s_{M}^{\frac{1}{\zeta-1}}\left(\frac{1}{\gamma}\right)^{\frac{\zeta}{\zeta-1}} s_{D}^{\frac{1}{\varepsilon-1}}\left(\frac{1}{\beta}\right)^{\frac{\varepsilon}{\varepsilon-1}}\left(\frac{p_{D}}{q_{D}}\right) \propto s_{M}^{\frac{1}{\zeta-1}} s_{D}^{\frac{1}{\varepsilon-1}},
$$

where we have substituted for $Q$ using (4). (43) shows that measuring the effect of input trade on the unit cost requires knowledge of the counterfactual material share in the autarky equilibrium, $s_{M}^{A u t} .{ }^{72}$ Because this object is not observed in the data, we can use (4) and (42) to compute it :

$$
s_{M}^{A u t}=\frac{\left(\frac{\gamma}{1-\gamma}\right)^{\zeta} \beta^{-\frac{\varepsilon}{\varepsilon-1}(1-\zeta)}\left(\frac{p_{D / q_{D}}}{w}\right)^{1-\zeta}}{1+\left(\frac{\gamma}{1-\gamma}\right)^{\zeta} \beta^{-\frac{\varepsilon}{\varepsilon-1}(1-\zeta)}\left(\frac{p_{D} / q_{D}}{w}\right)^{1-\zeta}} .
$$

72. The Cobb-Douglas assumption in (1) in the main text bypasses this issue because it implies that the material share is constant and given by $\gamma$. In the non-Cobb-Douglas case, the material share endogenously reacts to changes in the import environment. A move to autarky, for example, makes materials relatively more expensive and should induce firms to substitute towards primary inputs. 
The firm-level gains from input trade are therefore given by

$$
\left.\ln \left(\frac{u^{A u t}}{u}\right)\right|_{p_{D}, w}=\ln \left(\frac{1+\left(\frac{\gamma}{1-\gamma}\right)^{\zeta} \beta^{-\frac{\varepsilon}{\varepsilon-1}(1-\zeta)}\left(\frac{p_{D} / q_{D}}{w}\right)^{1-\zeta} s_{D}^{\frac{1-\zeta}{\varepsilon-1}}}{1+\left(\frac{\gamma}{1-\gamma}\right)^{\zeta} \beta^{-\frac{\varepsilon}{\varepsilon-1}(1-\zeta)}\left(\frac{p_{D} / q_{D}}{w}\right)^{1-\zeta}}\right)^{\frac{1}{\zeta-1}}
$$

(44) is the generalization of (7) for the case where the aggregator between materials and primary factors is CES. We see that, in this case, quantifying the change in the unit cost relative to autarky requires knowledge of additional parameters $\left[\beta, \zeta, p_{D} / q_{D}\right]$ to predict the material share in autarky. Under the additional assumption that there is no variation in $\beta$ and $p_{D} / q_{D}$ across firms, we can bypass the estimation of some of these additional parameters. In this case, all firms would feature the same material share in autarky, which is given by the material share of a domestic firm in the observed trade equilibrium, $s_{M}^{D}$. In this case, (44) reduces to

$$
\left.\ln \left(\frac{u^{A u t}}{u}\right)\right|_{p_{D}, w}=\ln \left(1-s_{M}^{D}+s_{D}^{\frac{1-\zeta}{\varepsilon-1}} \times s_{M}^{D}\right)^{\frac{1}{\zeta-1}}
$$

so that only micro-data on domestic expenditure shares $s_{D}$ and the two elasticities of substitution $\varepsilon$ and $\zeta$ are required. ${ }^{73}$

Extension 2 : General Production Function for Materials. In Section (2), we assumed that material services were a CES aggregator of a domestic variety $z_{D}$ and a foreign input bundle $x_{I}$. Suppose now that the aggregator for materials is given by a general function

$$
x=g\left(q_{D} z_{D}, x_{I}\right)
$$

We continue to assume that materials $x$ and primary factors $l$ are combined with a Cobb-Douglas production function given in (1). Again let $A(\Sigma)$ be the price index of the import bundle and $Q(\Sigma)$ be the price index of materials. Consider any shock to the trading environment that affects $A(\Sigma)$. Then

$$
\left.d \ln (u)\right|_{p_{D}, w}=\gamma \times\left. d \ln (Q)\right|_{p_{D}}=\gamma \frac{z_{I} A}{u} \frac{d A}{A}=\gamma\left(1-s_{D}\right) d \ln (A) .
$$

The optimality conditions from the cost-minimization problem imply that

$$
d \ln (A)=-\frac{\left(-\frac{1}{\varepsilon_{L}}\right)}{1-\frac{1}{\varepsilon_{L}}} \frac{1}{1-s_{D}} d \ln \left(s_{D}\right)
$$

where

$$
-\frac{1}{\varepsilon_{L}} \equiv \frac{\partial \ln \left(\frac{\partial g\left(q_{D} z_{D}, x_{I}\right) / \partial x_{D}}{\partial g\left(q_{D} z_{D}, x_{I}\right) / \partial x_{I}}\right)}{\partial \ln \left(\frac{q_{D} z_{D}}{x_{I}}\right)}
$$

73. Note that, when $\zeta \rightarrow 1$, (45) reduces to the expression in $(7):\left.\lim _{\zeta \rightarrow 1} \ln \left(\frac{u^{A u t}}{u}\right)\right|_{p_{D}, w}=\frac{\gamma}{1-\varepsilon} \ln \left(s_{D}\right)$. 
is the local elasticity of substitution. Substituting this into (47) yields

$$
\left.d \ln (u)\right|_{p_{D}, w}=\gamma \frac{\frac{1}{\varepsilon_{L}}}{1-\frac{1}{\varepsilon_{L}}} d \ln \left(s_{D}\right)=-\frac{\gamma}{1-\varepsilon_{L}} d \ln \left(s_{D}\right) .
$$

In case the elasticity of substitution is constant, i.e. $\varepsilon_{L}=\varepsilon,(48)$ can be integrated to yield (7).

Extension 3 : Multiple Foreign Products. In the main analysis, we assumed that firms source a single product from each sourcing country. In the data, firms often import multiple products from a given country. We now explore how (41) would change in a multi-product environment. Consider first the case where the product aggregator is nested in the country aggregator, i.e. the production structure is given by (1)-(3), where

$$
q_{c i} z_{c} \equiv \psi_{c i}\left(\left[q_{k c i} z_{k c}\right]_{k \in K_{c i}}\right)
$$

$k$ is a product index, $K_{c i}$ denotes the set of products that firm $i$ sources from country $c, \psi_{c i}$ is a constant-returns-to-scale production function and (49) applies also to the domestic variety. As long as the number of products sourced domestically does not change when firms are forced into inputautarky, the analysis in the main text remains entirely unchanged and the firm-level gains are still given by (7).

Consider next the case where the country aggregator is nested in the product aggregator. Suppose for example that the production structure for intermediates $x$ is given by

$$
\begin{aligned}
x & =\left(\sum_{k=1}^{K}\left(\eta_{k} x_{k}\right)^{\frac{\iota-1}{\iota}}\right)^{\frac{\iota}{\iota-1}} \\
x_{k} & =\left(\beta_{k i}\left(q_{k D} z_{k D}\right)^{\frac{\varepsilon_{k}-1}{\varepsilon_{k}}}+\left(1-\beta_{k i}\right) x_{k I}^{\frac{\varepsilon_{k}-1}{\varepsilon_{k}}}\right)^{\frac{\varepsilon_{k}}{\varepsilon_{k}-1}} \\
x_{k I} & =h_{k i}\left(\left[q_{k c i} z_{k c}\right]_{c \in \Sigma_{k i}}\right) .
\end{aligned}
$$

Note that the sourcing strategy is now a list of countries for each product. Letting $Q_{i}$ and $Q_{k i}$ denote the price indices for materials $x$ and product-specific material services $x_{k}$ respectively, it can be easily shown that

$$
\begin{aligned}
Q_{i} & =\left(\sum_{k=1}^{K}\left(Q_{k i} / \eta_{k}\right)^{1-\iota}\right)^{\frac{1}{1-\iota}} \\
Q_{k i} & =\left(s_{k D i}\right)^{\frac{1}{\varepsilon_{k}-1}} \beta_{k i}^{-\frac{\varepsilon_{k}}{\varepsilon_{k}-1}} p_{k D} / q_{k D},
\end{aligned}
$$

where $s_{k D i}$ is firm $i$ 's domestic expenditure share for product $k$. The firm-level gains are therefore 
given by

$$
\left.\ln \left(\frac{u^{A u t}}{u}\right)\right|_{p_{D}, w}=\frac{\gamma}{\iota-1} \times \ln \left(\sum_{k=1}^{K} \chi_{k i}\left(s_{k D i}\right)^{\frac{\iota-1}{1-\varepsilon_{k}}}\right)
$$

where

$$
\chi_{k i} \equiv \frac{\left(\beta_{k i}^{-\frac{\varepsilon_{k}}{\varepsilon_{k}-1}} p_{k D} / q_{k D}\right)^{1-\iota}}{\sum_{k=1}^{K}\left(\beta_{k i}^{-\frac{\varepsilon_{k}}{\varepsilon_{k}-1}} p_{k D} / q_{k D}\right)^{1-\iota}} .
$$

We see that the producer gains are akin to a weighted average of the product-specific producer gains $\left(s_{k D i}\right)^{\frac{\ell-1}{1-\varepsilon_{k}}}$. In our empirical application, we cannot implement (51) because we do not observe domestic shares at the product level $s_{k D i}$ in the French data. Note that implementing (51) also requires measuring the weights $\chi_{k i}$. In the case where (50) takes the Cobb-Douglas form, i.e. $\iota=1$ as in Halpern et al. (2015), (51) simplifies to

$$
\left.\ln \left(\frac{u^{A u t}}{u}\right)\right|_{p_{D}, w}=\sum_{k=1}^{K} \eta_{k} \frac{\gamma}{1-\varepsilon_{k}} \ln \left(s_{D i}^{k}\right)
$$

Thus, in the Cobb-Douglas case, the producer gains are a weighted average of the product-specific producer gains.

\subsection{Proof of Proposition 1}

The consumer price index associated with (8) is given by

$$
P=\prod_{s=1}^{S}\left(P_{s} / \alpha_{s}\right)^{\alpha_{s}} \text { where } P_{s}=\left(\int_{0}^{N_{s}} p_{i s}^{1-\sigma_{s}} d i\right)^{\frac{1}{1-\sigma_{s}}}
$$

and $P_{s}$ is the price index for sector $s$. Using (52), the consumer price gains from input trade can be expressed as

$$
G \equiv \ln \left(\frac{P^{A u t}}{P}\right)=\sum_{s=1}^{S} \alpha_{s} \ln \left(\frac{P_{s}^{A u t}}{P_{s}}\right) .
$$

We now express $P_{s}^{A u t} / P_{s}$ in terms of observables. Note that monopolistic competition implies a constant markup pricing rule, $p_{i s}=\frac{\sigma_{s}}{\sigma_{s}-1} u_{i s}$. Using the expression for the firm's unit cost in terms of its domestic expenditure share in (6), we find that

$$
P_{s}=\frac{\sigma_{s}}{\sigma_{s}-1}\left(\frac{1}{\gamma_{s}}\right)^{\gamma_{s}}\left(\frac{1}{1-\gamma_{s}}\right)^{1-\gamma_{s}}\left(\frac{p_{D s}}{q_{D s}}\right)^{\gamma_{s}}\left(\int_{0}^{N_{s}}\left(\tilde{\varphi}_{i}^{-1}\left(s_{D i}\right)^{\gamma_{s} /\left(\varepsilon_{s}-1\right)}\right)^{1-\sigma_{s}} d i\right)^{\frac{1}{1-\sigma_{s}}}
$$

which is (10) in the main text. Given the aggregator in (9), the price index of the domestic bundle is given by

$$
p_{D s}=\zeta_{s}^{*} \prod_{j=1}^{S} P_{j}^{\zeta_{j}^{s}} \text { where } \zeta_{s}^{*} \equiv \prod_{j=1}^{S}\left(\zeta_{j}^{s}\right)^{-\zeta_{j}^{s}}
$$


Note that (53) implies

$$
\frac{P_{s}^{A u t}}{P_{s}}=\left(\frac{p_{D s}^{A u t}}{p_{D s}}\right)^{\gamma_{s}}\left(\frac{\int_{0}^{N_{s}} \tilde{\varphi}_{i}^{\sigma_{s}-1} d i}{\int_{0}^{N_{s}}\left(\tilde{\varphi}_{i} s_{D i}^{\frac{\gamma_{s}}{1-\varepsilon_{s}}}\right)^{\sigma_{s}-1} d i}\right)^{\frac{1}{1-\sigma_{s}}}=\left(\frac{p_{D s}^{A u t}}{p_{D s}}\right)^{\gamma_{s}}\left(\int_{0}^{N_{s}} \omega_{i} \frac{\gamma_{s}\left(1-\sigma_{s}\right)}{D i{ }^{1-\varepsilon_{s}}} d i\right)^{\frac{1}{1-\sigma_{s}}},
$$

where $\omega_{i}$ is firm $i^{\prime} s$ share in total value added in sector $s$ and the second equality follows from $v a_{i}=\kappa_{s} \tilde{\varphi}_{i}^{\sigma_{s}-1} s_{D i}^{\frac{\gamma_{s}\left(\sigma_{s}-1\right)}{1-\varepsilon_{s}}}$. With (55) at hand, we can express the consumer price gains as

$$
G=\sum_{s=1}^{S} \gamma_{s} \alpha_{s} \pi_{s}+\sum_{s=1}^{S} \alpha_{s} \Lambda_{s}
$$

where $\pi_{s} \equiv \ln \left(\frac{p_{D s}^{A u t}}{p_{D s}}\right)$ and $\Lambda_{s}$ is given by (13) in the main text. As $\Lambda_{s}$ are observable from the micro-data, obtaining $G$ reduces to solving for $\left[\pi_{s}\right]_{s=1}^{S}$. Note that (54) and (55) jointly imply

$$
\pi_{s}=\sum_{j=1}^{S} \zeta_{j}^{s} \gamma_{j} \pi_{j}+\sum_{j=1}^{S} \zeta_{j}^{s} \Lambda_{j} .
$$

(57) gives an $S \times S$ system of equations that characterizes the equilibrium $\left[\pi_{s}\right]_{s=1}^{S}$. Letting $\pi \equiv$ $\left[\pi_{1}, \pi_{2}, \ldots, \pi_{s}\right]$ be a column vector, we can express the system in (57) in matrix form as $\pi=\Xi \Gamma \pi+\Xi \Lambda$. Its solution is given by $\pi=(\mathcal{I}-\Xi \Gamma)^{-1} \Xi \Lambda$. Using (56), the consumer price gains $G$ are therefore given by

$$
G=\alpha^{\prime} \Gamma \pi+\alpha^{\prime} \Lambda=\alpha^{\prime} \Gamma(\mathcal{I}-\Xi \times \Gamma)^{-1} \Xi \Lambda+\alpha^{\prime} \Lambda
$$

For counterfactuals other than autarky, (55) should be replaced by

$$
\frac{P_{s}^{\prime}}{P_{s}}=\left(\frac{p_{D s}^{\prime}}{p_{D s}}\right)^{\gamma_{s}}\left(\frac{\int_{0}^{N_{s}}\left(\tilde{\varphi}_{i}\left(s_{D i}^{\prime}\right)^{\gamma_{s} /\left(1-\varepsilon_{s}\right)}\right)^{\sigma_{s}-1} d i}{\int_{0}^{N_{s}}\left(\tilde{\varphi}_{i}\left(s_{D i}\right)^{\gamma_{s} /\left(1-\varepsilon_{s}\right)}\right)^{\sigma_{s}-1} d i}\right)^{\frac{1}{1-\sigma_{s}}}=\left(\frac{p_{D s}^{\prime}}{p_{D s}}\right)^{\gamma_{s}}\left(\int_{0}^{N_{s}} \omega_{i}\left(\frac{s_{D i}}{s_{D i}^{\prime}}\right)^{\frac{\gamma_{s}\left(1-\sigma_{s}\right)}{1-\varepsilon_{s}}} d i\right)^{\frac{1}{1-\sigma_{s}}}
$$

where $s_{D i}^{\prime}$ denotes the counterfactual domestic share and $P_{s}^{\prime}, p_{D s}^{\prime}$ denote the counterfactual price indices. It follows that the consumer price gains associated with the policy, $G \equiv \ln \left(P^{\prime} / P\right)$, are given by (58) where $\Lambda_{s}$ is given by (13). This proves Proposition 1.

\subsection{Proposition 1 with Variable Markups}

Consumer preferences in (8) and (16) imply that firm i's demand is given by

$$
y_{i}=\left(\frac{p_{i}}{p_{j s}}\right)^{-\theta_{s}}\left(\frac{p_{j s}}{P_{s}}\right)^{-\sigma_{s}} Y_{s},
$$


where the variety and sector-level price indices are

$$
\begin{aligned}
p_{j s} & =\left(\sum_{i=1}^{N_{j s}} p_{i}^{1-\theta_{s}}\right)^{\frac{1}{1-\theta_{s}}} \\
P_{s} & =\left(\int_{0}^{N_{s}} p_{j s}^{1-\sigma_{s}} d j\right)^{\frac{1}{1-\sigma_{s}}}
\end{aligned}
$$

Firm revenue $r_{i}$ can be written as

$$
r_{i} \equiv p_{i} y_{i}=p \Phi_{j s}
$$

Assuming that firms compete in a la Cournot, the profit maximization problem is given by

$$
\max _{y_{i}}\left(p_{i}\left(y_{i}, y_{-i}\right)-c_{i}\right) y_{i}
$$

where $c_{i}$ denotes firm $i$ 's marginal cost and $p_{i}\left(y_{i}, y_{-i}\right)$ is defined by (59)-(61). As in Atkeson and Burstein (2008), firms internalize the effect of their pricing decisions on $y_{j s}$ but not on $Y_{s}$. The profit-maximizing price can therefore be written as

$$
p_{i}=\frac{\left(\frac{1}{\sigma} \omega_{i}+\frac{1}{\theta}\left(1-\omega_{i}\right)\right)^{-1}}{\left(\frac{1}{\sigma} \omega_{i}+\frac{1}{\theta}\left(1-\omega_{i}\right)\right)^{-1}-1} \times c_{i} \equiv \mu_{i} \times c_{i},
$$

where $\mu_{i}$ denotes the markup over marginal cost. (63) provides a system of equations that characterizes optimal prices $\left[p_{i}\right]$ given marginal costs $\left[c_{i}\right]$. Using $(59)$, it is straightforward to show that

$$
\omega_{i} \equiv \frac{p_{i} y_{i}}{p_{j s} y_{j s}}=\left(\frac{p_{i}}{p_{j s}}\right)^{1-\theta_{s}},
$$

where $\omega_{i}$ denotes the variety-level expenditure share on firm i's good. In particular, note that (64) implies that $\mu_{i}=\mu\left(\frac{p_{i}}{p_{j s}}\right)$, i.e. markups are a function of relative prices. (63) and (64) establish (18) in the main text.

The change in sectoral price indices are

$$
\ln \left(\frac{P_{s}^{\prime}}{P_{s}}\right)=\frac{1}{1-\sigma_{s}} \ln \left(\int_{0}^{N_{s}}\left(\frac{p_{j s}^{\prime}}{p_{j s}}\right)^{1-\sigma_{s}} \omega_{j s} d j\right),
$$

where we used that

$$
\omega_{j s}=\frac{p_{j s}^{1-\sigma_{s}}}{\int_{0}^{N_{s}} p_{j s}^{1-\sigma_{s}} d j} .
$$

In turn, the change in variety-level price indices is

$$
\frac{p_{j s}^{\prime}}{p_{j s}}=\left(\sum_{i=1}^{N_{j s}}\left(\frac{p_{i}^{\prime}}{p_{i}}\right)^{1-\theta_{s}} \omega_{i}\right)^{\frac{1}{1-\theta_{s}}} .
$$


Computing the change in the consumer price index therefore reduces to computing $\left[p_{i}^{\prime} / p_{i}\right]$. Equation (63) implies

$$
\frac{p_{i}^{\prime}}{p_{i}}=\frac{\mu\left(\frac{p_{i}^{\prime}}{p_{j s}^{\prime}}\right)}{\mu_{i}} \times \frac{c_{i}^{\prime}}{c_{i}}
$$

where $\mu_{i}$ can be computed with data on the firm's revenue share $\omega_{i}$ via (18). Using (6), we have that

$$
\frac{c_{i}^{\prime}}{c_{i}}=\left(\frac{s_{D i}^{\prime}}{s_{D i}}\right)^{\frac{\gamma_{s}}{\varepsilon_{s}-1}}\left(\frac{p_{D s}^{\prime}}{p_{D s}}\right)^{\gamma_{s}}
$$

It follows from (67)-(68) that computing $p_{i}^{\prime} / p_{i}$ reduces to computing the counterfactual relative prices $p_{i}^{\prime} / p_{j s}^{\prime}$ and $p_{D s}^{\prime} / p_{D s}$. Combining (6) and (63), we obtain

$$
p_{i}^{\prime}=\mu\left(\frac{p_{i}^{\prime}}{p_{j s}^{\prime}}\right) \mu_{i}^{-1} r_{i}^{\frac{1}{1-\theta_{s}}}\left(\frac{s_{D i}^{\prime}}{s_{D i}}\right)^{\frac{\gamma_{s}}{\varepsilon_{s}-1}}\left(\frac{p_{D s}^{\prime}}{p_{D s}}\right)^{\gamma_{s}} \Phi_{j s}^{-\frac{1}{1-\theta_{s}}},
$$

where we used (62) to substitute for unobserved efficiency :

$$
\widetilde{\varphi}_{i}=r_{i}^{\frac{1}{\theta_{s}-1}} \mu_{i} s_{D i}^{\frac{\gamma_{s}}{\varepsilon_{s}-1}} p_{D s}^{\gamma_{s}} \Phi_{j s}^{\frac{1}{1-\theta_{s}}}
$$

Using (60), (69) can be expressed as

$$
\left(\frac{p_{i}^{\prime}}{p_{j s}^{\prime}}\right)^{1-\theta_{s}}=\frac{\left(\mu\left(\frac{p_{i}^{\prime}}{p_{j s}^{\prime}}\right) \mu_{i}^{-1}\right)^{1-\theta_{s}} \omega_{i}\left(s_{D i}^{\prime} / s_{D i}\right)^{\frac{\gamma_{s}}{\varepsilon_{s}-1}\left(1-\theta_{s}\right)}}{\sum_{\nu=1}^{N_{j s}}\left(\mu\left(\frac{p_{\nu}^{\prime}}{p_{j s}^{\prime}}\right) \mu_{\nu}^{-1}\right)^{1-\theta_{s}} \omega_{\nu}\left(s_{D \nu}^{\prime} / s_{D \nu}\right)^{\frac{\gamma_{s}}{\varepsilon_{s}-1}\left(1-\theta_{s}\right)}} .
$$

(70), provide a system of equations that characterizes counterfactual relative prices $\left[p_{i}^{\prime} / p_{j s}^{\prime}\right]$ given data $\left[\omega_{i}, s_{D i}^{\prime} / s_{D i}\right]$. Given the expression for $\mu\left(\frac{p_{i}^{\prime}}{p_{j s}^{\prime}}\right)$ in (63), we can derive equation (19) in the main text. Equations (65)-(66) together with (67)-(68) imply :

$$
\ln \left(\frac{P_{s}^{\prime}}{P_{s}}\right)=\gamma_{s} \ln \left(\frac{p_{D s}^{\prime}}{p_{D s}}\right)+\Lambda_{s}
$$

where $\Lambda_{s}$ is defined in (17) in the main text. This completes the proof.

\subsection{Data Description}

Our main data set stems from the information system of the French custom administration (DGDDI) and contains the majority of import and export flows by French manufacturing firms. The data is collected at the 8-digit (NC8) level. A firm located within the French metropolitan territory must report detailed information as long as the following criteria are met. For imports from outside the EU, reporting is required from each firm and flow if the imported value exceeds 1,000 Euros. For within EU imports, import flows have to be reported as long as the firm's annual trade value 
exceeds 100,000 Euros. ${ }^{74}$ However, some firms that are below the threshold (ca. 10,000 firm-year observations out of ca. 130,000) voluntarily report. ${ }^{75}$

In spite of this limitation, the attractive feature of the French data is the presence of unique firm identifiers (the SIREN code) that is available in all French administrative files. Hence, various datasets can be matched to the trade data at the firm level. To learn about the characteristics of the firms in our sample we employ fiscal files. ${ }^{76}$ Sales are deflated using price indices of value added at the 3 digit level obtained from the French national accounts. To measure the expenditure on domestic inputs, we subtract the total import value from the total expenditure on wares and inputs reported in the fiscal files. Capital is measured at book value (historical cost).

Finally, we incorporate information on the ownership structure from the LIFI/DIANE (BvDEP) files. These files are constructed at INSEE using a yearly survey (LIFI) that describes the structure of ownership of all firms in the private sector whose financial investments in other firms (participation) are higher than 1.2 million Euros or have sales above 60 million Euros or have more than 500 employees. This survey is complemented with the information about ownership structure available in the DIANE (BvDEP) files, which are constructed using the annual mandatory reports to commercial courts and the register of firms that are controlled by the State.

Using these datasets, we construct a non-balanced panel dataset spanning the period from 2001 to 2006. Some basic characteristics of importing and non-importing firms are contained in Table 6 . For comparison, we also report the results for exporting firms.

As expected, importers are larger, more capital intensive and have higher revenue productivity see also Bernard et al. (2012). Furthermore, import and export status are highly correlated.

\subsection{Production Function Estimation}

In this section, we show how the set-up laid out in Section 3 can be used to retrieve structural estimates of $\gamma_{s}$ and $\epsilon_{s}$. First, we augment firms' production function to include physical capital and also explicitly introduce time subscripts to clarify the timing assumptions underlying our structural estimation. We therefore write our production function as

$$
y_{i t s}=\varphi_{i t} \cdot k_{i t}^{\phi_{k s}} \cdot l_{i t}^{\phi_{l s}} \cdot x_{i t}^{\gamma_{s}}
$$

where $\phi_{k s}$ and $\phi_{l s}$ denote the capital and labor elasticities in sector $s$. We make the standard assumption that the productivity term $\varphi_{i t}$ can be decomposed into two components according to

74. This threshold was in effect between 2001 and 2006, which is period we focus on. Between 1993 and 2001 , the threshold was ca. 40,000 euros. After 2006, it was raised to 150,000 euros and to 460,000 euros after 2011.

75. The existence of this administrative threshold induces a censoring of small EU importers. In results available upon request, we use the time-variation in the reporting thresholds (see footnote 74) to show that this concern is unlikely to severely affect our results. The reason is related to the weak relation between domestic expenditure shares and firm size shown in Figure 2.

76. The firm level accounting information is retrieved from two different files : the BRN ("Bénéfices Réels Normaux") and the RSI ("Régime Simplifié d'Imposition"). The BRN contains the balance sheet of all firms in the traded sectors with sales above 730,000 Euros. The RSI is the counterpart of the BRN for firms with sales below 730,000 Euros. Although the details of the reporting differs, for our purposes these two data sets contain essentially the same information. Their union covers nearly the entire universe of French firms. 
TABLE 6 - Characteristics of importers, exporters and domestic firms

\begin{tabular}{lccccc}
\hline & $\begin{array}{c}\text { Full } \\
\text { sample }\end{array}$ & Importers & $\begin{array}{c}\text { Non } \\
\text { importers }\end{array}$ & Exporters & $\begin{array}{c}\text { Non } \\
\text { exporters }\end{array}$ \\
\hline Employment & 25 & 92 & 8 & 81 & 9 \\
Sales & 5,455 & 21,752 & 1,379 & 19,171 & 1,468 \\
Sales per worker & 126 & 208 & 105 & 196 & 105 \\
Value added & 1,515 & 5,972 & 400 & 5,294 & 416 \\
Value added per worker & 45 & 55 & 43 & 55 & 43 \\
Capital & 2,217 & 8,728 & 588 & 7,661 & 634 \\
Capital per worker & 44 & 64 & 40 & 61 & 40 \\
Inputs & 2,600 & 10,225 & 693 & 8,943 & 756 \\
Domestic share & 0.943 & 0.698 & 1 & 0.790 & 0.986 \\
Share of importers & 0.200 & 1 & 0 & 0.677 & 0.061 \\
Share of exporters & 0.225 & 0.762 & 0.091 & 1 & 0 \\
Share of firms that are & 0.029 & 0.131 & 0.004 & 0.113 & 0.005 \\
part of an international group & & & & & 32.359 \\
Productivity (factor shares) & 39.173 & 65.450 & 32.989 & 63.858 & 146,496 \\
Number of observations (firm * year) & 650,401 & 130,135 & 520,266 & 503,905 \\
Number of firms & 172,244 & 38,240 & 148,619 & 44,648 & 146,423
\end{tabular}

Notes : Sales, wages, expenditures on imports or exports are all expressed in 2005 prices using a 3-digit industry level price deflator. Our capital measure is the book value reported in firms' balance sheets ("historical cost"). A firm is member of an international group if at least one affiliate or the headquarter is located outside of France.

$\varphi_{i t}=\varphi_{i t}^{o b s} \exp \left(\epsilon_{i t}\right)$, where $\varphi_{i t}^{o b s}$ is observed by the firm and $\epsilon_{i t}$ captures both measurement error and idiosyncratic shocks to production. We assume that $\epsilon_{i t}$ is i.i.d. across firms and time and is independent of all other shocks. We also assume that log productivity follows a flexible AR(1) process

$$
\ln \left(\varphi_{i t}^{o b s}\right)=n\left(\varphi_{i t-1}^{o b s}\right)+\chi_{i t}
$$

where $\chi_{i t}$ is an iid shock.

In equation (71), we can again replace the (unobserved) physical quantities of intermediate inputs $x_{i t}$ with the (observed) level of spending in materials and express the appropriate deflator via the firm's domestic share (see (5)), This implies that firm output is given by

$$
y_{i t s}=\varphi_{i t}^{o b s} \cdot s^{-\frac{\gamma_{s}}{\epsilon_{s}-1}} \cdot k_{i t}^{\phi_{k s}} \cdot l_{i t}^{\phi_{l s}} \cdot m_{i t}^{\gamma_{s}} \times \beta_{i}^{\frac{\epsilon_{s} \gamma_{s}}{\epsilon_{s}-1}} \times B_{s t} \times \exp \left(\epsilon_{i t}\right)
$$

where $m_{i t}$ is total material spending by firm $i$ and $B_{s t}$ collects general equilibrium variables which are common to all firms in industry $s$. Importantly, notice that by not directly observing physical quantities of intermediate inputs (but only expenditures), the firm's production function includes the term $\beta_{i}^{\frac{\epsilon_{s} \gamma_{s}}{\epsilon_{s}-1}}$. Allowing for heterogeneity in terms of this home-bias $\beta_{i}$ will break the usual identifying assumptions for the production function parameters : even if intermediate inputs are strictly increasing in $\varphi_{i t}$ (see Ackerberg et al. (2015) and Levinsohn and Petrin (2003)), variation in $\beta_{i}$ will still affect both $y_{i t s}$ and the demand for intermediary inputs. Alternatively, the "compound" productivity variable $\tilde{\varphi}_{i t}=\varphi_{i t} \times \beta_{i}^{\frac{\epsilon_{s} \gamma_{s}}{\epsilon_{s}-1}}$ does not satisfy the structure in (72) but contains a fixed component, 
which is generically correlated with firms' material spending. ${ }^{77}$ We therefore assume in this section that there is no such heterogeneity in home-bias, i.e. $\beta_{i}=\beta$.

To turn (73) into an estimation equation, note that in our data firms' physical output is not directly observable - the fiscal files only report firm revenue. We therefore follow De Loecker (2011) and rely on specific assumptions about the demand structure. ${ }^{78}$ In particular, the CES demand implies that prices can be written by

$$
\frac{p_{i}}{P_{s}}=\left(\frac{y_{i}}{Y_{s}}\right)^{-\frac{1}{\sigma_{s}}} \exp \left(\xi_{i s t}\right),
$$

where $s$ denotes the industry in which the firm operates. Additionally, we include $\xi_{\text {ist }}$ as an unobserved demand shock. We follow De Loecker (2011) and De Loecker et al. (2016) and decompose this demand shock into two components : $\xi_{i s t}=\xi_{s t}+\tilde{\xi}_{i t}$. Here, $\xi_{s}$ will be captured by industry dummies, and the residual shocks $\tilde{\xi}_{i t}$ are assumed to be i.i.d. across firms and time. Firm revenue can therefore be written as

$$
R e v_{i j s}=p_{i j s} \cdot y_{i j s}=y_{i j s}^{\frac{\sigma_{s}-1}{\sigma_{s}}} Y_{s}^{\frac{1}{\sigma_{s}}} P_{s} \times \exp \left(\xi_{j}+\xi_{s}+\tilde{\xi}_{i t}\right)
$$

Taking logs and substituting (73) yields the estimating equation

$$
\begin{aligned}
\ln \left(\operatorname{Rev}_{i s t}\right)= & \frac{\sigma_{s}-1}{\sigma_{s}} \ln \left(\varphi_{i t}\right)+\tilde{\phi}_{k s} \ln \left(k_{i s t}\right)+\tilde{\phi}_{l s} \ln \left(l_{i s t}\right)+\tilde{\gamma}_{s} \ln \left(m_{i s t}\right) \\
- & \frac{\tilde{\gamma}_{s}}{\epsilon_{s}-1} \ln \left(s_{\text {Dist }}\right)+\ln \left(C_{s t}\right)+\tilde{\xi}_{i t}+\epsilon_{i t} .
\end{aligned}
$$

where $\tilde{\gamma}_{s}=\frac{\sigma_{s}-1}{\sigma_{s}} \cdot \gamma_{s}$ and $\tilde{\phi}_{k s}$ and $\tilde{\phi}_{l s}$ are defined accordingly. Furthermore, $C_{s t}$ collects all terms that are common to all firms in a same industry $s$ (and are controlled for using time dummies).

Identification and estimation of this equation follows closely De Loecker (2011) and Edmond et al. (2015). The precise timing assumptions are as follows. ${ }^{79}$ The firm

1. observes the state variables $\left(k_{i t}, l_{i t}, \Sigma_{i t}\right)$ as well as the realization of productivity $\varphi_{i t}^{o b s}=$ $n\left(\varphi_{i t-1}^{o b s}\right)+\chi_{i t}$,

2. observes the prices of intermediate inputs (both domestic and internationally sourced) and makes optimal input choice,

3. observe the shocks $\epsilon_{i t}$ and $\xi_{i t}$,

4. sets prices and produces output,

5. makes choices on future state variables $\left(k_{i t+1}, l_{i t+1}, \Sigma_{i t+1}\right)$.

77. Introducing fixed effects would fix this problem, but at the usual cost of worsening measurement error problems (Griliches and Hausman, 1986).

78. In our baseline specification, firms operate in a common segment such that $\sigma_{s}$ is not identified. If we assume, as in De Loecker (2011), that firms operate in different sub-segments $j s$ facing however the same demand elasticity, then we would identify $\sigma_{s}$.

79. These timing assumptions are very similar to Halpern et al. (2015). 
Given this timing, the estimation procedure is as follows :

1. We follow Levinsohn and Petrin (2003) and rely on material demand to proxy for productivity $\varphi_{i t}^{o b s}$ by inverting $m$ :

$$
m_{i t}=m_{s}\left(k_{i t}, l_{i t}, \Sigma_{i t}, \varphi_{i t}^{o b s}\right) \Longleftrightarrow \ln \left(\varphi_{i t}^{o b s}\right)=h_{s}\left(m_{i t}, k_{i t}, l_{i t}, \Sigma_{i t}\right) .
$$

In practice we proxy firms' sourcing strategy by firms' import status and the number of varieties sourced internationally. Note that since the firm is a price taker on input markets, the price of inputs (conditional on the sourcing strategy) does not depend on $\varphi_{i t}^{o b s}$. This ensures that $m_{s}($. is invertible.

2. We rely on $h_{s}$ to proxy for firm productivity. Under our assumptions in $(72), \chi_{i t}$ is uncorrelated with the state variables as well as with lagged values of all inputs. Hence, we can estimate the production function technological parameters $\tilde{\phi}_{k s}, \tilde{\phi}_{l s}, \tilde{\gamma}_{s}$ and $\epsilon_{s}$ using the following moment conditions :

$$
\mathbb{E}\left(\chi_{i t} \times\left(\begin{array}{c}
k_{i t} \\
l_{i t} \\
k_{i t-1} \\
l_{i t-1} \\
m_{i t-1} \\
m_{i t-2} \\
z_{i t}
\end{array}\right)\right)=0
$$

where $z_{i t}$ is the Bartik type instrument in (30). Note that this instrument is indeed exogenous under our timing assumptions if foreign supply shocks are unexpected. See also Hummels et al. (2011). We take advantage of these moments in a the IV regression framework suggested by Levinsohn and Petrin (2012) and Wooldridge (2009). More specifically, we consider the equation

$$
\begin{aligned}
\ln \left(\operatorname{Rev}_{i s t}\right)= & \tilde{\phi}_{k s} \ln \left(k_{i t}\right)+\tilde{\phi}_{l s} \ln \left(l_{i t}\right)+\tilde{\gamma}_{s} \ln \left(m_{i t}\right)-\frac{\tilde{\gamma}_{s}}{\epsilon_{s}-1} \ln \left(s_{D i t}\right)+ \\
& \frac{\theta_{s}-1}{\theta_{s}} n\left(h_{s}\left(X_{t-1}\right)\right)+D_{t}+\chi_{i t}+\tilde{\xi}_{i t}+\epsilon_{i t}
\end{aligned}
$$

where

$$
n\left(h_{s}\left(X_{t-1}\right)\right)=n\left(h_{s}\left(m_{i t-1}, k_{i t-1}, l_{i t-1}, \Sigma_{i t-1}\right)\right)
$$

is the control function for productivity (see (75) and $n($.$) stems from the productivity pro-$ cess (see $(72))$. In practice we parametrize $n(h()$.$) by a first-order polynomial and use the$ instruments in (76).

Besides this parametrization with Cobb-Douglas technology, we also implement a more flexible translog specification, where we continue to assume a constant output elasticity for materials but allow for higher order terms in capital and labor. ${ }^{80}$ We report the parameters of interest for both specifications

80. More specifically, we included the squared terms $\ln (k)^{2}$ and $\ln (l)^{2}$ and the interaction term $\ln (k) \times \ln (l)$. 
in Table 7 below. The estimates for the other coefficients $\left(\phi_{k}\right.$ and $\left.\phi_{l}\right)$ are available in Tables 12 and 13 in the Online Appendix.

\subsection{The Elasticity Bias : Using $\varepsilon$ from Aggregate Trade Flows}

Table 8 reports the consumer price gains from input trade for different values of the elasticity of substitution $\varepsilon$. Columns one and two replicate the results for our baseline estimate $\varepsilon=2.38$. While column one reports the results based on the micro-data, column two reports the gains based on aggregate data, $\Lambda_{A g g, s}^{A u t}$. These results correspond to the ones reported in Table 4 above. In the remaining columns, we report the gains for a range of values of $\varepsilon$ from studies that rely on aggregate data to estimate such elasticity. For example, Costinot and Rodríguez-Clare (2014) take $\varepsilon=5$ as their baseline. The tables show that the gains are very sensitive to the value of $\varepsilon$. Table 8 shows that the economy-wide gains predicted by an aggregate approach under $\varepsilon=5$ are about $65 \%$ lower than the gains predicted by the approach that relies on micro-data.

\subsection{Comparing Models of Importing : Detailed Derivations for Section 3.4}

Because of our assumption that fixed costs do not vary by country, countries can be indexed by their quality $q$. We first show that the price index of the import bundle takes the power form in (35). The import price index is given by

$$
A(\Sigma)=\left(\int_{q \in \Sigma}(p(q) / q)^{1-\kappa} d G(q)\right)^{\frac{1}{1-\kappa}}=\left(\int_{q \in \Sigma} q^{\kappa-1} d G(q)\right)^{\frac{1}{1-\kappa}}
$$

As quality is Pareto distributed, (77) becomes

$$
A(\Sigma)^{1-\kappa}=\theta q_{\min }^{\theta} \int_{q \in \Sigma} q^{\kappa-1} q^{-\theta-1} d q
$$

Because fixed costs are constant across countries, the sourcing set $\Sigma$ can be parametrized by a quality cutoff $\bar{q}$. In particular, the firm selects countries with high enough quality, i.e. $q \in \Sigma$ as long as $q \geq \bar{q}$. It follows that

$$
A(\bar{q})^{1-\kappa}=q_{\min }^{\theta} \frac{\theta}{\theta-(\kappa-1)} \bar{q}^{\kappa-1-\theta} .
$$

We can rewrite this expression in terms of the mass of countries sourced, $n$, which is given by

$$
n=P(q \in \Sigma)=P(q \geq \bar{q})=q_{\min }^{\theta} \bar{q}^{-\theta} .
$$

Substituting (79) into (78) yields

$$
A(n)=q_{\min }^{-1}\left(\frac{\theta}{\theta-(\kappa-1)}\right)^{\frac{1}{1-\kappa}} n^{-\left(\frac{1}{\kappa-1}\right)}
$$


TABle 7 - Production Function Estimation : Parameters

\begin{tabular}{|c|c|c|c|c|c|c|c|c|}
\hline \multirow[b]{2}{*}{ Industry } & \multirow[b]{2}{*}{ ISIC } & \multicolumn{3}{|c|}{ Cobb-Douglas } & \multicolumn{3}{|c|}{ Translog in $(k, l)$} & \multirow[t]{2}{*}{ Observations } \\
\hline & & $-\frac{\tilde{\gamma}_{s}}{\epsilon_{s}-1}$ & $\tilde{\gamma}_{s}$ & $\epsilon_{s}$ & $-\frac{\tilde{\gamma}_{s}}{\epsilon_{s}-1}$ & $\tilde{\gamma}_{s}$ & $\epsilon_{s}$ & \\
\hline Mining & $10-14$ & $\begin{array}{l}0.309^{*} \\
(0.177)\end{array}$ & $\begin{array}{c}0.119 \\
(0.076)\end{array}$ & $\begin{array}{l}0.616^{*} \\
(0.324)\end{array}$ & $\begin{array}{l}0.341^{*} \\
(0.184)\end{array}$ & $\begin{array}{l}0.087 \\
(0.075)\end{array}$ & $\begin{array}{c}0.745^{* * *} \\
(0.254)\end{array}$ & 4,393 \\
\hline $\begin{array}{l}\text { Food, tobacco, } \\
\text { beverages }\end{array}$ & $15-16$ & $\begin{array}{c}-0.358^{* * * *} \\
(0.034)\end{array}$ & $\begin{array}{c}0.459^{* * *} \\
(0.047)\end{array}$ & $\begin{array}{c}2.285^{* * *} \\
(0.212)\end{array}$ & $\begin{array}{c}-0.223^{* * *} \\
(0.031)\end{array}$ & $\begin{array}{c}0.398^{* * *} \\
(0.046)\end{array}$ & $\begin{array}{c}2.789^{* * *} \\
(0.381)\end{array}$ & 129,567 \\
\hline $\begin{array}{l}\text { Textiles and } \\
\text { leather }\end{array}$ & $17-19$ & $\begin{array}{c}-0.226^{* * *} \\
(0.071)\end{array}$ & $\begin{array}{c}0.233^{* * *} \\
(0.069)\end{array}$ & $\begin{array}{c}2.031^{* * *} \\
(0.546)\end{array}$ & $\begin{array}{c}-0.241^{* * *} \\
(0.071)\end{array}$ & $\begin{array}{c}0.238^{* * *} \\
(0.069)\end{array}$ & $\begin{array}{c}1.986^{* * *} \\
(0.500)\end{array}$ & 19,002 \\
\hline $\begin{array}{l}\text { Food and wood } \\
\text { products }\end{array}$ & 20 & $\begin{array}{c}-0.252^{* * *} \\
(0.028)\end{array}$ & $\begin{array}{c}0.352^{* * *} \\
(0.047)\end{array}$ & $\begin{array}{c}2.397 * * * \\
(0.279)\end{array}$ & $\begin{array}{c}-0.197^{* * * *} \\
(0.026)\end{array}$ & $\begin{array}{c}0.383^{* * *} \\
(0.046)\end{array}$ & $\begin{array}{c}2.943^{* * *} \\
(0.399)\end{array}$ & 16,748 \\
\hline $\begin{array}{l}\text { Paper, printing, } \\
\text { publishing }\end{array}$ & $21-22$ & $\begin{array}{c}-0.163^{* * *} \\
(0.042)\end{array}$ & $\begin{array}{c}0.315^{* * *} \\
(0.058)\end{array}$ & $\begin{array}{c}2.932^{* * *} \\
(0.709)\end{array}$ & $\begin{array}{c}-0.141^{* * * *} \\
(0.043)\end{array}$ & $\begin{array}{c}0.314^{* * *} \\
(0.059)\end{array}$ & $\begin{array}{c}3.233^{* * *} \\
(0.910)\end{array}$ & 34,301 \\
\hline Chemicals & 24 & $\begin{array}{c}0.111 \\
(0.093)\end{array}$ & $\begin{array}{c}0.767^{* * *} \\
(0.159)\end{array}$ & $\begin{array}{l}-5.877 \\
(5.244)\end{array}$ & $\begin{array}{c}0.040 \\
(0.088)\end{array}$ & $\begin{array}{c}0.697^{* * *} \\
(0.150)\end{array}$ & $\begin{array}{l}-16.38 \\
(36.46)\end{array}$ & 7,502 \\
\hline $\begin{array}{l}\text { Rubber and } \\
\text { plastics products }\end{array}$ & 25 & $\begin{array}{c}-0.126^{* * *} \\
(0.048)\end{array}$ & $\begin{array}{c}0.202^{* *} \\
(0.094)\end{array}$ & $\begin{array}{c}2.611^{* *} \\
(1.190)\end{array}$ & $\begin{array}{c}-0.170^{* * * *} \\
(0.060)\end{array}$ & $\begin{array}{c}0.081 \\
(0.149)\end{array}$ & $\begin{array}{l}1.478 \\
(1.003)\end{array}$ & 11,989 \\
\hline $\begin{array}{l}\text { Non-metallic } \\
\text { mineral products }\end{array}$ & 26 & $\begin{array}{c}-0.383^{* * *} \\
(0.063)\end{array}$ & $\begin{array}{c}0.311^{* * *} \\
(0.080)\end{array}$ & $\begin{array}{c}1.813^{* * *} \\
(0.263)\end{array}$ & $\begin{array}{c}-0.288^{* * * *} \\
(0.061)\end{array}$ & $\begin{array}{c}0.307^{* * *} \\
(0.079)\end{array}$ & $\begin{array}{c}2.067^{* * *} \\
(0.382)\end{array}$ & 14,587 \\
\hline Basic metals & 27 & $\begin{array}{r}-0.678^{*} \\
(0.397)\end{array}$ & $\begin{array}{l}-0.143 \\
(0.519)\end{array}$ & $\begin{array}{l}0.788 \\
(0.655)\end{array}$ & $\begin{array}{r}-0.697^{*} \\
(0.394)\end{array}$ & $\begin{array}{l}-0.158 \\
(0.513)\end{array}$ & $\begin{array}{c}0.773 \\
(0.623)\end{array}$ & 2,435 \\
\hline Metal products & 28 & $\begin{array}{c}-0.402^{* * *} \\
(0.023)\end{array}$ & $\begin{array}{c}0.151^{* * *} \\
(0.026)\end{array}$ & $\begin{array}{l}1.374^{* * *} \\
(0.0734)\end{array}$ & $\begin{array}{c}-0.347^{* * *} \\
(0.023)\end{array}$ & $\begin{array}{c}0.156^{* * *} \\
(0.025)\end{array}$ & $\begin{array}{l}1.450^{* * *} \\
(0.0865)\end{array}$ & 61,017 \\
\hline $\begin{array}{l}\text { Machinery and } \\
\text { equipment }\end{array}$ & 29 & $\begin{array}{c}-0.191^{* * *} \\
(0.028)\end{array}$ & $\begin{array}{c}0.323^{* * *} \\
(0.048)\end{array}$ & $\begin{array}{c}2.688^{* * *} \\
(0.415)\end{array}$ & $\begin{array}{c}-0.178^{* * *} \\
(0.028)\end{array}$ & $\begin{array}{c}0.323^{* * *} \\
(0.048)\end{array}$ & $\begin{array}{c}2.808^{* * *} \\
(0.459)\end{array}$ & 27,450 \\
\hline $\begin{array}{l}\text { Office and } \\
\text { computing machinery }\end{array}$ & 30 & $\begin{array}{l}-0.078 \\
(0.134)\end{array}$ & $\begin{array}{c}0.123 \\
(0.189)\end{array}$ & $\begin{array}{c}2.564 \\
(3.823)\end{array}$ & $\begin{array}{l}-0.059 \\
(0.131)\end{array}$ & $\begin{array}{c}0.118 \\
(0.188)\end{array}$ & $\begin{array}{l}2.996 \\
(5.615)\end{array}$ & 655 \\
\hline Electrical machinery & 31 & $\begin{array}{c}-0.180^{* * *} \\
(0.055)\end{array}$ & $\begin{array}{c}0.334^{* * *} \\
(0.084)\end{array}$ & $\begin{array}{c}2.859^{* * *} \\
(0.910)\end{array}$ & $\begin{array}{c}-0.201^{* * *} \\
(0.052)\end{array}$ & $\begin{array}{c}0.334^{* * *} \\
(0.082)\end{array}$ & $\begin{array}{c}2.659^{* * *} \\
(0.735)\end{array}$ & 8,326 \\
\hline $\begin{array}{l}\text { Radio and } \\
\text { communication }\end{array}$ & 32 & $\begin{array}{c}-0.301^{*} \\
(0.170)\end{array}$ & $\begin{array}{l}0.238 \\
(0.208)\end{array}$ & $\begin{array}{l}1.790^{*} \\
(1.071)\end{array}$ & $\begin{array}{l}-0.276 \\
(0.177)\end{array}$ & $\begin{array}{l}0.258 \\
(0.209)\end{array}$ & $\begin{array}{l}1.934 \\
(1.279)\end{array}$ & 3,146 \\
\hline $\begin{array}{l}\text { Medical and optical } \\
\text { instruments }\end{array}$ & 33 & $\begin{array}{c}-0.243^{* * *} \\
(0.037)\end{array}$ & $\begin{array}{c}0.306^{* * *} \\
(0.049)\end{array}$ & $\begin{array}{c}2.261^{* * *} \\
(0.319)\end{array}$ & $\begin{array}{c}-0.195^{* * *} \\
(0.040)\end{array}$ & $\begin{array}{c}0.304^{* * *} \\
(0.048)\end{array}$ & $\begin{array}{c}2.558^{* * *} \\
(0.454)\end{array}$ & 22,541 \\
\hline $\begin{array}{l}\text { Motor vehicles, } \\
\text { trailers }\end{array}$ & 34 & $\begin{array}{c}-0.203^{* * *} \\
(0.077)\end{array}$ & $\begin{array}{c}0.599 * * \\
(0.288)\end{array}$ & $\begin{array}{l}3.958^{*} \\
(2.388)\end{array}$ & $\begin{array}{c}-0.169^{* *} \\
(0.072)\end{array}$ & $\begin{array}{c}0.608^{* *} \\
(0.281)\end{array}$ & $\begin{array}{l}4.605 \\
(2.972)\end{array}$ & 4,870 \\
\hline Transport equipment & 35 & $\begin{array}{l}-0.098 \\
(0.150)\end{array}$ & $\begin{array}{c}0.462^{* * *} \\
(0.129)\end{array}$ & $\begin{array}{l}5.705 \\
(7.770)\end{array}$ & $\begin{array}{l}-0.106 \\
(0.141)\end{array}$ & $\begin{array}{c}0.477^{* * *} \\
(0.123)\end{array}$ & $\begin{array}{l}5.515 \\
(6.577)\end{array}$ & 3,949 \\
\hline $\begin{array}{l}\text { Manufacturing, } \\
\text { recycling }\end{array}$ & $36-37$ & $\begin{array}{c}-0.386^{* * *} \\
(0.049)\end{array}$ & $\begin{array}{c}0.303^{* * *} \\
(0.040)\end{array}$ & $\begin{array}{c}1.786^{* * *} \\
(0.167)\end{array}$ & $\begin{array}{c}-0.321^{* * *} \\
(0.047)\end{array}$ & $\begin{array}{c}0.308^{* * *} \\
(0.039)\end{array}$ & $\begin{array}{c}1.958^{* * *} \\
(0.216)\end{array}$ & 34,863 \\
\hline
\end{tabular}

Notes : Robust standard errors in parentheses with ***, **, and * respectively denoting significance at the $1 \%, 5 \%$ and $10 \%$ levels. The table contains the results of estimating (32) with the instruments given in (30). For non-importers, the instrument is set to zero in the full sample specifications. Estimation relies on data for the years 2004-2006, because two lags are required to build the appropriate instruments for the estimation of the production function. Standard errors for the estimates of $\varepsilon_{s}$ are retrieved by the delta-method. 
TABle 8 - The Consumer Price Gains for Different Values of $\varepsilon$

\begin{tabular}{l|ccccccc}
\hline & Micro Data & \multicolumn{6}{|c}{ Aggregate Data } \\
\cline { 2 - 7 } & \multicolumn{7}{c}{$\varepsilon$} \\
& 2.38 & 2.38 & 3 & 4 & 5 & 6 \\
\hline Entire Economy & 9.04 & 9.9 & 6.72 & 4.43 & 3.31 & 2.64 \\
Manufacturing Sector & 27.52 & 30.8 & 20.32 & 13.12 & 9.69 & 7.68 \\
\hline
\end{tabular}

Notes: The table reports the reduction in consumer prices for the entire economy $\left(P^{A u t} / P-1\right) \times 100$ (first row) and the manufacturing sector $\left(P_{M}^{A u t} / P_{M}-1\right) \times 100$ (second row) for different values of the elasticity of substitution $\varepsilon$. In the first two columns, we report the baseline results under $\varepsilon=2.38$ for comparison. Column one is based on Proposition 1 where $\Lambda_{s}$ are computed with micro data as reported in Table 4 . The remaining columns contain results based on an aggregate model, i.e. they are based on Proposition 1 where the sectoral gains are measured by $\Lambda_{A g g, s}^{A u t}$ as per (21) instead of $\Lambda_{s}^{A u t}$. The values for $\Xi, \gamma_{s}, \sigma_{s}$ and $\alpha_{s}$ employed for all calculations are given in Table 1.

which is (35) in the main text where

$$
\begin{aligned}
z & \equiv q_{\min }^{-1}\left(\frac{\theta}{\theta-(\kappa-1)}\right)^{\frac{1}{1-\kappa}} \\
\eta & \equiv \frac{1}{\kappa-1}
\end{aligned}
$$

This completes the characterization of (35). The following proposition characterizes the solution to the extensive margin problem.

Proposition 2. Consider the setup above and suppose that

$$
\eta(\varepsilon-1)<1 \text { and } \eta \gamma(\sigma-1)<1
$$

Then, the firm's profit maximization problem (36) has a unique solution for any value of $\tilde{\varphi}$ and $f$. The optimal mass of countries sourced is given by a function $n(\tilde{\varphi}, f)$ and an efficiency cutoff $\bar{\varphi}(f)$ such that $n(\tilde{\varphi}, f)=0$ for $\varphi \leq \bar{\varphi}(f)$ with $\bar{\varphi}(\cdot)$ increasing. Furthermore, $n(\varphi, f)$ is increasing in efficiency $\tilde{\varphi}$ and decreasing in the fixed costs of sourcing $f$.

Démonstration. The firm's maximization problem follow from (36), (37) and (38) as

$\pi=\max _{n}\left\{\tilde{\varphi}^{(\sigma-1)}\left(\frac{p_{D}}{q_{D}}\right)^{\gamma(1-\sigma)}\left(\left(1+\left(\frac{1-\beta}{\beta}\right)^{\varepsilon}\left(\left(\frac{p_{D}}{q_{D}}\right) \frac{1}{z} n^{\eta}\right)^{\varepsilon-1}\right)^{\frac{\gamma(\sigma-1)}{\varepsilon-1}}\right) \times B-\left(n f+f_{I} \mathbb{I}(n>0)\right)\right\}$.

Conditional on importing, the optimal mass of countries is characterized by the following first order condition :

$$
\left(\frac{1-\beta}{\beta}\right)^{\frac{\varepsilon(\sigma-1)}{\varepsilon-1}}\left(\left(\frac{\beta}{1-\beta}\right)^{\varepsilon}\left(\frac{q_{D}}{p_{D}}\right)^{\varepsilon-1}+\left(\frac{1}{z}\right)^{\varepsilon-1} n^{\eta(\varepsilon-1)}\right)^{\frac{\gamma(\sigma-1)}{\varepsilon-1}-1} z^{1-\varepsilon} n^{\eta(\varepsilon-1)-1}=\frac{1}{\eta \gamma(\sigma-1)} \frac{1}{B} \frac{f}{\tilde{\varphi}^{\sigma-1}},
$$

The second order condition is given by

$$
\left(\left(\frac{\beta}{1-\beta}\right)^{\varepsilon}\left(\frac{q_{D}}{p_{D}}\right)^{\varepsilon-1}+z^{1-\varepsilon} n^{\eta(\varepsilon-1)}\right)^{\frac{\gamma(\sigma-1)}{\varepsilon-1}-1} n^{\eta(\varepsilon-1)-2} \times
$$




$$
\{(\eta(\varepsilon-1)-1)+(\gamma(\sigma-1)-\varepsilon+1) \eta l(n)\}<0
$$

where

$$
l(n) \equiv \frac{z^{1-\varepsilon} n^{\eta(\varepsilon-1)}}{\left(\frac{\beta}{1-\beta}\right)^{\varepsilon}\left(\frac{q_{D}}{p_{D}}\right)^{\varepsilon-1}+z^{1-\varepsilon} n^{\eta(\varepsilon-1)}} \in[0,1) .
$$

It follows that (81) is satisfied if and only if

$$
\eta(\varepsilon-1)-1+(\gamma(\sigma-1)-\varepsilon+1) \eta l(n)<0 .
$$

Because we allow for arbitrary values of $\varphi$ and $f$, we need to verify that (82) holds for any value of $n$. Sufficient conditions for this are given by

$$
\eta(\varepsilon-1)<1
$$

and

$$
\eta \gamma(\sigma-1)<1 .
$$

If (83) is not satisfied, there exists a range of values of $n$ close enough to zero such that (82) is violated. ${ }^{81}$ (83) is therefore necessary. If $\gamma(\sigma-1)-\varepsilon+1 \leq 0$, then (82) is satisfied for all $n$. If $\gamma(\sigma-1)-\varepsilon+1>0$, then (82) holds for all $n$ if and only if

$$
\eta(\varepsilon-1)-1+(\gamma(\sigma-1)-\varepsilon+1) \eta l(1)<0 .
$$

As $l(1)<1$, a sufficient condition for (85) is given by (84). This proves that, under (83)-(84), the optimal mass of countries conditional on importing is uniquely characterized by (80) for any values of $\tilde{\varphi}$ and $f .{ }^{82}$ The firm becomes an importer whenever $\pi_{I} \geq \pi_{D}$, where $\pi_{I}$ are optimal profits conditional on importing and $\pi_{D}$ are profits as a non-importer. It can be shown that this condition is satisfied whenever

$$
\left[\left(1+\left(\frac{1-\beta}{\beta}\right)^{\varepsilon}\left(\frac{p_{D}}{q_{D}} z^{-1} n^{\eta}\right)^{\varepsilon-1}\right)^{\frac{\gamma(\sigma-1)}{\varepsilon-1}}-1\right]\left(q_{D} / p_{D}\right)^{\gamma(\sigma-1)} \Gamma \tilde{\varphi}^{\sigma-1}-f n-f_{I}>0
$$

where $n$ is the solution to (80). It follows the firm's profit maximization problem in (36) has a unique solution for any value of $\varphi$ and $f$.

Note that, under (83)-(84), the left hand side of (80) is decreasing in $n$. Therefore, the optimal mass of countries sourced is weakly increasing in $\varphi$ and weakly decreasing in $f$. Holding $n$ fixed, an increase in $\varphi$ tends to increase the left hand side of (86). Additionally, $\pi_{I}$ is increasing in $\varphi$. It follows that $\pi_{I}-\pi_{D}$ is increasing in $\varphi$ for a given $f$. This proves that $n=0$ if and only if $\varphi \leq \bar{\varphi}(f)$ where $\bar{\varphi}(\cdot)$ is implicitly defined as the value of $\varphi$ that makes the left hand side of (86) equal to zero. The fact that $\bar{\varphi}(f)$ is increasing in $f$ follows from the fact that $\pi_{I}-\pi_{D}$ is decreasing in $f$ for a given $\varphi$. ${ }^{83}$ This proves Proposition 2.

To solve for the aggregate allocations, we have to consider the general equilibrium of the economy.

81. This follows from the fact that $l(n)$ is continuous and strictly increasing.

82. When the solution to (80) exceeds unity, the solution is given by $n=1$. Clearly, $n=0$ cannot be a solution as the firm always prefers to be a non-importer and avoid payment of $f_{I}$. Note that our calibrated and estimated parameters satisfy (83)-(84) - see Table 1.

83. To see why this is the case, note that the left hand side of (86) is decreasing in $f$ given $\varphi$ and $n$. Additionally, $\pi_{I}$ is decreasing in $f$. 
The formal derivation and the analytical characterization is contained in Section A.8 in the Online Appendix.

\subsection{Estimation of $\eta$}

To solve for firms' optimal domestic shares in the heterogenous fixed cost model, we require an estimate for $\eta$. To do so, we need to take a stand on what the counterpart of the number varieties, $n$, is in the data. We focus on the number of countries the firm sources its products from, i.e. the number of foreign varieties. ${ }^{84}$ Using this assumption we can estimate $\eta$ from the cross-sectional relationship between firms' domestic expenditure share and the number of sourcing countries, because the theory predicts a log-linear relationship between $n$ and $\frac{1-s_{D}}{s_{D}}$ (see (38)). Hence, we estimate $\eta$ from the following regression :

$$
\ln \left(\frac{1-s_{\text {Dist }}}{s_{\text {Dist }}}\right)=\delta_{s}+\delta_{t}+\delta_{N K}+\eta(\varepsilon-1) \ln \left(n_{i s t}\right)+u_{i s t},
$$

where $n_{i s t}$ denotes firm $i$ 's average number of countries per product sourced, $\delta_{N K}$ contains a set of fixed effects for the number of products sourced and $\delta_{s}$ and $\delta_{t}$ are sector and year fixed effects. Hence, we identify $\eta$ from firms sourcing the same number of products from a different number of supplier countries. We measure products at the 8-digit level.

Table 9 contains the results of estimating (87). Columns one and two show that it is important to control for the number of products sourced as import-intensive firms source both more varieties perproduct and more products on international markets - without the product fixed effects, the estimated $\eta$ increases substantially. ${ }^{85}$ Columns three and four show that the estimate of $\eta$ is virtually unaffected by additional firm-level controls that can affect firms' import behavior conditional on the number of varieties sourced. In column five, we focus on a subsample of firm-product pairs that source their respective products from at least two supplier countries. In this case, the estimated $\eta$ decreases as the single-variety importers have very high domestic shares in the data. For our quantitative analysis, we take column five as the benchmark. ${ }^{86}$ The implied value of $\eta$ is 0.382 and it is precisely estimated.

84. This notion of "varieties" is widely used in the literature - see e.g. Broda and Weinstein (2006) and Goldberg et al. (2010). Moreover, the choice of the number of products sourced may be determined to a large degree by technological considerations, while the demand for multiple supplier countries within a given product category may plausibly stem from love-for-variety effects, which are at the heart of the mechanism stressed by our theory. However, we note that the analysis that follows can be done under alternative interpretations of $n$.

85. Recall that $\eta$ is a combination of different structural parameters of the economy. While $\eta$ is sufficient to characterize the welfare gains from trade, one might be interested in decomposing the returns to international sourcing into the the elasticity of substitution across varieties $\kappa$, the dispersion in input quality $\theta$, and the elasticity of input prices with respect to quality $\nu$. To do so, we need two additional pieces of information : import prices (to identify $\nu$ ) and data on firms' expenditure shares across trading partners (to identify $\theta$ ).

86. We are concerned that the single-variety observations may not help identify the extensive margin channel emphasized by our theory but rather pick-up other variation across firms. Additionally, a non-parametric regression shows that the log linear relation between $n$ and $\left(1-s_{D}\right) / s_{D}$ in (87) fits the data better in the sample with at least two varieties than in the full sample (results available upon request). 
TABLE 9 - Estimating $\eta$

\begin{tabular}{|c|c|c|c|c|c|c|}
\hline \multicolumn{7}{|l|}{ Dep. Variable $: \ln \left(\frac{1-s_{D}}{s_{D}}\right)$} \\
\hline & \multicolumn{4}{|c|}{ All Importers } & \multirow{3}{*}{$\begin{array}{c}>1 \text { variety } \\
0.526^{* * *} \\
(0.011)\end{array}$} & \multirow{3}{*}{$\begin{array}{c}>2 \text { varieties } \\
0.463^{* * *} \\
(0.019)\end{array}$} \\
\hline $\ln$ (Number of Varieties) & $\begin{array}{c}1.308^{* * *} \\
(0.009)\end{array}$ & $\begin{array}{c}0.707^{* * *} \\
(0.010)\end{array}$ & $\begin{array}{c}0.733^{* * *} \\
(0.010)\end{array}$ & $\begin{array}{c}0.739^{* * *} \\
(0.010)\end{array}$ & & \\
\hline ln (Capital / Employment) & & & & $\begin{array}{c}-0.070 * * * \\
(0.006)\end{array}$ & & \\
\hline Exporter Dummy & & & $\begin{array}{c}-0.395^{* * *} \\
(0.013)\end{array}$ & $\begin{array}{c}-0.388^{* * *} \\
(0.013)\end{array}$ & $\begin{array}{c}-0.254^{* * *} \\
(0.017)\end{array}$ & $\begin{array}{c}-0.198^{* * *} \\
(0.029)\end{array}$ \\
\hline International Group & & & $\begin{array}{c}0.150^{* * *} \\
(0.016)\end{array}$ & $\begin{array}{c}0.174^{* * *} \\
(0.016)\end{array}$ & $\begin{array}{c}0.216^{* * *} \\
(0.016)\end{array}$ & $\begin{array}{c}0.223^{* * *} \\
(0.019)\end{array}$ \\
\hline Control for Num of products & No & Yes & Yes & Yes & Yes & Yes \\
\hline Implied Eta & $\begin{array}{c}0.950^{* * * *} \\
(0.260)\end{array}$ & $\begin{array}{c}0.513^{* * * *} \\
(0.142)\end{array}$ & $\begin{array}{c}0.532^{* * * *} \\
(0.147)\end{array}$ & $\begin{array}{c}0.536^{* * * *} \\
(0.148)\end{array}$ & $\begin{array}{c}0.382^{* * *} \\
(0.106)\end{array}$ & $\begin{array}{c}0.336^{* * *} \\
(0.096)\end{array}$ \\
\hline Observations & 120,344 & 120,344 & 120,344 & 120,344 & 73,651 & 35,751 \\
\hline
\end{tabular}

Notes : Robust standard errors in parentheses with ${ }^{* * *},{ }^{* *}$ and ${ }^{*}$ respectively denoting significance at the $1 \%, 5 \%$ and $10 \%$ levels. All regressions include year fixed effects and 3-digit industry fixed effects. The number of varieties is the average number of countries a firm sources its foreign products from. To back out the value for $\eta$, we use our benchmark value for $\varepsilon=2.378$ from Section 3. 


\section{The Gains from Input Trade with Heterogeneous Importers by Joaquin Blaum, Claire Lelarge and Michael Peters}

\section{Online Appendix (Not for Publication)}

This Appendix contains the following additional results and material :

1. Details about the identification of the Input-Output Matrix $\Xi$,

2. Estimates of the production function coefficients,

3. Empirical evidence on the systematic heterogeneity in import behavior,

4. A description of the bootstrap procedure,

5. Empirical results on the Elasticity Bias at the sector level,

6. Additional results for economy with variable mark-ups,

7. An extension of the welfare equation (40) to a multi-sector environment,

8. Details about the algorithm used to calibrate the model of Section 3.4.

\section{A.1 Identification of the Input-Output and Demand Structure}

We use the French input-output tables from the OECD to discipline the demand parameters $\left[\alpha_{s}\right]$ and the matrix of input-output linkages $\Xi$. To determine $\Xi$, we focus on the intermediate supply from each industry $j$ to each industry $s$. We abstract from any taxes and subsidies. As $\Xi$ can be identified from expenditure shares by sourcing sector, see (24), we set

$$
\zeta_{j}^{s}=\frac{\text { Intermediate supply from industry } j \text { to industry } s}{\text { Intermediate consumption at final prices from industry } s} .
$$

That is, $\zeta_{j}^{s}$ measures the importance of sector $j$ in the production process of sector $s$. By construction, this ensures that $\sum_{j=1}^{S} \zeta_{j}^{s}=1$ for all $s$. We arrange the input-output matrix so that the columns contain the distribution of expenditure for the different sectors :

$$
\Xi=\left[\begin{array}{ccc}
\zeta_{1}^{1} & \zeta_{1}^{2} & \zeta_{1}^{S} \\
\zeta_{2}^{1} & & \\
& & \\
\zeta_{S}^{1} & & \zeta_{S}^{S}
\end{array}\right]
$$

To determine $\left[\alpha_{s}\right]$, we also use the input-output tables as they contain information on the composition of final demand. Since there is no trade in final goods in the theory, we exclude any exports and imports in final goods in the data. More specifically, the input-output tables report final consumption expenditure by households on sector $j$, denoted by $H H F C_{j}$. Following (24), we hence set

$$
\alpha_{s}=\frac{H H F C_{s}}{\sum_{j=1}^{S} H H F C_{j}} .
$$


TABLE $10-$ Measurement of $\alpha_{s}$ and $\gamma_{s}$

\begin{tabular}{|c|c|c|c|c|c|c|c|c|}
\hline \multicolumn{6}{|c|}{ Direct Data } & \multicolumn{2}{|c|}{ Aggregation } & \multirow[b]{2}{*}{$\gamma$} \\
\hline ISIC & $\alpha$ & $\begin{array}{l}\text { Value } \\
\text { Added }\end{array}$ & $\begin{array}{c}\text { Intermediate } \\
\text { Purchases }\end{array}$ & $\gamma$ & $\Lambda$ & $\begin{array}{c}\text { Coarse } \\
\text { Classification }\end{array}$ & $\alpha$ & \\
\hline 1 & $\alpha_{1}$ & $V A_{1}$ & $X_{1}$ & $\frac{X_{1}}{X_{1}+V A_{1}}$ & 0 & \multirow{4}{*}{ Non-Manufacturing } & \multirow{4}{*}{$\alpha_{S}$ from $(88)$} & \multirow{4}{*}{$\gamma_{S}$ from $(89)$} \\
\hline 2 & $\alpha_{2}$ & $V A_{2}$ & $X_{2}$ & $\frac{X_{2}}{X_{2}+V A_{2}}$ & 0 & & & \\
\hline 3 & & & & & 0 & & & \\
\hline$\ldots$ & & & & & 0 & & & \\
\hline 10 & $\alpha_{10}$ & $V A_{10}$ & $X_{10}$ & \multirow{4}{*}{$\begin{array}{l}\text { Estimate } \\
\text { from } \\
\text { micro-data }\end{array}$} & \multirow{4}{*}{$\begin{array}{l}\text { "Read off" } \\
\text { from } \\
\text { micro-data }\end{array}$} & \multirow{4}{*}{ Manufacturing } & $\alpha_{10}$ & $\gamma_{10}$ \\
\hline 16 & & & & & & & & \\
\hline$\ldots$ & & & & & & & & \\
\hline 37 & $\alpha_{37}$ & $V A_{37}$ & $X_{37}$ & & & & $\alpha_{37}$ & $\gamma_{37}$ \\
\hline 40 & $\alpha_{40}$ & $V A_{40}$ & $X_{40}$ & $\frac{X_{40}}{X_{40}+V A_{40}}$ & 0 & \multirow{3}{*}{ Non-Manufacturing } & \multirow{3}{*}{$\alpha_{S}$ from (88) } & \multirow{3}{*}{$\gamma_{S}$ from $(89)$} \\
\hline$\ldots$ & & & & & 0 & & & \\
\hline 99 & $\alpha_{99}$ & $V A_{99}$ & $X_{99}$ & $\frac{X_{99}}{X_{99}+V A_{99}}$ & 0 & & & \\
\hline
\end{tabular}

The OECD input-output tables report their data at the 2-digit level of ISIC Rev. 3, which gives 37 manufacturing industries. To deal with the non-manufacturing industries, we group them into a "residual" sector which we denote by $S$. To incorporate this sector in the analysis, we set

$$
\alpha_{S}=1-\sum_{j \in M} \alpha_{j}
$$

where $M$ is the set of manufacturing sectors. Because in our theory this sector is not engaged in foreign sourcing ${ }^{87}$, we set

$$
\Lambda_{S}=0 .
$$

The input-output structure of sector $S$ can be recovered from the input-output tables. In particular, we set

$$
\zeta_{j}^{S} \equiv \frac{\sum_{n=1}^{N M} \text { Intermediate supply from industry } j \text { to industry } n}{\sum_{n=1}^{N M} \text { Intermediate consumption at final prices to industry } n},
$$

where $N M$ is the set of non-manufacturing sectors. To measure the materials coefficient in the production of sector $S$, we employ the Input-Output Matrix for the non-manufacturing sectors. As we observe value added and intermediary spending for each sector, we set

$$
\gamma_{S}=\frac{\sum_{n=1}^{N M} X_{n}}{\sum_{n=1}^{N M}\left(X_{n}+V A_{n}\right)},
$$

where $X_{n}$ denotes total intermediary spending by sector $n$. Table 10 summarizes how $\left[\alpha_{s}\right]$ and $\left[\gamma_{s}\right]$ are computed.

The input-output matrix $\Xi$ used in our empirical analysis is contained in Table 11.

87. Note that this sector may nevertheless benefit from input trade if it sources output from the manufacturing industries. 


\begin{tabular}{|c|c|c|c|c|c|c|c|c|c|c|c|c|c|c|c|c|c|c|c|}
\hline$\Omega$ & $\mid \begin{array}{l}0 \\
\infty \\
0 \\
0\end{array}$ & 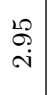 & $\left|\begin{array}{c}\infty \\
ٌ \\
0\end{array}\right|$ & 号 & $\mid \begin{array}{c}v \\
\tilde{\sigma} \\
\dot{\infty}\end{array}$ & 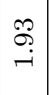 & $\begin{array}{l}2 \\
\stackrel{2}{0} \\
0\end{array}$ & $\begin{array}{l}0 \\
\stackrel{2}{2} \\
-i\end{array}$ & $\mid \begin{array}{c}\mathscr{L} \\
\stackrel{0}{0} \\
0\end{array}$ & $\stackrel{\infty}{\stackrel{\infty}{\rightarrow}}$ & 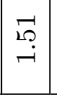 & $\stackrel{\leftrightarrow}{\stackrel{\leftrightarrow}{0}}$ & $\underset{\sim}{\stackrel{7}{-}}$ & $\stackrel{\sim}{\circ}$ & $\stackrel{0}{\circ}$ & $\begin{array}{c}0 \\
\infty \\
0 \\
0\end{array}$ & 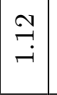 & 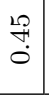 & $\begin{array}{l}\overrightarrow{1} \\
8 \\
0\end{array}$ \\
\hline $\begin{array}{l}\hat{\alpha} \\
\vdots \\
0 \\
\hat{\sigma}\end{array}$ & $\begin{array}{l}\mathcal{N} \\
\infty \\
0 \\
0\end{array}$ & $\stackrel{\infty}{\stackrel{\infty}{0}}$ & $\mid \begin{array}{l}2 \\
2 \\
0 \\
10\end{array}$ & $\begin{array}{l}9 \\
10 \\
10\end{array}$ & $\begin{array}{l}\vec{N} \\
\stackrel{i}{i}\end{array}$ & $\stackrel{\overrightarrow{7}}{\underset{+}{+}}$ & $\begin{array}{l}\mathscr{O} \\
\stackrel{+}{+} \\
\end{array}$ & $\mid \begin{array}{l}0 \\
\infty \\
-\end{array}$ & 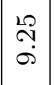 & $\underset{\sim}{\mathfrak{N}}$ & $\begin{array}{l}\vec{b} \\
\dot{\infty}\end{array}$ & $\stackrel{-}{\circ}$ & $\underset{\stackrel{\leftrightarrow}{\leftrightarrow}}{\rightarrow}$ & |ִ & 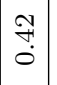 & 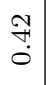 & $\mid \begin{array}{l}2 \\
\stackrel{0}{0}\end{array}$ & $\begin{array}{l}10 \\
0 \\
0 \\
0\end{array}$ & \\
\hline$\stackrel{20}{\circ}$ & 0 & $\begin{array}{l}\overrightarrow{0} \\
\dot{0}\end{array}$ & $\mid \begin{array}{c}\infty \\
\stackrel{0}{0}\end{array}$ & $\begin{array}{l}7 \\
0 \\
0\end{array}$ & $\mid \begin{array}{c}1 \\
\mathfrak{3} \\
0 \\
0\end{array}$ & $\begin{array}{l}\mathscr{\%} \\
- \\
-1\end{array}$ & $\mid \begin{array}{c}\vec{b} \\
-\end{array}$ & \begin{tabular}{|c}
$\mathscr{0}$ \\
$\stackrel{0}{0}$
\end{tabular} & $\begin{array}{l}\infty \\
\stackrel{N}{N} \\
i\end{array} \mid$ & $\begin{array}{l}\vec{\infty} \\
\stackrel{+}{+}\end{array}$ & $\left|\begin{array}{l}\stackrel{m}{\leftrightarrow} \\
\dot{\leftrightarrow}\end{array}\right|$ & $\begin{array}{l}5 \\
0 \\
0\end{array}$ & 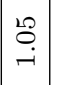 & $\begin{array}{l}\stackrel{D}{ } \\
\stackrel{+}{+}\end{array}$ & $\mid \begin{array}{c}\mathbb{1} \\
\infty \\
\infty\end{array}$ & $\begin{array}{l}-1 \\
0 \\
0\end{array}$ & $\left|\begin{array}{c}\hat{\alpha} \\
\hat{o} \\
\tilde{g}\end{array}\right|$ & $\begin{array}{c}\hat{0} \\
\stackrel{0}{0} \\
\stackrel{0}{0}\end{array}$ & $\begin{array}{l}\stackrel{g}{\circ} \\
\stackrel{+}{N}\end{array}$ \\
\hline$\vec{m}$ & 0 & $\begin{array}{l}\stackrel{+}{0} \\
\stackrel{0}{0}\end{array}$ & $\stackrel{\vec{H}}{-}$ & 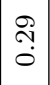 & 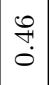 & $\stackrel{\mathscr{\leftrightarrow}}{\rightarrow}$ & $\mid \begin{array}{c}1 \\
1 \\
0 \\
0\end{array}$ & $\underset{\stackrel{\Re}{\stackrel{\sim}{\sim}}}{-}$ & $\begin{array}{l}\mathbb{Z} \\
\infty\end{array}$ & $\begin{array}{l}\mathcal{O} \\
\infty \\
\infty\end{array}$ & $\left|\begin{array}{r}\vec{H} \\
\overrightarrow{+}\end{array}\right|$ & 0 & $\mid \begin{array}{l}\hat{D} \\
\dot{\infty}\end{array}$ & $\begin{array}{l}\infty \\
\stackrel{\infty}{\rightarrow} \\
\rightarrow\end{array}$ & 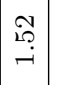 & 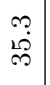 & $\begin{array}{l}\overrightarrow{1} \\
0\end{array}$ & $\underset{\rightarrow}{\stackrel{\leftrightarrow}{-}}$ & \begin{tabular}{l}
0 \\
$\mathscr{H}$ \\
\multirow{2}{*}{}
\end{tabular} \\
\hline$\cong$ & 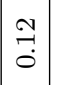 & $\begin{array}{l}\infty \\
\stackrel{0}{0}\end{array}$ & $\mid \begin{array}{c}1 \\
\infty \\
0 \\
0\end{array}$ & 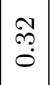 & $\begin{array}{l}\vec{i} \\
\vec{i}\end{array}$ & $\stackrel{\beth}{\stackrel{-}{ت}}$ & $\begin{array}{l}\stackrel{\sim}{1} \\
\sim \\
\infty\end{array} \mid$ & $\mid \begin{array}{l}\infty \\
\stackrel{\sim}{i} \\
\text {. }\end{array}$ & $\mid \begin{array}{l}0 \\
\stackrel{0}{0} \\
10\end{array}$ & $\begin{array}{l}\vec{\infty} \\
\infty \\
\infty\end{array}$ & $\left|\begin{array}{c}\hat{\infty} \\
\infty \\
\infty\end{array}\right|$ & $\begin{array}{l}\mathcal{O} \\
\stackrel{i}{i}\end{array}$ & $\begin{array}{c}\vec{D} \\
\infty \\
i\end{array}$ & $\begin{array}{l}\infty \\
\stackrel{0}{\exists} \\
\exists\end{array}$ & $\mid$\begin{tabular}{l|}
$\vec{\rho}$ \\
$\ddot{g}$ \\
$\vec{g}$
\end{tabular} & $\begin{array}{l}\overleftrightarrow{N} \\
\stackrel{0}{0}\end{array}$ & $\mid \begin{array}{l}20 \\
\stackrel{0}{0}\end{array}$ & \begin{tabular}{c} 
î \\
\multirow{2}{0}{} \\
0
\end{tabular} & 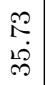 \\
\hline ๙ิ & $\mid \begin{array}{l}0 \\
0 \\
0\end{array}$ & $\begin{array}{l}\infty \\
\stackrel{0}{0}\end{array}$ & $\left|\begin{array}{l}0 \\
0 \\
0 \\
0\end{array}\right|$ & $\begin{array}{c}1 \\
\tilde{o} \\
0\end{array}$ & 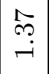 & $\begin{array}{l}\overrightarrow{1} \\
0 \\
0\end{array}$ & $\begin{array}{l}1 \\
0 \\
10 \\
1\end{array}$ & $\stackrel{\mid}{\longrightarrow}$ & $\mid \begin{array}{l}2 \\
\stackrel{i}{i}\end{array}$ & $\begin{array}{l}5 \\
\sigma \\
10 \\
10\end{array}$ & $\mid \begin{array}{c}\stackrel{2}{\stackrel{\leftrightarrow}{-}} \\
-\end{array}$ & $\begin{array}{l}\stackrel{\sim}{\Im} \\
\rightarrow \\
-1\end{array}$ & $\mid \begin{array}{c}\infty \\
0 \\
0\end{array}$ & $\begin{array}{l}0 \\
\stackrel{\infty}{0} \\
\dot{m}\end{array}$ & 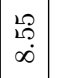 & 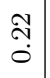 & $\begin{array}{l}0 \\
0 \\
0\end{array}$ & 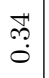 & 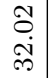 \\
\hline$\vec{m}$ & {$\left[\begin{array}{l}0 \\
0 \\
0\end{array}\right.$} & $\stackrel{\sim}{7}$ & F & :̊ & $\stackrel{\stackrel{\sim}{-}}{\rightarrow}$ & $\underset{\mathcal{F}}{\stackrel{T}{+}}$ & $\mid \begin{array}{l}\infty \\
0 \\
0 \\
0\end{array}$ & $\begin{array}{l}\vec{\infty} \\
0 \\
0\end{array}$ & $\begin{array}{l}\mathscr{I} \\
= \\
=\end{array}$ & $\begin{array}{l}\vec{F} \\
\dot{g} \\
\vec{g}\end{array}$ & $\left|\begin{array}{l}\infty \\
\stackrel{\infty}{N} \\
\end{array}\right|$ & $\begin{array}{l}\stackrel{2}{0} \\
\dddot{o} \\
0\end{array}$ & $\mid \begin{array}{l}0 \\
\stackrel{0}{0} \\
-1\end{array}$ & $\Rightarrow$ & $\left|\begin{array}{c}\mathcal{N} \\
\stackrel{N}{N}\end{array}\right|$ & 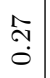 & $\begin{array}{l}0 \\
0 \\
0\end{array}$ & $\begin{array}{l}\overrightarrow{0} \\
\dot{0}\end{array}$ & $\begin{array}{l}\vec{A} \\
\infty \\
\infty \\
\text { N }\end{array}$ \\
\hline$\stackrel{\circ}{ }$ & $\begin{array}{l}2 \\
\stackrel{2}{0} \\
0\end{array}$ & $\overrightarrow{0}$ & $\mid$\begin{tabular}{c}
$\infty$ \\
\multirow{2}{0}{} \\
0
\end{tabular} & $\begin{array}{l}2 \\
0 \\
0\end{array}$ & $\left|\begin{array}{c}0 \\
0 \\
0 \\
0\end{array}\right|$ & $\begin{array}{c}1 \\
\stackrel{2}{a} \\
0 \\
0\end{array}$ & 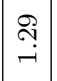 & $\begin{array}{l}7 \\
0 \\
0\end{array}$ & $\begin{array}{c}\infty \\
\stackrel{0}{0} \\
0\end{array}$ & $\begin{array}{l}\stackrel{1}{2} \\
0 \\
0\end{array}$ & $\begin{array}{l}\overrightarrow{0} \\
0 \\
0\end{array}$ & $\begin{array}{l}\vec{b} \\
\overrightarrow{0} \\
\infty\end{array}$ & $\begin{array}{l}\mathscr{g} \\
\dot{\infty} \\
\dot{n}\end{array}$ & 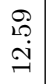 & 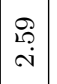 & $\stackrel{m}{\rightarrow}$ & $\begin{array}{c}\tilde{O} \\
\dot{0} \\
\dot{0}\end{array}$ & $\overrightarrow{0}$ & 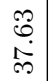 \\
\hline$\stackrel{\mathrm{N}}{ }$ & $\frac{7}{3}$ & $\stackrel{7}{0}$ & 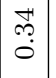 & ঙ্ণী & $\stackrel{\vec{\sigma}}{-}$ & $\begin{array}{l}\stackrel{\infty}{\stackrel{\sim}{\sim}} \\
\sim\end{array}$ & 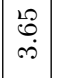 & $\mid \begin{array}{l}0 \\
0 \\
0\end{array}$ & 0 & 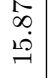 & 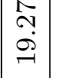 & 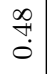 & $\underset{\mathscr{P}}{\stackrel{\sim}{\sim}}$ & $\begin{array}{l}\vec{\infty} \\
\infty \\
\dot{\infty}\end{array}$ & 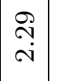 & $\begin{array}{l}: \\
: \\
0\end{array}$ & $\vec{\leftrightarrow}$ & $\begin{array}{l}0 \\
0 \\
0\end{array}$ & \\
\hline$\stackrel{\infty}{\sim}$ & $\mid \begin{array}{c}0 \\
\stackrel{0}{0} \\
0\end{array}$ & $\stackrel{1}{0}$ & $\stackrel{ }{\stackrel{\sim}{0}}$ & 品 & $\begin{array}{l}0 \\
0 \\
0\end{array}$ & $\begin{array}{l}\tilde{\delta} \\
\dot{\infty}\end{array}$ & $\left|\begin{array}{l}\stackrel{\Re}{A} \\
\text { ì }\end{array}\right|$ & $\stackrel{0}{0}$ & $\left|\begin{array}{c}\mathcal{N} \\
\stackrel{i}{N}\end{array}\right|$ & $\begin{array}{l}\vec{D} \\
\dot{d} \\
\sim\end{array}$ & $\begin{array}{l}\vec{\Delta} \\
\dot{+}\end{array}$ & 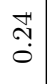 & $\begin{array}{l}\vec{N} \\
\stackrel{i}{i}\end{array}$ & 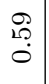 & $\begin{array}{l}\overrightarrow{0} \\
\dot{0}\end{array}$ & 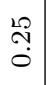 & $\begin{array}{l}7 \\
0\end{array}$ & $\begin{array}{l}\infty \\
\stackrel{0}{0} \\
0\end{array}$ & 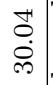 \\
\hline$\hat{N}$ & {$\left[\begin{array}{l}2 \\
\infty \\
+ \\
+\end{array}\right.$} & $\stackrel{1}{0}$ & $\begin{array}{c}\text { Ǹ } \\
\text { O }\end{array}$ & 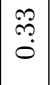 & $\begin{array}{l}0 \\
0\end{array}$ & $\begin{array}{l}\mathcal{S} \\
\vec{i}\end{array}$ & $\begin{array}{l}0 \\
0 \\
0\end{array}$ & $\mid \begin{array}{c}\infty \\
\infty \\
0 \\
0\end{array}$ & $\mid \begin{array}{c}\overrightarrow{0} \\
\vec{\forall}\end{array}$ & $\begin{array}{l}\mathscr{S} \\
\dot{0}\end{array}$ & $\sim$ & $\begin{array}{l}\overrightarrow{0} \\
0 \\
0\end{array}$ & 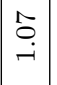 & $\stackrel{\vec{m}}{\circ}$ & $\mid \begin{array}{c}\mathscr{d} \\
\stackrel{\leftrightarrow}{0} \\
0\end{array}$ & 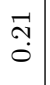 & $\mid \begin{array}{l}28 \\
0 \\
0\end{array}$ & 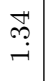 & 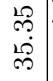 \\
\hline$\stackrel{\sim}{\circ}$ & $\begin{array}{l}\infty \\
\infty \\
\infty \\
\infty\end{array}$ & $\begin{array}{l}\mathscr{0} \\
\stackrel{\circ}{0}\end{array}$ & $\underset{\stackrel{H}{0}}{\stackrel{F}{0}}$ & $\begin{array}{l}\mathscr{O} \\
\dot{i}\end{array}$ & 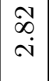 & $\begin{array}{l}\vec{m} \\
\dot{m}\end{array}$ & $\underset{H}{\stackrel{H}{-}}$ & 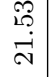 & $\mid \begin{array}{l}\vec{N} \\
\dot{n}\end{array}$ & 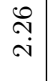 & 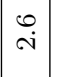 & $\begin{array}{l}\stackrel{0}{0} \\
\stackrel{0}{0}\end{array}$ & $\left|\begin{array}{l}D \\
D \\
0\end{array}\right|$ & $\begin{array}{l}\hat{\alpha} \\
\stackrel{0}{0}\end{array}$ & 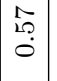 & $\stackrel{\stackrel{\sim}{\circ}}{\circ}$ & $\mid \begin{array}{l}0 \\
\stackrel{0}{0}\end{array}$ & $\stackrel{\Re}{\stackrel{P}{0}}$ & 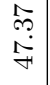 \\
\hline$\stackrel{\llcorner}{\mathrm{N}}$ & $\mid \begin{array}{l}0 \\
\stackrel{N}{0} \\
0\end{array}$ & 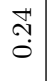 & 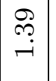 & $\begin{array}{c}\infty \\
\dddot{0} \\
0\end{array}$ & 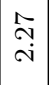 & $\left|\begin{array}{c}0 \\
\multirow{q}{q}{} \\
\dot{q}\end{array}\right|$ & $\left|\begin{array}{l}\mathfrak{N} \\
\stackrel{\mathfrak{N}}{\sim}\end{array}\right|$ & $\begin{array}{l}0 \\
\stackrel{0}{0}\end{array}$ & $\left|\begin{array}{c}\hat{\sigma} \\
\stackrel{-}{-}\end{array}\right|$ & 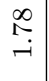 & $\left|\begin{array}{l}\stackrel{R}{A} \\
i\end{array}\right|$ & $\begin{array}{l}\infty \\
\stackrel{0}{0}\end{array}$ & \begin{tabular}{|l}
$\vec{N}$ \\
$\tilde{O}$
\end{tabular} & $\stackrel{\circ}{\stackrel{\rho}{0}}$ & $\left|\begin{array}{c}\text { Ñ} \\
\text { ठ }\end{array}\right|$ & $\begin{array}{l}n \\
0 \\
0\end{array}$ & 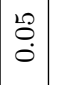 & $\stackrel{\mathscr{\vartheta}}{\stackrel{0}{0}}$ & |ll \\
\hline$\vec{N}$ & $\stackrel{\infty}{-}$ & 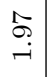 & $\mid \begin{array}{l}\infty \\
0\end{array}$ & $\begin{array}{c}n \\
0 \\
0\end{array}$ & $\begin{array}{l}\tilde{O} \\
\dot{\infty} \\
\dot{\infty}\end{array}$ & $\left|\begin{array}{l}\infty \\
\stackrel{1}{0} \\
\tilde{n}\end{array}\right|$ & $\begin{array}{l}\infty \\
\stackrel{\infty}{\infty} \\
\end{array}$ & $\begin{array}{l}\vec{\infty} \\
0 \\
0\end{array}$ & $\begin{array}{l}R \\
2 \\
0\end{array} \mid$ & $\underset{\vec{i}}{\stackrel{M}{i}}$ & $\left|\begin{array}{c}\infty \\
\stackrel{1}{0}\end{array}\right|$ & $\begin{array}{l}0 \\
\dot{0} \\
\dot{0}\end{array}$ & 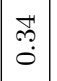 & $\stackrel{m}{\rightarrow}$ & 今) & $\begin{array}{l}n \\
0 \\
0\end{array}$ & $\mid \begin{array}{l}\overrightarrow{0} \\
\dot{O}\end{array}$ & $\begin{array}{l}\infty \\
\stackrel{0}{0}\end{array}$ & 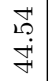 \\
\hline $\begin{array}{l}\underset{N}{N} \\
\stackrel{\Lambda}{N}\end{array}$ & $\vec{F}$ & 苞 & $\mid \begin{array}{l}0 \\
0 \\
0 \\
0\end{array}$ & $\mid \begin{array}{r}\hat{O} \\
- \\
-\end{array}$ & $\mid \begin{array}{l}\Re \\
\stackrel{\mathscr{Z}}{ }\end{array}$ & $\begin{array}{l}\mathscr{O} \\
\dot{L S}\end{array}$ & $\mid \begin{array}{c}\hat{\omega} \\
- \\
-\end{array}$ & $\vec{~}$ & $\begin{array}{l}\infty \\
0 \\
0\end{array}$ & $\begin{array}{l}\infty \\
\stackrel{0}{0} \\
0\end{array}$ & $\mid \begin{array}{c}1 \\
\infty \\
0 \\
0\end{array}$ & $\begin{array}{l}\infty \\
\stackrel{0}{0}\end{array}$ & 点 & $\begin{array}{l}20 \\
\overrightarrow{0} \\
0\end{array}$ & 今) & $\stackrel{7}{0}$ & $\mid \begin{array}{l}28 \\
0 \\
0\end{array}$ & $\stackrel{\infty}{\circ}$ & $\stackrel{\vec{F}}{\vec{F}}$ \\
\hline 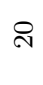 & $\begin{array}{l}\tilde{O} \\
\dot{0}\end{array}$ & 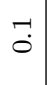 & $\mid \begin{array}{l}\infty \\
0 \\
0\end{array}$ & $\begin{array}{l}\hat{y} \\
\dot{0} \\
\dot{m}\end{array}$ & 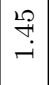 & $\underset{\stackrel{\leftrightarrow}{:}}{-}$ & $\mid \begin{array}{l}1 \\
0 \\
0\end{array}$ & $\begin{array}{l}\vec{\infty} \\
0 \\
0\end{array}$ & 芯 & $\begin{array}{l}\vec{b} \\
\dot{b} \\
\dot{0}\end{array}$ & $\left|\begin{array}{l}\vec{m} \\
\dot{\infty}\end{array}\right|$ & $\begin{array}{l}\infty \\
\stackrel{0}{0} \\
0\end{array}$ & $\mid \begin{array}{c}\infty \\
\stackrel{\infty}{0} \\
0\end{array}$ & $\begin{array}{l}\stackrel{8}{0} \\
0\end{array}$ & $\begin{array}{l}0 \\
\dot{0} \\
0\end{array}$ & 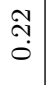 & $\begin{array}{l}\overrightarrow{0} \\
\dot{0}\end{array}$ & $\stackrel{\text { Fै }}{\circ}$ & \\
\hline$\stackrel{2}{N}$ & 0 & $\begin{array}{c}\hat{N} \\
\text { N }\end{array}$ & 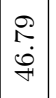 & $\stackrel{m}{\stackrel{9}{0}}$ & זִ & 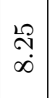 & 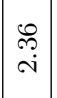 & $\stackrel{9}{\stackrel{9}{0}}$ & $\ddot{0}$ & $\stackrel{0}{\stackrel{-}{-}}$ & $\begin{array}{l}: \\
\stackrel{\leftrightarrow}{-}\end{array}$ & $\begin{array}{l}\overrightarrow{0} \\
\dot{0}\end{array}$ & 文 & $\begin{array}{l}\hat{\Delta} \\
\stackrel{0}{0}\end{array}$ & 文 & $\stackrel{\sim}{\circ}$ & $\begin{array}{l}\overrightarrow{0} \\
\dot{0}\end{array}$ & 宊 & \\
\hline 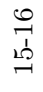 & $\stackrel{\stackrel{7}{7}}{0}$ & 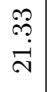 & $\begin{array}{l}7 \\
0\end{array}$ & $\mid \begin{array}{c}\infty \\
ٌ \\
0\end{array}$ & $\mid \begin{array}{l}\text { î̀ } \\
\text { iv }\end{array}$ & $\stackrel{\stackrel{L}{9}}{\stackrel{-}{-}}$ & $\begin{array}{l}\mathscr{I} \\
\stackrel{1}{i} \\
\text { | }\end{array}$ & $\mid \begin{array}{c}R \\
R \\
0\end{array}$ & $\begin{array}{l}8 \\
0 \\
0\end{array}$ & $\stackrel{\stackrel{\leftrightarrow}{\oplus}}{\rightarrow}$ & $\begin{array}{l}R \\
T \\
0\end{array}$ & $\begin{array}{l}\tilde{O} \\
\dot{0}\end{array}$ & $\underset{ }{\stackrel{H}{0}}$ & $\begin{array}{l}\mathscr{8} \\
\dot{0}\end{array}$ & $\overrightarrow{0}$ & $\begin{array}{l}\stackrel{8}{0} \\
\dot{0}\end{array}$ & $\begin{array}{l}0 \\
\dot{0}\end{array}$ & $\stackrel{1}{\circ}$ & $\begin{array}{l}\infty \\
\stackrel{\infty}{\infty} \\
\infty \\
\infty \\
0\end{array}$ \\
\hline $\begin{array}{l}\vec{H} \\
\vec{d}\end{array}$ & $\begin{array}{l}\stackrel{O}{0} \\
\infty \\
\infty\end{array}$ & $\stackrel{\infty}{\stackrel{\leftrightarrow}{0}}$ & $\mid$\begin{tabular}{l}
0 \\
\multirow{2}{*}{} \\
0
\end{tabular} & 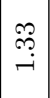 & $\underset{⿱}{\stackrel{H}{-}}$ & 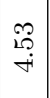 & $\mid \begin{array}{c}0 \\
0 \\
-1 \\
-1\end{array}$ & $\left|\begin{array}{l}0 \\
i \\
\infty \\
\infty \\
\infty\end{array}\right|$ & $\begin{array}{l}0 \\
0 \\
0\end{array}$ & $\begin{array}{l}28 \\
20 \\
100\end{array}$ & 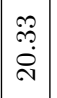 & 0 & $\begin{array}{c}\vec{b} \\
0 \\
0\end{array}$ & $\stackrel{\leftrightarrow}{0}$ & 占 & $\begin{array}{l}\infty \\
\stackrel{\infty}{0} \\
0\end{array}$ & $\stackrel{20}{\stackrel{20}{0}}$ & $\stackrel{\sim}{\sim}$ & $\begin{array}{l}\text { ड़ } \\
\stackrel{\leftrightarrow}{*}\end{array}$ \\
\hline 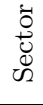 & 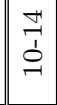 & $\begin{array}{l}0 \\
\stackrel{1}{1} \\
\rightarrow\end{array}$ & $\mid \begin{array}{c}\stackrel{9}{1} \\
\stackrel{1}{-}\end{array}$ & ๙ & $\begin{array}{l}\mathbb{N} \\
\stackrel{N}{N}\end{array}$ & $\vec{N}$ & $\stackrel{20}{\mathrm{~N}}$ & $\stackrel{\sim}{\sim}$ & ล & $\stackrel{\infty}{\sim}$ & $\stackrel{\curvearrowright}{*}$ & $\ddot{\circ}$ & $\vec{N}$ & $\tilde{~}$ & $\ddot{m}$ & $\vec{m}$ & 20 & $\begin{array}{l}\hat{0} \\
0 \\
b \\
\tilde{\omega}\end{array}$ & Un \\
\hline
\end{tabular}




\section{A.2 Estimating the Parameters of the Production Function}

Here we report the production function coefficients complementing our analysis of Table (7). In Table 12, we report the coefficients for capital and labor $\left(\phi_{k s}, \phi_{l s}\right)$, firms domestic share $\left(-\frac{\gamma_{s}}{\varepsilon_{s}-1}\right)$ and material spending $\left(\gamma_{s}\right)$ for the Cobb-Douglas specification. For convenience we also report the implied elasticity of substitution $\varepsilon_{s}$.

Table 13 contains the same results for the translog specification, i.e. a production function where we include the squared terms for (log) capital and (log) labor and their interaction. We continue to assume that the elasticity of intermediate inputs is constant. This is required for our result linking firm-level domestic shares to unit-cost changes (see (7)).

Finally, in Table 14 we also report the implied production function parameters from the factor share approach. Note that this method imposes the assumption of constant returns, so that $\phi_{k s}+$ $\phi_{l s}+\gamma_{s}=1$.

\section{A.3 Firm-level heterogeneity in the gains from input trade}

We can measure the firm-level gains from input trade from $\frac{\gamma_{s}}{1-\varepsilon} \ln \left(s_{\text {Dist }}\right)$ (see $\left.(7)\right)$. One can then use the micro-data to learn about the firm-level correlates of this heterogeneity. In particular, consider a regression of the firm-level gains $\frac{\gamma_{s}}{1-\varepsilon} \ln \left(s_{\text {Dist }}\right)$ on different firm-characteristics, which according to (5) could reflect firm-variation in exogenous "import capabilities" (such as prices $\left[p_{c i} / q_{c i}\right]$ or the home bias $\beta_{i}$ ) and firms' endogenous sourcing strategies $\Sigma_{i}$. Consider Table 15, which contains the results of regressions of the form $\frac{\gamma_{s}}{1-\varepsilon} \ln \left(s_{\text {Dist }}\right)=\delta_{s}+\delta_{t}+o_{i s t}^{\prime} \psi+u_{i s t}$, where $\delta_{s}$ and $\delta_{t}$ are industry and time fixed effects and $o_{i s t}$ is a vector of firm characteristics. We find that bigger firms and exporters see higher gains. When we restrict the analysis to the sample of importers, the positive relation between firm size and the firm-level gains becomes substantially weaker. This is consistent with the pattern documented in Figure 2. When we consider the role of firms' sourcing strategies, we find a strong positive relation between firms' extensive margin (which we measure by the average number of countries that the firm sources its products from) and the firm-level gains. This is consistent with theories where import participation in foreign markets reduces firms' unit costs. The importance of other firm characteristics is substantially diminished once this extensive margin is controlled for.

\section{A.4 Bootstrap Procedure}

We sample firms from the empirical distribution with replacement to construct 200 replicates of our micro-data. For each of these samples, we re-calculate $\sigma_{s}$ and re-estimate $\varepsilon$ and $\left[\gamma_{s}\right]$ following the

factor shares approach explained in Section 3.2 and then re-calculate $\left[\Lambda_{s}\right]$ and $\left[s_{D s}^{A g g}\right]$. Figure 5 depicts the bootstrap distributions of these variables. For the three sector-level variables, we report the distribution of the sectoral averages, e.g. the upper right panel displays the distribution of $\frac{1}{S} \sum_{s=1}^{S} \gamma_{s}$. While the variation in $\gamma$ and $s_{D}^{A g g}$ is relatively modest, there is a quite a bit of uncertainty regarding $\varepsilon$. This is consistent with the non-negligible standard errors reported in Table 2 . We conclude that it is the variation in $\varepsilon$ which induces most of the variation in $\Lambda$ and therefore in the consumer price gains from input trade reported in Table 4. 
TABLE 12 - Production Function Coefficient Estimates, by 2-digit Sector : Cobb-Douglas

\begin{tabular}{|c|c|c|c|c|c|c|}
\hline Industry & ISIC & $\tilde{\phi}_{k s}$ & $\tilde{\phi}_{l s}$ & $-\frac{\tilde{\gamma}_{s}}{\epsilon_{s}-1}$ & $\tilde{\gamma}_{s}$ & $\epsilon_{s}$ \\
\hline Mining & $10-14$ & $\begin{array}{c}0.434^{* * *} \\
(0.047)\end{array}$ & $\begin{array}{c}0.420^{* * *} \\
(0.047)\end{array}$ & $\begin{array}{l}0.309^{*} \\
(0.177)\end{array}$ & $\begin{array}{c}0.119 \\
(0.076)\end{array}$ & $\begin{array}{l}0.616^{*} \\
(0.324)\end{array}$ \\
\hline $\begin{array}{l}\text { Food, tobacco, } \\
\text { beverages }\end{array}$ & $15-16$ & $\begin{array}{c}0.108^{* * *} \\
(0.007)\end{array}$ & $\begin{array}{c}0.193^{* * *} \\
(0.007)\end{array}$ & $\begin{array}{c}-0.358^{* * *} \\
(0.034)\end{array}$ & $\begin{array}{c}0.459^{* * *} \\
(0.047)\end{array}$ & $\begin{array}{c}2.285^{* * *} \\
(0.212)\end{array}$ \\
\hline $\begin{array}{l}\text { Textiles and } \\
\text { leather }\end{array}$ & $17-19$ & $\begin{array}{c}0.181^{* * *} \\
(0.020)\end{array}$ & $\begin{array}{c}0.392^{* * *} \\
(0.024)\end{array}$ & $\begin{array}{c}-0.226^{* * *} \\
(0.071)\end{array}$ & $\begin{array}{c}0.233^{* * *} \\
(0.069)\end{array}$ & $\begin{array}{c}2.031^{* * *} \\
(0.546)\end{array}$ \\
\hline $\begin{array}{l}\text { Food and wood } \\
\text { products }\end{array}$ & 20 & $\begin{array}{c}0.128^{* * *} \\
(0.019)\end{array}$ & $\begin{array}{c}0.344^{* * *} \\
(0.019)\end{array}$ & $\begin{array}{c}-0.252^{* * *} \\
(0.028)\end{array}$ & $\begin{array}{c}0.352^{* * *} \\
(0.047)\end{array}$ & $\begin{array}{c}2.397^{* * *} \\
(0.279)\end{array}$ \\
\hline $\begin{array}{l}\text { Paper, printing, } \\
\text { publishing }\end{array}$ & $21 \_22$ & $\begin{array}{c}0.085^{* * *} \\
(0.013)\end{array}$ & $\begin{array}{c}0.418^{* * *} \\
(0.019)\end{array}$ & $\begin{array}{c}-0.163^{* * *} \\
(0.042)\end{array}$ & $\begin{array}{c}0.315^{* * *} \\
(0.058)\end{array}$ & $\begin{array}{c}2.932^{* * *} \\
(0.709)\end{array}$ \\
\hline Chemicals & 24 & $\begin{array}{c}0.041 \\
(0.039)\end{array}$ & $\begin{array}{c}0.152^{* * *} \\
(0.059)\end{array}$ & $\begin{array}{c}0.111 \\
(0.093)\end{array}$ & $\begin{array}{c}0.767^{* * *} \\
(0.159)\end{array}$ & $\begin{array}{l}-5.877 \\
(5.244)\end{array}$ \\
\hline $\begin{array}{l}\text { Rubber and } \\
\text { plastics products }\end{array}$ & 25 & $\begin{array}{c}0.119^{* * *} \\
(0.024)\end{array}$ & $\begin{array}{c}0.435^{* * *} \\
(0.041)\end{array}$ & $\begin{array}{c}-0.126^{* * *} \\
(0.048)\end{array}$ & $\begin{array}{c}0.202^{* *} \\
(0.094)\end{array}$ & $\begin{array}{c}2.611^{* *} \\
(1.190)\end{array}$ \\
\hline $\begin{array}{l}\text { Non-metallic } \\
\text { mineral products }\end{array}$ & 26 & $\begin{array}{c}0.131^{* * *} \\
(0.024)\end{array}$ & $\begin{array}{c}0.340^{* * *} \\
(0.024)\end{array}$ & $\begin{array}{c}-0.383^{* * *} \\
(0.063)\end{array}$ & $\begin{array}{c}0.311^{* * *} \\
(0.080)\end{array}$ & $\begin{array}{c}1.813^{* * *} \\
(0.263)\end{array}$ \\
\hline Basic metals & 27 & $\begin{array}{c}0.137 \\
(0.104)\end{array}$ & $\begin{array}{c}0.478^{* * *} \\
(0.159)\end{array}$ & $\begin{array}{r}-0.678^{*} \\
(0.397)\end{array}$ & $\begin{array}{l}-0.143 \\
(0.519)\end{array}$ & $\begin{array}{c}0.788 \\
(0.655)\end{array}$ \\
\hline Metal products & 28 & $\begin{array}{c}0.171^{* * *} \\
(0.009)\end{array}$ & $\begin{array}{c}0.451^{* * *} \\
(0.011)\end{array}$ & $\begin{array}{c}-0.402^{* * *} \\
(0.023)\end{array}$ & $\begin{array}{c}0.151^{* * *} \\
(0.026)\end{array}$ & $\begin{array}{l}1.374^{* * *} \\
(0.0734)\end{array}$ \\
\hline $\begin{array}{l}\text { Machinery and } \\
\text { equipment }\end{array}$ & 29 & $\begin{array}{c}0.130^{* * *} \\
(0.013)\end{array}$ & $\begin{array}{c}0.353^{* * *} \\
(0.017)\end{array}$ & $\begin{array}{c}-0.191^{* * *} \\
(0.028)\end{array}$ & $\begin{array}{c}0.323^{* * *} \\
(0.048)\end{array}$ & $\begin{array}{c}2.688^{* * *} \\
(0.415)\end{array}$ \\
\hline $\begin{array}{l}\text { Office and } \\
\text { computing machinery }\end{array}$ & 30 & $\begin{array}{c}0.114 \\
(0.074)\end{array}$ & $\begin{array}{c}0.389^{* * *} \\
(0.095)\end{array}$ & $\begin{array}{l}-0.078 \\
(0.134)\end{array}$ & $\begin{array}{c}0.123 \\
(0.189)\end{array}$ & $\begin{array}{c}2.564 \\
(3.823)\end{array}$ \\
\hline Electrical machinery & 31 & $\begin{array}{c}0.109^{* * *} \\
(0.022)\end{array}$ & $\begin{array}{c}0.354^{* * *} \\
(0.028)\end{array}$ & $\begin{array}{c}-0.180^{* * *} \\
(0.055)\end{array}$ & $\begin{array}{c}0.334^{* * *} \\
(0.084)\end{array}$ & $\begin{array}{c}2.859^{* * *} \\
(0.910)\end{array}$ \\
\hline $\begin{array}{l}\text { Radio and } \\
\text { communication }\end{array}$ & 32 & $\begin{array}{c}0.116^{* *} \\
(0.054)\end{array}$ & $\begin{array}{c}0.478^{* * *} \\
(0.115)\end{array}$ & $\begin{array}{l}-0.301^{*} \\
(0.170)\end{array}$ & $\begin{array}{c}0.238 \\
(0.208)\end{array}$ & $\begin{array}{l}1.790^{*} \\
(1.071)\end{array}$ \\
\hline $\begin{array}{l}\text { Medical and optical } \\
\text { instruments }\end{array}$ & 33 & $\begin{array}{c}0.137^{* * *} \\
(0.014)\end{array}$ & $\begin{array}{c}0.308^{* * *} \\
(0.013)\end{array}$ & $\begin{array}{c}-0.243^{* * *} \\
(0.037)\end{array}$ & $\begin{array}{c}0.306^{* * *} \\
(0.049)\end{array}$ & $\begin{array}{c}2.261^{* * *} \\
(0.319)\end{array}$ \\
\hline $\begin{array}{l}\text { Motor vehicles, } \\
\text { trailers }\end{array}$ & 34 & $\begin{array}{c}0.078 \\
(0.072)\end{array}$ & $\begin{array}{c}0.300^{* * *} \\
(0.100)\end{array}$ & $\begin{array}{c}-0.203^{* * *} \\
(0.077)\end{array}$ & $\begin{array}{c}0.599^{* *} \\
(0.288)\end{array}$ & $\begin{array}{l}3.958^{*} \\
(2.388)\end{array}$ \\
\hline Transport equipment & 35 & $\begin{array}{c}0.079^{* *} \\
(0.037)\end{array}$ & $\begin{array}{c}0.295^{* * *} \\
(0.043)\end{array}$ & $\begin{array}{l}-0.098 \\
(0.150)\end{array}$ & $\begin{array}{c}0.462^{* * *} \\
(0.129)\end{array}$ & $\begin{array}{c}5.705 \\
(7.770)\end{array}$ \\
\hline $\begin{array}{l}\text { Manufacturing, } \\
\text { recycling }\end{array}$ & $36-37$ & $\begin{array}{c}0.156^{* * *} \\
(0.013)\end{array}$ & $\begin{array}{c}0.339^{* * *} \\
(0.012)\end{array}$ & $\begin{array}{c}-0.386^{* * *} \\
(0.049)\end{array}$ & $\begin{array}{c}0.303^{* * *} \\
(0.040)\end{array}$ & $\begin{array}{c}1.786^{* * *} \\
(0.167)\end{array}$ \\
\hline
\end{tabular}

Notes : Robust standard errors in parentheses with ***,**, and * respectively denoting significance at the $1 \backslash \%, 5 \backslash \%$ and $10 \backslash \%$ levels. The table contains the results of estimating (74) with the instruments given in (76). For non-importers, the instrument is set to zero in the full sample specifications. Estimation relies on data for the years 2004-2006, because two lags are required to build the appropriate instruments for the estimation of the production function. Standard errors for the estimates of $\varepsilon$ are retrieved by delta-method. 
TABLE 13 - Production Function Coefficient Estimates, by 2-digit Sector : Translog

\begin{tabular}{|c|c|c|c|c|c|c|c|c|c|}
\hline Industry & ISIC & $\tilde{\phi}_{k s}$ & $\tilde{\phi}_{l s}$ & $\tilde{\phi}_{k^{2} s}$ & $\tilde{\phi}_{l^{2} s}$ & $\tilde{\phi}_{k l s}$ & $-\frac{\tilde{\gamma}_{s}}{\epsilon_{s}-1}$ & $\tilde{\gamma}_{s}$ & $\epsilon_{s}$ \\
\hline Mining & $10-14$ & $\begin{array}{c}0.175^{* * *} \\
(0.064)\end{array}$ & $\begin{array}{c}0.700^{* * *} \\
(0.084)\end{array}$ & $\begin{array}{c}0.032^{* * *} \\
(0.006)\end{array}$ & $\begin{array}{c}0.043^{* * *} \\
(0.015)\end{array}$ & $\begin{array}{c}-0.067^{* * *} \\
(0.019)\end{array}$ & $\begin{array}{l}0.341^{*} \\
(0.184)\end{array}$ & $\begin{array}{c}0.087 \\
(0.075)\end{array}$ & $\begin{array}{c}0.745^{* * *} \\
(0.254)\end{array}$ \\
\hline $\begin{array}{l}\text { Food, tobacco, } \\
\text { beverages }\end{array}$ & $15-16$ & $\begin{array}{c}0.019^{* *} \\
(0.009)\end{array}$ & $\begin{array}{c}0.299^{* * *} \\
(0.009)\end{array}$ & $\begin{array}{c}0.019^{* * *} \\
(0.001)\end{array}$ & $\begin{array}{c}0.047^{* * *} \\
(0.002)\end{array}$ & $\begin{array}{c}-0.047^{* * *} \\
(0.002)\end{array}$ & $\begin{array}{c}-0.223^{* * *} \\
(0.031)\end{array}$ & $\begin{array}{c}0.398^{* * *} \\
(0.046)\end{array}$ & $\begin{array}{c}2.789^{* * *} \\
(0.381)\end{array}$ \\
\hline $\begin{array}{l}\text { Textiles and } \\
\text { leather }\end{array}$ & $17-19$ & $\begin{array}{c}0.147^{* * *} \\
(0.024)\end{array}$ & $\begin{array}{c}0.506^{* * *} \\
(0.025)\end{array}$ & $\begin{array}{c}0.016^{* * *} \\
(0.003)\end{array}$ & $\begin{array}{c}0.036^{* * *} \\
(0.005)\end{array}$ & $\begin{array}{c}-0.053^{* * *} \\
(0.006)\end{array}$ & $\begin{array}{c}-0.241 * * * \\
(0.071)\end{array}$ & $\begin{array}{c}0.238^{* * *} \\
(0.069)\end{array}$ & $\begin{array}{c}1.986^{* * *} \\
(0.500)\end{array}$ \\
\hline $\begin{array}{l}\text { Food and wood } \\
\text { products }\end{array}$ & 20 & $\begin{array}{c}-0.065^{* * *} \\
(0.024)\end{array}$ & $\begin{array}{c}0.494^{* * *} \\
(0.025)\end{array}$ & $\begin{array}{c}0.032^{* * *} \\
(0.002)\end{array}$ & $\begin{array}{c}0.057^{* * *} \\
(0.003)\end{array}$ & $\begin{array}{c}-0.070^{* * *} \\
(0.005)\end{array}$ & $\begin{array}{c}-0.197^{* * *} \\
(0.026)\end{array}$ & $\begin{array}{c}0.383^{* * *} \\
(0.046)\end{array}$ & $\begin{array}{c}2.943^{* * *} \\
(0.399)\end{array}$ \\
\hline $\begin{array}{l}\text { Paper, printing, } \\
\text { publishing }\end{array}$ & $21 \_22$ & $\begin{array}{c}0.061^{* * *} \\
(0.017)\end{array}$ & $\begin{array}{c}0.486^{* * *} \\
(0.023)\end{array}$ & $\begin{array}{c}0.012^{* * *} \\
(0.002)\end{array}$ & $\begin{array}{c}0.055^{* * *} \\
(0.003)\end{array}$ & $\begin{array}{c}-0.051^{* * *} \\
(0.005)\end{array}$ & $\begin{array}{c}-0.141^{* * *} \\
(0.043)\end{array}$ & $\begin{array}{c}0.314^{* * *} \\
(0.059)\end{array}$ & $\begin{array}{c}3.233^{* * *} \\
(0.910)\end{array}$ \\
\hline Chemicals & 24 & $\begin{array}{c}-0.092^{* *} \\
(0.038)\end{array}$ & $\begin{array}{c}0.356^{* * *} \\
(0.063)\end{array}$ & $\begin{array}{c}0.028^{* * *} \\
(0.003)\end{array}$ & $\begin{array}{c}0.045^{* * *} \\
(0.007)\end{array}$ & $\begin{array}{c}-0.067^{* * *} \\
(0.008)\end{array}$ & $\begin{array}{c}0.040 \\
(0.088)\end{array}$ & $\begin{array}{c}0.697^{* * *} \\
(0.150)\end{array}$ & $\begin{array}{l}-16.38 \\
(36.46)\end{array}$ \\
\hline $\begin{array}{l}\text { Rubber and } \\
\text { plastics products }\end{array}$ & 25 & $\begin{array}{c}0.062 \\
(0.038)\end{array}$ & $\begin{array}{c}0.569^{* * *} \\
(0.069)\end{array}$ & $\begin{array}{c}0.018^{* * *} \\
(0.003)\end{array}$ & $\begin{array}{c}0.038^{* * *} \\
(0.004)\end{array}$ & $\begin{array}{c}-0.046^{* * *} \\
(0.006)\end{array}$ & $\begin{array}{c}-0.170^{* * *} \\
(0.060)\end{array}$ & $\begin{array}{c}0.081 \\
(0.149)\end{array}$ & $\begin{array}{l}1.478 \\
(1.003)\end{array}$ \\
\hline $\begin{array}{l}\text { Non-metallic } \\
\text { mineral products }\end{array}$ & 26 & $\begin{array}{c}0.122^{* * *} \\
(0.029)\end{array}$ & $\begin{array}{c}0.204^{* * *} \\
(0.036)\end{array}$ & $\begin{array}{l}-0.005 \\
(0.004)\end{array}$ & $\begin{array}{l}-0.007 \\
(0.007)\end{array}$ & $\begin{array}{c}0.030^{* * *} \\
(0.010)\end{array}$ & $\begin{array}{c}-0.288^{* * *} \\
(0.061)\end{array}$ & $\begin{array}{c}0.307^{* * *} \\
(0.079)\end{array}$ & $\begin{array}{c}2.067^{* * *} \\
(0.382)\end{array}$ \\
\hline Basic metals & 27 & $\begin{array}{c}0.083 \\
(0.154)\end{array}$ & $\begin{array}{c}0.524^{* * *} \\
(0.114)\end{array}$ & $\begin{array}{c}0.010 \\
(0.013)\end{array}$ & $\begin{array}{c}0.018 \\
(0.020)\end{array}$ & $\begin{array}{l}-0.022 \\
(0.031)\end{array}$ & $\begin{array}{r}-0.697^{*} \\
(0.394)\end{array}$ & $\begin{array}{l}-0.158 \\
(0.513)\end{array}$ & $\begin{array}{c}0.773 \\
(0.623)\end{array}$ \\
\hline Metal products & 28 & $\begin{array}{c}0.074^{* * *} \\
(0.013)\end{array}$ & $\begin{array}{c}0.583^{* * *} \\
(0.014)\end{array}$ & $\begin{array}{c}0.025^{* * *} \\
(0.001)\end{array}$ & $\begin{array}{c}0.065^{* * *} \\
(0.002)\end{array}$ & $\begin{array}{c}-0.074^{* * *} \\
(0.003)\end{array}$ & $\begin{array}{c}-0.347^{* * *} \\
(0.023)\end{array}$ & $\begin{array}{c}0.156^{* * *} \\
(0.025)\end{array}$ & $\begin{array}{r}1.450^{* * *} \\
(0.0865)\end{array}$ \\
\hline $\begin{array}{l}\text { Machinery and } \\
\text { equipment }\end{array}$ & 29 & $\begin{array}{c}0.059^{* * *} \\
(0.017)\end{array}$ & $\begin{array}{c}0.445^{* * *} \\
(0.020)\end{array}$ & $\begin{array}{c}0.020^{* * *} \\
(0.002)\end{array}$ & $\begin{array}{c}0.051^{* * *} \\
(0.003)\end{array}$ & $\begin{array}{c}-0.057^{* * *} \\
(0.004)\end{array}$ & $\begin{array}{c}-0.178^{* * *} \\
(0.028)\end{array}$ & $\begin{array}{c}0.323^{* * *} \\
(0.048)\end{array}$ & $\begin{array}{c}2.808^{* * *} \\
(0.459)\end{array}$ \\
\hline $\begin{array}{l}\text { Office and } \\
\text { computing machinery }\end{array}$ & 30 & $\begin{array}{c}0.333^{* * *} \\
(0.113)\end{array}$ & $\begin{array}{c}0.139 \\
(0.103)\end{array}$ & $\begin{array}{c}-0.047^{* * *} \\
(0.017)\end{array}$ & $\begin{array}{l}-0.020 \\
(0.024)\end{array}$ & $\begin{array}{c}0.082^{* *} \\
(0.037)\end{array}$ & $\begin{array}{l}-0.059 \\
(0.131)\end{array}$ & $\begin{array}{c}0.118 \\
(0.188)\end{array}$ & $\begin{array}{l}2.996 \\
(5.615)\end{array}$ \\
\hline Electrical machinery & 31 & $\begin{array}{c}0.109^{* * *} \\
(0.027)\end{array}$ & $\begin{array}{c}0.374^{* * *} \\
(0.031)\end{array}$ & $\begin{array}{c}0.009^{* * *} \\
(0.002)\end{array}$ & $\begin{array}{c}0.047^{* * *} \\
(0.004)\end{array}$ & $\begin{array}{c}-0.042^{* * *} \\
(0.006)\end{array}$ & $\begin{array}{c}-0.201 * * * \\
(0.052)\end{array}$ & $\begin{array}{c}0.334^{* * *} \\
(0.082)\end{array}$ & $\begin{array}{c}2.659^{* * *} \\
(0.735)\end{array}$ \\
\hline $\begin{array}{l}\text { Radio and } \\
\text { communication }\end{array}$ & 32 & $\begin{array}{c}0.033 \\
(0.067)\end{array}$ & $\begin{array}{c}0.581^{* * *} \\
(0.114)\end{array}$ & $\begin{array}{c}0.029^{* * *} \\
(0.006)\end{array}$ & $\begin{array}{c}0.057^{* * *} \\
(0.010)\end{array}$ & $\begin{array}{c}-0.075^{* * *} \\
(0.013)\end{array}$ & $\begin{array}{l}-0.276 \\
(0.177)\end{array}$ & $\begin{array}{c}0.258 \\
(0.209)\end{array}$ & $\begin{array}{c}1.934 \\
(1.279)\end{array}$ \\
\hline $\begin{array}{l}\text { Medical and optical } \\
\text { instruments }\end{array}$ & 33 & $\begin{array}{c}0.082^{* * *} \\
(0.019)\end{array}$ & $\begin{array}{c}0.385^{* * *} \\
(0.019)\end{array}$ & $\begin{array}{c}0.016^{* * *} \\
(0.002)\end{array}$ & $\begin{array}{c}0.062^{* * *} \\
(0.003)\end{array}$ & $\begin{array}{c}-0.056^{* * *} \\
(0.004)\end{array}$ & $\begin{array}{c}-0.195^{* * *} \\
(0.040)\end{array}$ & $\begin{array}{c}0.304^{* * *} \\
(0.048)\end{array}$ & $\begin{array}{c}2.558^{* * *} \\
(0.454)\end{array}$ \\
\hline $\begin{array}{l}\text { Motor vehicles, } \\
\text { trailers }\end{array}$ & 34 & $\begin{array}{l}-0.022 \\
(0.077)\end{array}$ & $\begin{array}{c}0.481^{* * *} \\
(0.104)\end{array}$ & $\begin{array}{c}0.030^{* * *} \\
(0.005)\end{array}$ & $\begin{array}{c}0.071^{* * *} \\
(0.008)\end{array}$ & $\begin{array}{c}-0.091^{* * *} \\
(0.013)\end{array}$ & $\begin{array}{c}-0.169^{* *} \\
(0.072)\end{array}$ & $\begin{array}{c}0.608^{* *} \\
(0.281)\end{array}$ & $\begin{array}{c}4.605 \\
(2.972)\end{array}$ \\
\hline Transport equipment & 35 & $\begin{array}{c}0.063 \\
(0.059)\end{array}$ & $\begin{array}{c}0.394^{* * *} \\
(0.043)\end{array}$ & $\begin{array}{l}0.013^{*} \\
(0.007)\end{array}$ & $\begin{array}{c}0.073^{* * *} \\
(0.011)\end{array}$ & $\begin{array}{c}-0.070^{* * *} \\
(0.016)\end{array}$ & $\begin{array}{l}-0.106 \\
(0.141)\end{array}$ & $\begin{array}{c}0.477^{* * *} \\
(0.123)\end{array}$ & $\begin{array}{l}5.515 \\
(6.577)\end{array}$ \\
\hline $\begin{array}{l}\text { Manufacturing, } \\
\text { recycling }\end{array}$ & $36-37$ & $\begin{array}{l}-0.004 \\
(0.015)\end{array}$ & $\begin{array}{c}0.449^{* * *} \\
(0.016)\end{array}$ & $\begin{array}{c}0.027^{* * *} \\
(0.002)\end{array}$ & $\begin{array}{c}0.025^{* * *} \\
(0.003)\end{array}$ & $\begin{array}{c}-0.043^{* * *} \\
(0.004)\end{array}$ & $\begin{array}{c}-0.321^{* * *} \\
(0.047)\end{array}$ & $\begin{array}{c}0.308^{* * *} \\
(0.039)\end{array}$ & $\begin{array}{c}1.958^{* * * *} \\
(0.216)\end{array}$ \\
\hline
\end{tabular}

Notes : Robust standard errors in parentheses with ***, **, and * respectively denoting significance at the $1 \backslash \%, 5 \backslash \%$ and $10 \backslash \%$ levels. The table contains the results of estimating (74) with the instruments given in (76). For non-importers, the instrument is set to zero in the full sample specifications. Estimation relies on data for the years 2004-2006, because two lags are required to build the appropriate instruments for the estimation of the production function. Standard errors for the estimates of $\varepsilon$ are retrieved by delta-method. 
TABLE 14 - Production Function Coefficient Estimates, by 2-digit Sector : Factor Shares

\begin{tabular}{|l|c|cc|ccc|cc|}
\hline Industry & ISIC & \multicolumn{2}{|c|}{$\phi_{k}$} & & $\phi_{l}$ & & \multicolumn{2}{c|}{$\gamma$} \\
\hline \hline Mining & $10-14$ & $0.374^{* * *}$ & $(0.039)$ & $0.293^{* * *}$ & $(0.017)$ & $0.333^{* * *}$ & $(0.043)$ \\
Food, tobacco, beverages & $15-16$ & $0.098^{* * *}$ & $(0.004)$ & $0.177^{* * *}$ & $(0.003)$ & $0.725^{* * *}$ & $(0.006)$ \\
Textiles and leather & $17-19$ & $0.081^{* * *}$ & $(0.003)$ & $0.293^{* * *}$ & $(0.009)$ & $0.626^{* * *}$ & $(0.012)$ \\
Wood and wood products & 20 & $0.113^{* * *}$ & $(0.004)$ & $0.285^{* * *}$ & $(0.006)$ & $0.602^{* * *}$ & $(0.006)$ \\
Paper, printing, publishing & $21-22$ & $0.134^{* * *}$ & $(0.007)$ & $0.362^{* * *}$ & $(0.011)$ & $0.504^{* * *}$ & $(0.011)$ \\
Chemicals & 24 & $0.124^{* * *}$ & $(0.008)$ & $0.204^{* * *}$ & $(0.01)$ & $0.671^{* * *}$ & $(0.014)$ \\
Rubber and plastics products & 25 & $0.124^{* * *}$ & $(0.005)$ & $0.289^{* * *}$ & $(0.007)$ & $0.587^{* * *}$ & $(0.011)$ \\
Non-metallic mineral products & 26 & $0.178^{* * *}$ & $(0.01)$ & $0.294^{* * *}$ & $(0.012)$ & $0.529^{* * *}$ & $(0.015)$ \\
Basic metals & 27 & $0.124^{* * *}$ & $(0.01)$ & $0.202^{* * *}$ & $(0.015)$ & $0.674^{* * *}$ & $(0.021)$ \\
Metal products (ex machinery and equipment) & 28 & $0.108^{* * *}$ & $(0.002)$ & $0.412^{* * *}$ & $(0.008)$ & $0.479^{* * *}$ & $(0.009)$ \\
Machinery and equipment & 29 & $0.071^{* * *}$ & $(0.003)$ & $0.313^{* * *}$ & $(0.015)$ & $0.616^{* * *}$ & $(0.018)$ \\
Office and computing machinery & 30 & $0.037^{* * *}$ & $(0.012)$ & $0.150^{* * *}$ & $(0.032)$ & $0.813^{* * *}$ & $(0.04)$ \\
Electrical machinery & 31 & $0.096^{* * *}$ & $(0.008)$ & $0.306^{* * *}$ & $(0.011)$ & $0.598^{* * *}$ & $(0.014)$ \\
Radio and communication & 32 & $0.055^{* * *}$ & $(0.006)$ & $0.322^{* * *}$ & $(0.048)$ & $0.624^{* * *}$ & $(0.052)$ \\
Medical and optical instruments & 33 & $0.071^{* * *}$ & $(0.004)$ & $0.435^{* * *}$ & $(0.026)$ & $0.494^{* * *}$ & $(0.029)$ \\
Motor vehicles, trailers & 34 & $0.106^{* * *}$ & $(0.009)$ & $0.135^{* * *}$ & $(0.016)$ & $0.759^{* * *}$ & $(0.014)$ \\
Transport equipment & 35 & $0.152^{* * *}$ & $(0.019)$ & $0.499^{* * *}$ & $(0.03)$ & $0.349^{* * *}$ & $(0.044)$ \\
Manufacturing, recycling & $36-37$ & $0.084^{* * *}$ & $(0.003)$ & $0.283^{* * *}$ & $(0.009)$ & $0.633^{* * *}$ & $(0.012)$ \\
\hline
\end{tabular}

Notes : The table contains the production function parameters based on observed factor shares. See Section 3.2 in the main text for details.

TABLE 15 - Correlates of the Producer Gains

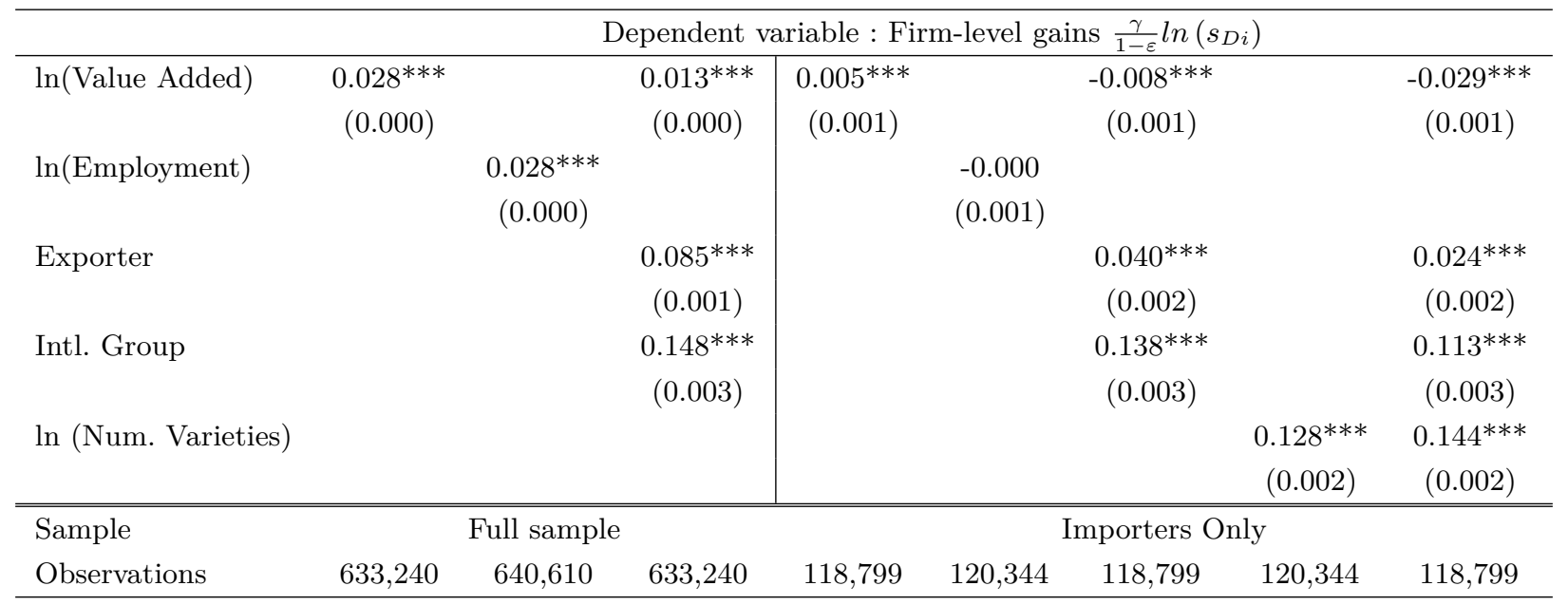

Notes : Robust standard errors in parentheses with ${ }^{* * *},{ }^{* *}$ and ${ }^{*}$ respectively denoting significance at the $1 \%, 5 \%$ and $10 \%$ levels. All regressions include year fixed effects and 3-digit industry fixed effects. The data corresponds to the full sample of firms between 2002 and 2006. The number of varieties is the number of countries the firm sources from (averaged across products). A firm is a member of an international group if at least one affiliate or the headquarter is located outside of France. 
Figure 5 - Bootstrap Distribution of Structural Parameters and Direct Price Reductions
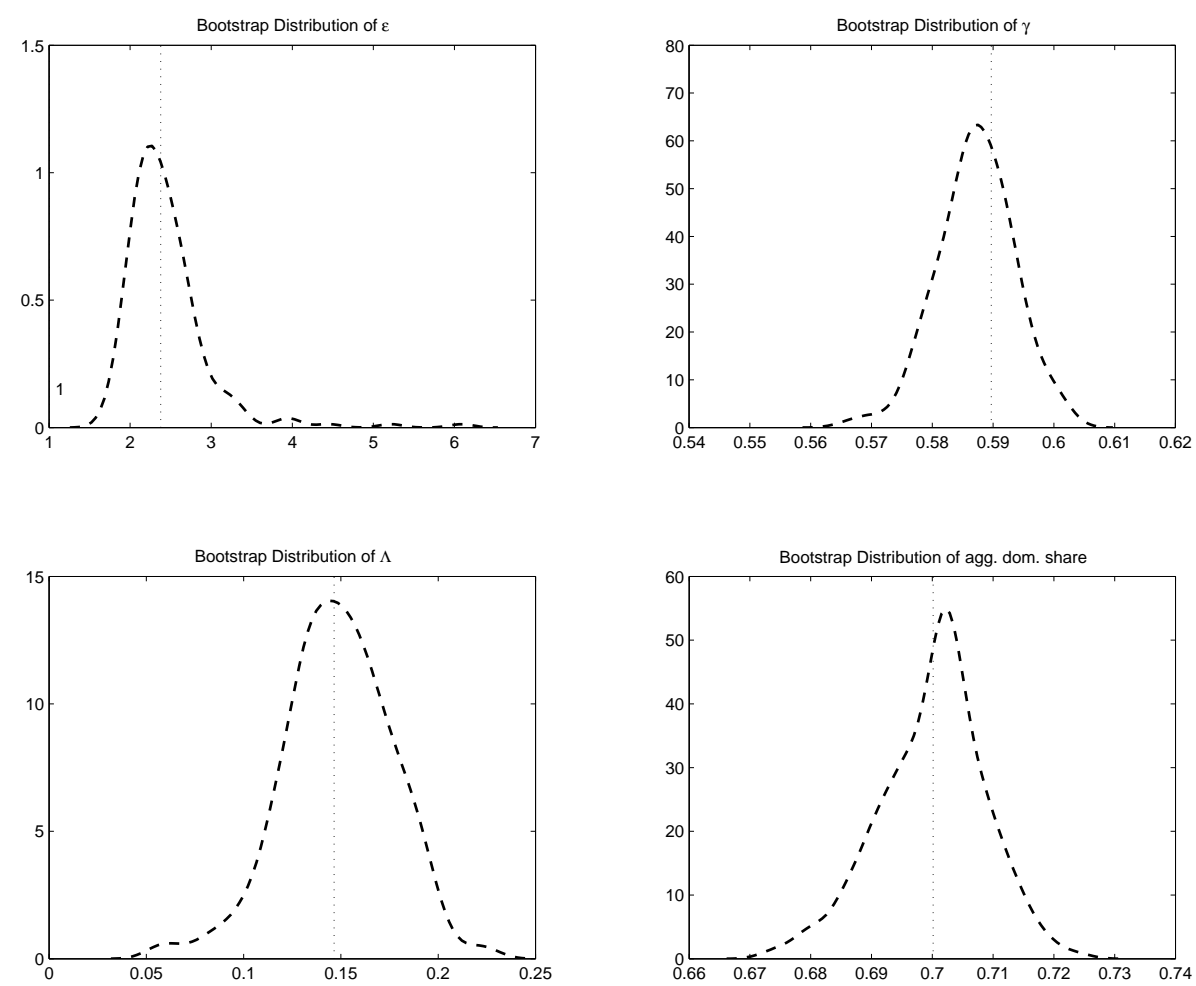

Notes : The upper left panel contains the bootstrap distribution of $\varepsilon$. The remaining panels depict the bootstrap distributions of $\frac{1}{S} \sum_{s=1}^{S} \gamma_{s}, \frac{1}{S} \sum_{s=1}^{S} \Lambda_{s}$ and $\frac{1}{S} \sum_{s=1}^{S} s_{D s}^{A g g}$. The point estimates used in the main analysis are reported as vertical lines. 
Figure 6 - Sampling Variation in the Consumer Price Gains and the Bias
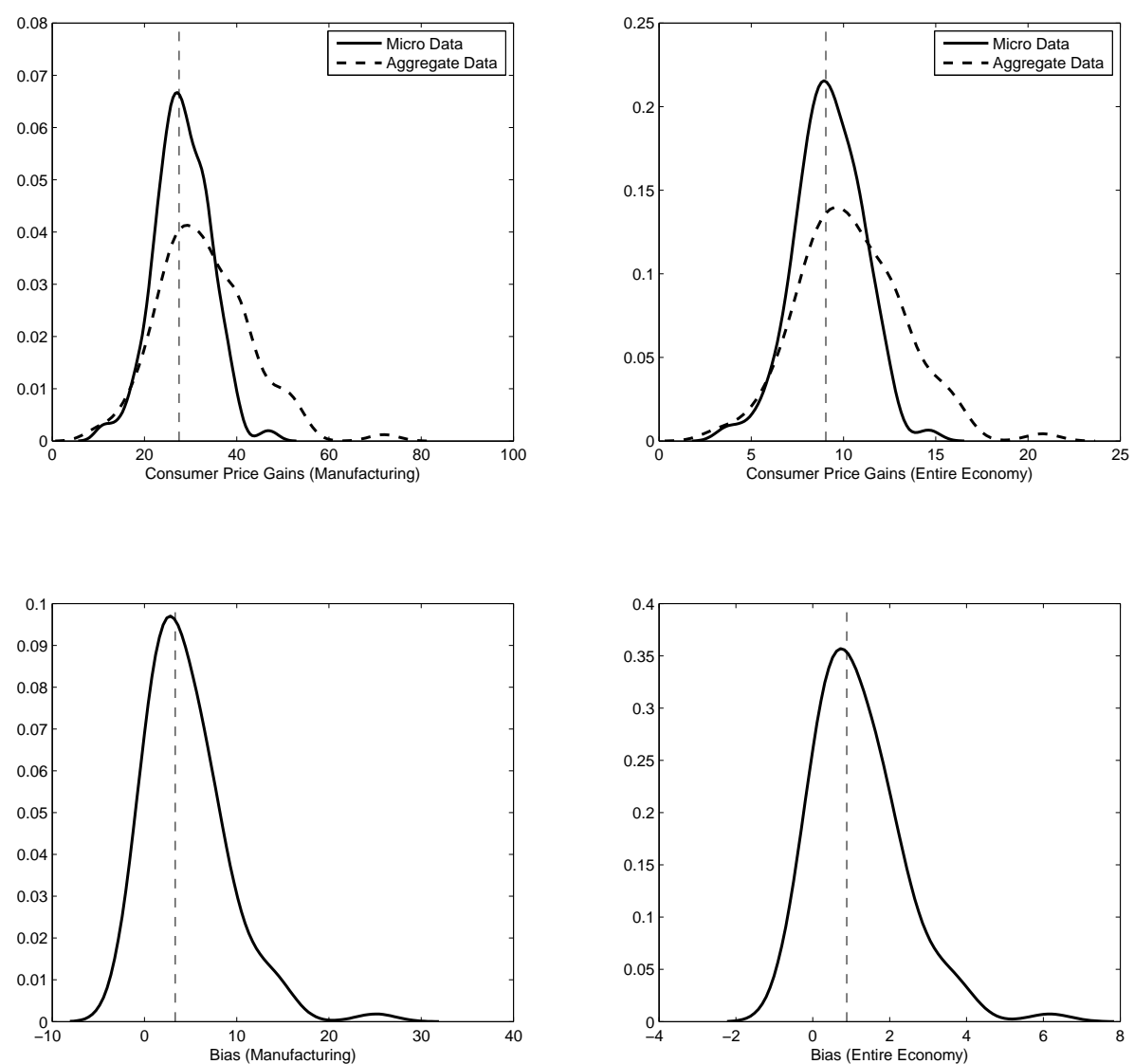

Notes : The top panels of the figure depict the bootstrap distribution of the consumer price gains from input trade for the manufacturing sector $\left(P_{M}^{A u t} / P_{M}-1\right) \times 100$ (left panel) and the entire economy $\left(P^{A u t} / P-1\right) \times 100$ (right panel). These are computed according to Proposition 1. We display the gains based on the micro data, i.e. using $\Lambda_{s}^{A u t}$, and aggregate data, i.e. using $\Lambda_{A g q, s}^{A u t}$. The bottom panels depict the bootstrap distribution of the bias from using aggregate data, which is computed according to (22). The bootstrap procedure is described in the Online Appendix. We use 200 iterations.

In Figure 6 we also show the entire distribution of the consumer price gains and the bias with respect to an aggregate approach.

\section{A.5 The Elasticity Bias for different sectors : Using $\varepsilon$ from Aggregate Trade Flows}

Table 16 reports the consumer price gains from input trade for different values of the elasticity of substitution $\varepsilon$ at the sectoral level. Columns one and two replicate the results for our baseline estimate $\varepsilon=2.38$. While column one reports the results based on the micro-data, column two reports the gains based on aggregate data, $\Lambda_{A g g, s}^{A u t}$. As in Table 8 above, we find the gains from input trade are very sensitive to the value of $\varepsilon$. 
TABle 16 - The Sectoral Consumer Price Gains for Different Values of $\varepsilon$

\begin{tabular}{|c|c|c|c|c|c|c|c|}
\hline \multirow[t]{3}{*}{ Industry } & \multirow[t]{3}{*}{ ISIC } & Micro Data & \multicolumn{5}{|c|}{ Aggregate Data } \\
\hline & & \multicolumn{6}{|c|}{$\varepsilon$} \\
\hline & & 2.38 & 2.38 & 3 & 4 & 5 & 6 \\
\hline Mining & $10-14$ & 2.96 & 2.5 & 1.72 & 1.14 & 0.86 & 0.68 \\
\hline Food, tobacco, beverages & $15-16$ & 11.06 & 12.62 & 8.53 & 5.61 & 4.18 & 3.33 \\
\hline Textiles and leather & $17-19$ & 31.14 & 31.87 & 20.99 & 13.55 & 10 & 7.92 \\
\hline Wood and wood products & 20 & 8.23 & 9.58 & 6.51 & 4.29 & 3.2 & 2.55 \\
\hline Paper, printing, publishing & $21-22$ & 12.15 & 10.96 & 7.43 & 4.89 & 3.65 & 2.91 \\
\hline Chemicals & 24 & 27.23 & 28.14 & 18.62 & 12.06 & 8.91 & 7.07 \\
\hline Rubber and plastics products & 25 & 20.12 & 21.53 & 14.37 & 9.37 & 6.95 & 5.52 \\
\hline Non-metallic mineral products & 26 & 13.42 & 13.29 & 8.98 & 5.9 & 4.39 & 3.5 \\
\hline Basic metals & 27 & 21.8 & 28.83 & 19.07 & 12.34 & 9.12 & 7.23 \\
\hline Metal products (ex machinery and equipment) & 28 & 8.17 & 7.7 & 5.24 & 3.47 & 2.59 & 2.07 \\
\hline Machinery and equipment & 29 & 17.64 & 18.23 & 12.23 & 7.99 & 5.94 & 4.72 \\
\hline Office and computing machinery & 30 & 20.42 & 37 & 24.22 & 15.56 & 11.45 & 9.06 \\
\hline Electrical machinery & 31 & 19.77 & 21.64 & 14.45 & 9.41 & 6.98 & 5.55 \\
\hline Radio and communication & 32 & 21.55 & 22.15 & 14.78 & 9.62 & 7.13 & 5.67 \\
\hline Medical and optical instruments & 33 & 17.9 & 15.9 & 10.7 & 7.01 & 5.21 & 4.15 \\
\hline Motor vehicles, trailers & 34 & 6.24 & 11.23 & 7.61 & 5.01 & 3.73 & 2.98 \\
\hline Transport equipment & 35 & 15.32 & 11.83 & 8.01 & 5.27 & 3.93 & 3.13 \\
\hline Manufacturing, recycling & $36-37$ & 12.87 & 14.06 & 9.48 & 6.23 & 4.63 & 3.69 \\
\hline Non-manufacturing & & 0 & 0 & 0 & 0 & 0 & 0 \\
\hline
\end{tabular}

Notes : The table reports the reduction in consumer prices at the sectoral level $\left(P_{s}^{A u t} / P_{s}-1\right) \times 100$ for different values of the elasticity of substitution $\varepsilon$. In the first two columns, we report the baseline results under $\varepsilon=2.38$ for comparison. Column one is based on Proposition 1 where $\Lambda_{s}$ are computed with micro data as reported in Table 4 . The remaining columns contain results based on an aggregate model, i.e. they are based on Proposition 1 where the sectoral gains are measured by $\Lambda_{A g g, s}^{A u t}$ as per $(21)$ instead of $\Lambda_{s}^{A u t}$. The values for $\Xi, \gamma_{s}, \sigma_{s}$ and $\alpha_{s}$ employed for all calculations are given in Table 1 . 


\section{A.6 Variable Mark-Ups : Empirical Results}

In this section we provide both additional results and the details for the empirical implementation of our variable mark-ups exercise contained in Section 3.3. First consider Table 17, which contains the calibrated demand elasticities $\left(\sigma_{s}, \theta_{s}\right)$ and the sectoral price gains. For comparison we also report the demand elasticity and the sectoral price gains of the constant mark-up economy (see Tables 1 and 4).

We now provide additional details for the implementation. As we showed in Section 6.3, the equilibrium mark-up of firm $i$ is given by

$$
\mu_{i}=\frac{\theta_{s}\left(1-\omega_{i j s}\right)+\sigma_{s} \omega_{i j s}}{\theta_{s}\left(1-\omega_{i j s}\right)+\sigma_{s} \omega_{i j s}-1} .
$$

Here $\omega_{i j s}$ is firm $i$ 's sales share in segment $j$ of sector $s$. Our calibration strategy is to calibrate the demand elasticities $\left(\theta_{s}, \sigma_{s}\right)$ to match the aggregate revenue-cost ratio, i.e. $\frac{\sum_{i} p_{i} y_{i}}{\sum_{i} \operatorname{Cost}_{i}}=R C R_{s}$, which is the same moment as in our benchmark economy (see (25)) and a moment related to the dispersion in mark-ups. Using (90) it is easy to show that

$$
\begin{aligned}
R C R_{s} & =\frac{\sum_{i} p_{i} y_{i}}{\sum_{i} p_{i} y_{i} \mu_{i}^{-1}}=\frac{1}{\sum_{i} \frac{p_{i} y_{i}}{\sum_{i} p_{i} y_{i}} \mu_{i}^{-1}}=\frac{1}{\sum_{i} \frac{p_{i} y_{i}}{\sum_{i \in j} p_{i} y_{i}} \frac{\sum_{i \in j} p_{i} y_{i}}{\sum_{i} p_{i} y_{i}} \mu_{i}^{-1}} \\
& =\left(\sum_{i} \omega_{i j} \omega_{j s}\left(1-\left(\frac{1}{\theta}\left(1-\omega_{i j}\right)+\frac{1}{\sigma} \omega_{i j}\right)\right)\right)^{-1} \\
& =\left(\left(1-\frac{1}{\theta}\left(1-\sum_{j \in s} \omega_{j s} \sum_{i \in j} \omega_{i j}^{2}\right)-\frac{1}{\sigma} \sum_{j \in s} \omega_{j s} \sum_{i \in j} \omega_{i j}^{2}\right)\right)^{-1} .
\end{aligned}
$$

Here $\omega_{i j}$ denotes firm $i^{\prime} s$ market in subsector $j$ and $\omega_{j s}$ denotes the share of subsector $j$ in industry $s$. Note that $H_{j s} \equiv \sum_{i \in j} \omega_{i j}^{2}$ is simply the Herfindahl index of subsector $j$ so that $\Omega_{s}=\sum_{j \in s} \omega_{j s} H_{j s}$ is the (weighted) average of the Herfindahl indices in sector $s$. Using the definition of $\Omega_{s}$ and (91) yields (33). To derive (34), note that 90 implies a linear relationship between inverse mark-ups and market shares, i.e.

$$
\mu_{i}^{-1}=\frac{\theta-1}{\theta}-\left(\frac{1}{\sigma}-\frac{1}{\theta}\right) \omega_{i j}
$$

Using the definition of quantiles, (34) follows directly from (92). Combining (33) and (34), we can solve for the parameters in terms of data moments. In particular, for any two quantiles $p_{1}$ and $p_{2}$ we get

$$
\begin{aligned}
\sigma_{s} & =\frac{R C R_{s}}{R C R_{s}-1+\left(1-\Omega_{s}\right) R C R_{s} \frac{q_{1 / \mu}^{p_{2}}-q_{1 / \mu}^{p_{1}}}{q_{\omega, s}^{1-p_{1}}-q_{\omega, s}^{1-p_{2}}}} \\
\theta_{s} & =\left(\frac{1}{\sigma_{s}}-\frac{q_{1 / \mu}^{p_{2}}-q_{1 / \mu}^{p_{1}}}{q_{\omega, s}^{1-p_{1}}-q_{\omega, s}^{1-p_{2}}}\right)^{-1} .
\end{aligned}
$$




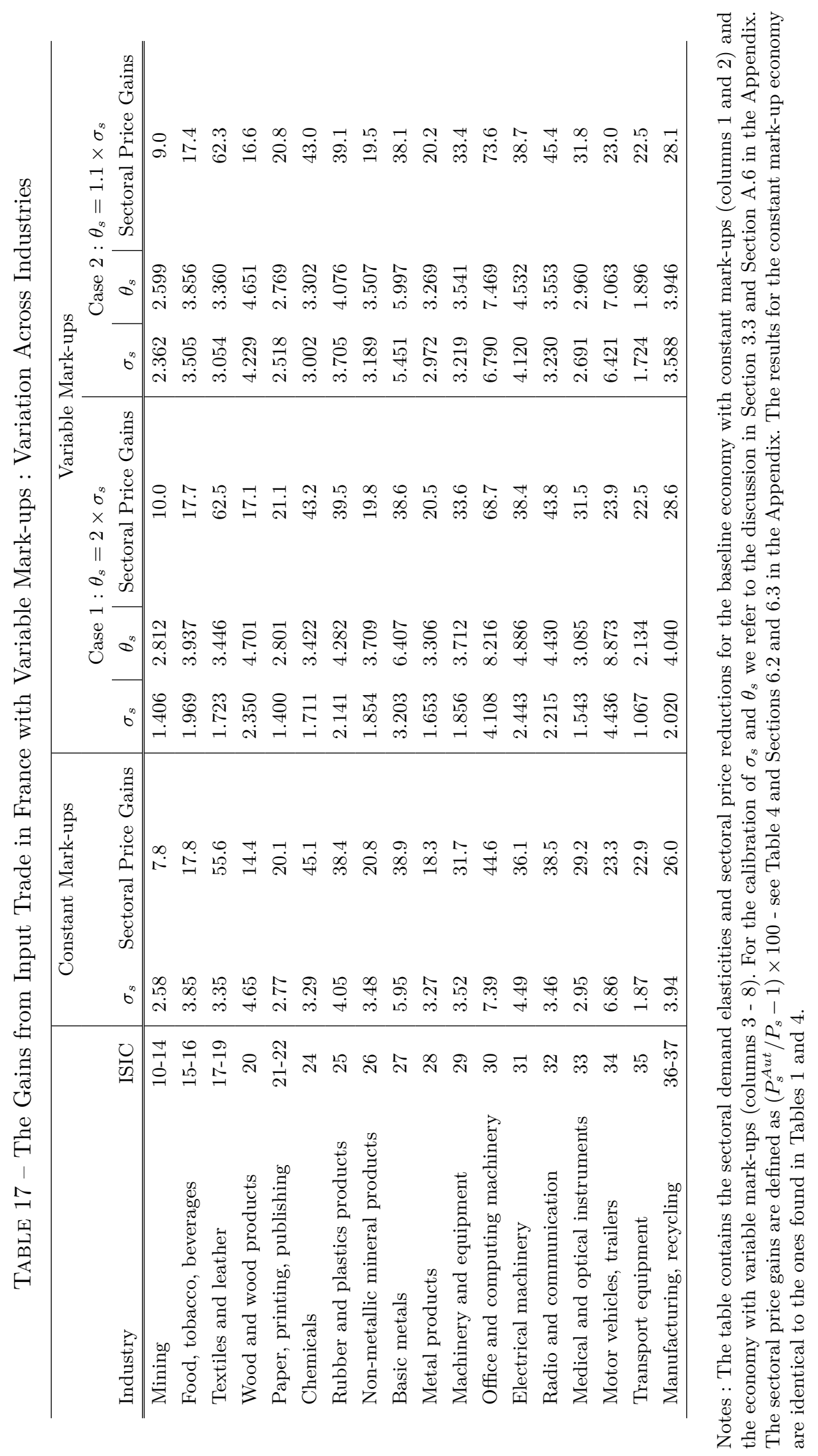


Empirically, we found it challenging to find solutions to these equations, which satisfy the theoretical restriction $1 \leq \sigma_{s} \leq \theta_{s}$. To see the source of the problem, consider Table 18 below. In this table we report - for all industries $s$ - the data on $R C R_{s}, \Omega_{s}, q_{1 / \mu}^{0.1}-q_{1 / \mu}^{0.01}$ and $q_{\omega, s}^{0.99}-q_{\omega, s}^{0.9}{ }^{88}$ To calculate the dispersion of mark-ups, we rely on two measures of mark-ups. To be consistent with our treatment of the $R C R_{s}$ we consider the simple accounting equation $\mu_{i}^{A C C}=\frac{p_{i} y_{i}}{w l_{i}+m_{i}+R k_{i}}$. As an alternative we follow the approach pioneered by Jan De Loecker and measure mark-ups from firms' cost-minimizing behavior as $\mu_{i}^{C M I N}=\frac{\phi_{l}}{w l_{i} / p_{i} y_{i}}$, where $\phi_{l}$ is the output elasticity of labor in the production function. The results are contained in columns $2-5$ in Table 18. In columns 6 and 7 we report the implied values for $\sigma_{s}$ and $\theta_{s}$ according to (93) and (94). It is clearly seen that all but one $\sigma_{s}$ is smaller than unity and that many $\theta_{s}$ are negative. The reason is that the dispersion in measured mark-ups is large relative to the dispersion in market shares. Hence, $\frac{q_{1 / \mu}^{p_{2}}-q_{1 / \mu}^{p_{1}}}{q_{\omega, s}^{1-p_{1}}-q_{\omega, s}^{1-p_{2}}}$ is large, which tends to reduce both $\sigma_{s}$ and $\theta_{s}$. One reason for this disconnect could be measurement error, if measured mark-ups are more affected than market shares. While a possibility, the implied measurement error must be quite large. Even if $q_{1 / \mu}^{p_{2}}-q_{1 / \mu}^{p_{1}}$ was only half as large, most implied $\sigma_{s}$ would still be below one.

We also pursued an alternative calibration strategy, which follows Edmond et al. (2015) closely. Using the observed mark-ups, we could have estimated $\sigma$ and $\theta$ from (92). Edmond et al. (2015) measure mark-ups from firms' labor shares (i.e. they use $\mu_{i}^{C M I N}$ ). (92) then implies the linear regression $\frac{w l_{i}}{p y_{i}}=\beta_{0}+\beta_{1} \omega_{i}+u_{i}$, where $\beta_{0}=\phi_{l} \frac{\theta-1}{\theta}$ and $\beta_{1}=-\phi_{l}\left(\frac{1}{\sigma}-\frac{1}{\theta}\right)$. Hence, the two demand elasticities are related via

$$
\theta=\frac{\beta_{0}+\beta_{1}}{\frac{\beta_{0}}{\sigma}+\beta_{1}} .
$$

It can be shown that together with (91), this implies

$$
\sigma_{s}=\left(\frac{\frac{\beta_{0, s}}{\beta_{0, s}+\beta_{1, s}}\left(1-\Omega_{s}\right)+\Omega_{s}}{\frac{R C R-1}{R C R}-\frac{\beta_{1, s}}{\beta_{0, s}+\beta_{1, s}}\left(1-\Omega_{s}\right)}\right),
$$

which identifies $\sigma_{s}$ directly from moments in the data. The results of this exercise are contained in columns 8 -11. In columns 8 and 9 we report the estimates for $\beta_{0}$ and $\beta_{1}$ and the corresponding standard errors. Reassuringly, our estimates for $\beta_{1}$ are consistently negative as required by the theory. Column 10 contains the implied $\sigma_{s}$ from (96) and column 11 the corresponding $\theta_{s}$. As before, we find estimates for $\sigma_{s}$, which are often below unity and implied values for $\theta_{s}$, which are negative. ${ }^{89}$ We can also compare our results with Edmond et al. (2015). They consider the exact same specification for Taiwanese firms but do not allow for their parameters to vary at the sector level. They estimate $\beta_{0}=0.64$ and $\beta_{1}=-0.5$ and arrive at $\sigma=1.24$ and $\theta=10.5 .{ }^{90}$ Hence, their "upper" demand

88. Here we decided to focus on the tail of large firms as these are arguably the firms, where the Atkeson and Burstein (2008) model is most applicable. We tried many other combinations of quantiles, which all yielded qualitatively similar results. These results are available upon request.

89. As a third possibility, we also allowed for $\beta_{0}$ to differ at the sub-segment level (by including sub-segment fixed effects) and only used $\beta_{1}=-\phi_{l}\left(\frac{1}{\sigma}-\frac{1}{\theta}\right)$ (together with an estimate of $\phi_{l}$ ) for identification. This strategy gave qualitatively similar results, which are available upon request.

90. Their strategy is to calibrate $\sigma$ within the context of a model to match the aggregate trade elasticity. Given $\sigma$ they then use their estimate for $\beta_{0}$ and $\beta_{1}$ to identify $\theta$. Note that their notation is different. They use $\gamma$ instead of $\theta$ and $\theta$ instead $\sigma$. 


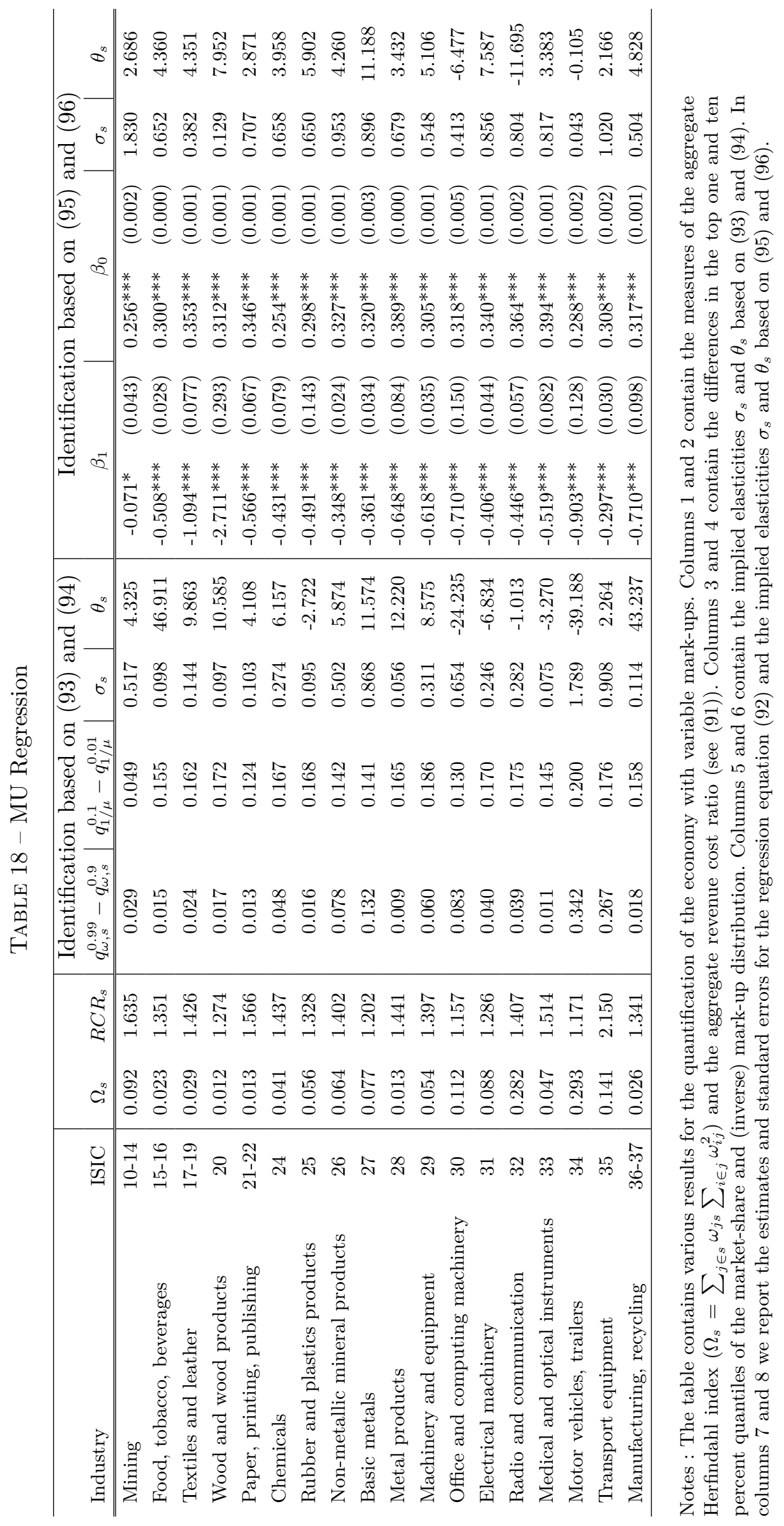


elasticity $\sigma$ is also small. In particular, from $\theta=\frac{\beta_{0}+\beta_{1}}{\frac{\beta_{0}}{\sigma}+\beta_{1}}$ it is easy to see that $\theta$ can only be positive if $\sigma<1.28 .^{91}$

\section{A.7 General equilibrium and Welfare in the Model of Section 3.4}

Consider the setup of Section 3.4. We now consider the aggregate allocations in this economy. An equilibrium has the usual definition :

Definition 1. An equilibrium is a set of prices $w,\left[p_{i}\right]$, labor demands for production and fixed costs $\left[l_{i}, l_{i}^{F}\right]$, differentiated product quantities, consumption levels and foreign demands $\left[y_{i}, c_{i}, y_{i}^{R O W}\right]$, domestic and international input demands by local firms $\left[y_{v i}\right],\left[z_{c i}\right]$ and sourcing strategies $\left[n_{i}\right]$ such that :

1. Firms maximize profits given by (36)-(37),

2. Consumers maximize utility given by (8) subject to their budget constraint

$$
\int_{i} p_{i} c_{i} d i=w L+\int_{i} \pi_{i} d i
$$

3. Trade is balanced (39),

4. Labor and good markets clear

$$
\begin{aligned}
L & =\int_{i}\left(l_{i}+l_{i}^{F}\right) d i \\
y_{i} & =c_{i}+y_{i}^{R O W}+\int_{\nu} y_{v i} d v .
\end{aligned}
$$

We fist characterize the general equilibrium in a multi-sector version of the economy of Section 3.4. In particular, we consider the multi-sector structure of Section 2. We derive a generalization of (40). We do not impose any assumptions on how firms' determine their extensive margin. That is, we allow for an arbitrary mapping $l_{\Sigma_{i}}$ which gives the labor resources that firm $i$ needs to spend in order to attain the sourcing strategy $\Sigma_{i}$. We assume that trade is balanced and that the value of exports in sector $s$ is given by $\alpha_{s}^{R O W} \times I M$, where $I M$ denotes the value of total spending on imported inputs.

Proposition 3. Let $W, I$ and $S$ denote welfare, consumer income and total spending, respectively. Then, the change in welfare relative to input autarky is given by

$$
\frac{W}{W^{A u t}}=\frac{I}{I^{A u t}} \times \frac{P^{A u t}}{P}
$$

91. When we pool all the data and estimate a common $\beta_{1}$ and $\beta_{0}$ we find $\beta_{1}=-0.517$ and $\beta_{0}=0.33$. Hence, we estimate the exact same slope parameter and a lower intercept. The difference in the intercept stems from the fact that we use revenue, while they use value added. According to the theory, this should not make a difference. Quantitatively, the results in Table 18 imply that $\sigma_{s}<1$ for many sectors even if $\beta_{0}=0.6$. 
where $I$ and $I^{\text {Aut }}$ are given by

$$
\begin{aligned}
I & =L+\sum_{s=1}^{S} S_{s} / \sigma_{s}-\sum_{s=1}^{S}\left(\int_{0}^{N_{s}} l_{\Sigma_{i}} d i\right), \\
I^{A u t} & =L+\sum_{s=1}^{S} S_{s}^{A u t} / \sigma_{s},
\end{aligned}
$$

and $\left[S_{j}\right]$ and $\left[S_{j}^{A u t}\right]$ solve

$$
S_{s}=\alpha_{s}\left(L-\sum_{j=1}^{S}\left(\int_{0}^{N_{j}} l_{\Sigma_{i}} d i\right)+\sum_{j=1}^{S} \frac{1+\frac{\zeta_{s}^{j}}{\alpha_{s}} \gamma_{j}\left(\sigma_{j}-1\right)}{\sigma_{j}} S_{j}\right)+\sum_{j=1}^{S}\left[\alpha_{s}^{R O W}-\zeta_{s}^{j}\right] \gamma_{j} \frac{\sigma_{j}-1}{\sigma_{j}} S_{j} \int_{0}^{N_{j}}\left(1-s_{D i}\right) \omega_{i} d i,
$$

and

$$
S_{s}^{A u t}=\alpha_{s}\left(L+\sum_{j=1}^{S} \frac{1+\zeta_{s}^{j} \gamma_{j}\left(\sigma_{j}-1\right) / \alpha_{s}}{\sigma_{j}} S_{j}^{A u t}\right)
$$

Furthermore, $G=\frac{P^{A u t}}{P}$ is given in Proposition 1 .

Démonstration. As labor is the only factor of production, consumer welfare is given by real income $W=I / P$, consumer income is given by

$$
I=L+\sum_{s=1}^{S}\left(\int_{0}^{N_{s}} \pi_{i} d i\right)
$$

Note that $L$ represents total labor income and $\pi_{i}$ denotes firm $i$ 's profits. To derive $\pi_{i}$, recall that firms in sector $s$ have a mark-up of $\sigma_{s} /\left(\sigma_{s}-1\right)$ so that variable profits gross of any extensive margin resource loss are given by

$$
\pi_{i}^{V}=\left(p_{i}-u_{i}\right) y_{i}=p_{i} y_{i} / \sigma_{s}
$$

Total revenue for firm $i$ is given by

$$
p_{i} y_{i}=\left(\frac{p_{i}}{P_{s}}\right)^{1-\sigma_{s}} S_{s},
$$

where $P_{s}$ is the consumer price index for sector $s$ and $S_{s}$ denotes total spending for sector $s$ goods. Hence,

$$
\pi_{i}=p_{i} y_{i} / \sigma_{s}-l_{\Sigma_{i}}=\frac{1}{\sigma_{s}}\left(\frac{p_{i}}{P_{s}}\right)^{1-\sigma_{s}} S_{s}-l_{\Sigma_{i}}
$$

so that

$$
I=L+\sum_{s=1}^{S} \frac{1}{\sigma_{s}} S_{s}-\sum_{s=1}^{S}\left(\int_{i}^{N_{s}} l_{\Sigma_{i}} d i\right)
$$

Hence, given $\left[S_{s}\right]$ and $\left[l_{\Sigma i}\right]$, total income $I$ is fully determined. Now consider $\left[S_{s}\right]_{s}$. Note that

$$
S_{s}=S_{s}^{C}+S_{s}^{X}+S_{s}^{R O W},
$$


where $S_{s}^{C}, S_{s}^{X}$ and $S_{s}^{R O W}$ denote total spending by consumers, intermediary producers and the rest of the world, respectively. For our economy, we have that $S_{c}^{C}=\alpha_{s} I$ and $S_{s}^{R O W}=\alpha_{s}^{R O W} I m$ as consumers spend a fraction $\alpha_{s}$ of their income $I$ on sector $s$ products and balanced trade requires that total spending by the rest of the world is equal to the value of imports $I m$, a fraction $\alpha_{s}^{R O W}$ of which is spent on sector $s$ products. To derive $S_{s}^{X}$, let total domestic intermediary purchases in sector $j$ be given by $X_{j}$. Then

$$
S_{s}^{X}=\sum_{j=1}^{S} \zeta_{s}^{j} X_{j}
$$

Letting $m_{i}$ be total material spending by firm $i$ and $s_{i}$ be total spending by firm $i$, we know that

$$
\begin{aligned}
X_{j} & =\int_{0}^{N_{j}} s_{D i} m_{i} d i=\int_{0}^{N_{j}} s_{D i} \gamma_{j} s_{i} d i=\int_{0}^{N_{j}} s_{D i} \gamma_{j} \frac{\sigma_{j}-1}{\sigma_{j}} p_{i} y_{i} d i \\
& =\gamma_{j} \frac{\sigma_{j}-1}{\sigma_{j}} S_{j} \int_{0}^{N_{j}} s_{D i}\left(\frac{p_{i}}{P_{j}}\right)^{1-\sigma_{j}} d i,
\end{aligned}
$$

where we used that firms in sector $j$ spend a fraction $\gamma_{j}$ of their total input spending $s_{i}$ on materials and that total spending $s_{i}$ accounts for a fraction $\left(\sigma_{j}-1\right) / \sigma_{j}$ of revenue. Hence, (98) and (99) imply that

$$
S_{s}^{X}=\sum_{j=1}^{S} \zeta_{s}^{j} \gamma_{j} \frac{\sigma_{j}-1}{\sigma_{j}} S_{j} \int_{i=0}^{N_{j}} s_{D i}\left(\frac{p_{i}}{P_{s}}\right)^{1-\sigma_{s}} d i
$$

Similarly, total import spending is equal to

$$
\begin{aligned}
I m & =\sum_{j=1}^{S} I_{j}=\sum_{j=1}^{S} \int_{0}^{N_{j}}\left(1-s_{D i}\right) m_{i} d i \\
& =\sum_{j=1}^{S} \gamma_{j} \frac{\sigma_{j}-1}{\sigma_{j}} S_{j} \int_{i=0}^{N_{j}}\left(1-s_{D, i}\right)\left(\frac{p_{i}}{P_{s}}\right)^{1-\sigma_{s}} d i .
\end{aligned}
$$

Hence (100) and (101) imply that

$$
\begin{aligned}
S_{s} & =\alpha_{s} I+\alpha_{s}^{R O W}\left(\sum_{j=1}^{S} \gamma_{j} \frac{\sigma_{j}-1}{\sigma_{j}} S_{j} \int_{0}^{N_{j}}\left(1-s_{D i}\right)\left(\frac{p_{i}}{P_{j}}\right)^{1-\sigma_{j}} d i\right)+\sum_{j=1}^{S} \zeta_{s}^{j} \gamma_{j} \frac{\sigma_{j}-1}{\sigma_{j}} S_{j} \int_{0}^{N_{j}} s_{D i}\left(\frac{p_{i}}{P_{j}}\right)^{1-\sigma_{j}} d i \\
& =\alpha_{s} I+\sum_{j=1}^{S} \zeta_{s}^{j} \gamma_{j} \frac{\sigma_{j}-1}{\sigma_{j}} S_{j}+\sum_{j=1}^{S}\left[\alpha_{s}^{R O W}-\zeta_{s}^{j}\right] \gamma_{j} \frac{\sigma_{j}-1}{\sigma_{j}} S_{j} \int_{i}^{N_{j}}\left(1-s_{D i}\right)\left(\frac{p_{i}}{P_{j}}\right)^{1-\sigma_{j}} d i .
\end{aligned}
$$

Using (97), we get that

$$
S_{s}=\alpha_{s}\left(L-\sum_{j=1}^{S}\left(\int_{i}^{N_{j}} l_{\Sigma_{i}} d i\right)+\sum_{j=1}^{S} \frac{1+\frac{\zeta_{s}^{j}}{\alpha_{s}} \gamma_{j}\left(\sigma_{j}-1\right)}{\sigma_{j}} S_{j}\right)+\sum_{j=1}^{S}\left[\alpha_{s}^{R O W}-\zeta_{s}^{j}\right] \gamma_{j} \frac{\sigma_{j}-1}{\sigma_{j}} S_{j} \int_{i}^{N_{j}}\left(1-s_{D i}\right)\left(\frac{p_{i}}{P_{j}}\right)^{1-\sigma_{j}} d i .
$$

Now note that

$$
\frac{v a_{i}}{\int_{0}^{N_{s}} v a_{i} d i}=\frac{p_{i} y_{i}}{\int_{0}^{N_{s}} p_{i} y_{i} d i}=\frac{\left(p_{i} / P_{s}\right)^{1-\sigma_{s}} S_{s}}{\int_{0}^{N_{s}}\left(p_{i} / P_{s}\right)^{1-\sigma_{s}} S_{s} d i}=\left(\frac{p_{i}}{P_{s}}\right)^{1-\sigma_{s}}
$$


Hence,

$$
S_{s}=\alpha_{s}\left(L-\sum_{j=1}^{S}\left(\int_{0}^{N_{j}} l_{\Sigma_{i}} d i\right)+\sum_{j=1}^{S} \frac{1+\frac{\zeta_{s}^{j}}{\alpha_{s}} \gamma_{j}\left(\sigma_{j}-1\right)}{\sigma_{j}} S_{j}\right)+\sum_{j=1}^{S}\left[\alpha_{s}^{R O W}-\zeta_{s}^{j}\right] \gamma_{j} \frac{\sigma_{j}-1}{\sigma_{j}} S_{j} \int_{0}^{N_{j}}\left(1-s_{D i}\right) \omega_{j}(102)
$$

where $\omega_{i}=\frac{v a_{i}}{\int_{i}^{N_{s}} v a_{i} d i}$. Given $L^{N E T}=L-\sum_{j=1}^{S}\left(\int_{0}^{N_{j}} l_{\Sigma_{i}} d i\right)$, (102) are $S$ equations in $S$ unknowns $S_{s}$, which we can easily solve. Now consider the case of autarky. There we have $l_{\Sigma_{i}}=0$ and $s_{D i}=1$. Hence, (102) yields

$$
S_{s}^{A u t}=\alpha_{s}\left(L+\sum_{j=1}^{S} \frac{1+\frac{\zeta_{s}^{j}}{\alpha_{s}} \gamma_{j}\left(\sigma_{j}-1\right)}{\sigma_{j}} S_{j}^{A u t}\right)
$$

In the case of a single sector (i.e. $S=1$ ) it has to be the case that

$$
\alpha_{S}=\alpha_{S}^{R O W}=\zeta_{S}^{S}=1
$$

Hence,

$$
S^{A u t}=L+\frac{1+\gamma(\sigma-1)}{\sigma} S^{A u t}=\frac{\sigma}{(1-\gamma)(\sigma-1)} L .
$$

Substituting this in (97) yields

$$
I^{A u t}=L+\frac{1}{\sigma} S=\frac{1+(1-\gamma)(\sigma-1)}{(1-\gamma)(\sigma-1)} L .
$$

Similarly, we get from (102) that

$$
\sum_{j=1}^{S}\left[\alpha_{s}^{R O W}-\zeta_{s}^{j}\right] \gamma_{j} \frac{\sigma_{j}-1}{\sigma_{j}} S_{j} \int_{0}^{N_{j}}\left(1-s_{D i}\right) \omega_{i} d i=0
$$

so that

$$
\begin{aligned}
S & =\frac{\sigma}{(1-\gamma)(\sigma-1)}\left(L-\left(\int_{i}^{N} l_{\Sigma_{i}} d i\right)\right) \\
I & =\frac{1+(1-\gamma)(\sigma-1)}{(1-\gamma)(\sigma-1)}\left(L-\left(\int_{i}^{N} l_{\Sigma_{i}} d i\right)\right) .
\end{aligned}
$$

This implies directly (40). This concludes the proof of Proposition 3.

\section{A.8 Calibrating the Model of Section 3.4}

We adopt a solution algorithm that allows us to bypass the computation of the general equilibrium variables within the calibration. Intuitively, we work with a normalized version of fixed costs, where these are scaled by an appropriate transformation of the general equilibrium variables. Because the equilibrium variables depend on firms' import behavior only through the domestic shares, which are itself a calibration target, we can compute them after the calibration. That is, we can first ensure that the moments of the joint distribution of value added and domestic shares are matched ${ }^{92}$, and

92. For this step, it is important that the dispersion and correlation moments are in logs. See below. 
then back out the underlying general equilibrium variables required to compute welfare. We also show that the parameter $z$ is not required for the calibration.

We first start with three aggregate variables, which are determined in equilibrium. In the singlesector version of the model, characterized in Section A.7 in the Online Appendix, we have that aggregate spending $S$ and the price level (which is also equal to the price of domestic varieties) is given by

$$
\begin{aligned}
S & =\frac{\sigma}{(1-\gamma)(\sigma-1)}\left(L-\left(\int_{i}^{N} l_{\Sigma_{i}} d i\right)\right) \\
P & =\left(\frac{\sigma}{\sigma-1}\left(\frac{1}{\gamma}\right)^{\gamma}\left(\frac{1}{1-\gamma}\right)^{1-\gamma}\left(\frac{1}{q_{D}}\right)^{\gamma} \gamma\right)^{\frac{1}{1-\gamma}},
\end{aligned}
$$

where

$$
\Upsilon=\left(\int_{i=0}^{N}\left(\frac{1}{\tilde{\varphi}_{i}}\left(s_{D, i}\right)^{\gamma /(\varepsilon-1)}\right)^{1-\sigma} d i\right)^{\frac{1}{1-\sigma}} .
$$

We start by noting that the firm's optimality conditions from the profit maximization problem, contained in Section 6.7, can be expressed in terms of $s_{D}$ instead of $n$. To see this, note that (38) and (35) imply

$$
n^{\eta(\varepsilon-1)}=\left(\frac{1-s_{D}}{s_{D}}\right)\left(\frac{\beta}{1-\beta}\right)^{\varepsilon} z^{\varepsilon-1}\left(\frac{q_{D}}{p_{D}}\right)^{\varepsilon-1} .
$$

Substituting (106) into the firm's first order condition (80), we obtain

$$
s_{D}^{\frac{1-\gamma(\sigma-1) \eta}{(\varepsilon-1) \eta}}\left(1-s_{D}\right)^{1-\frac{1}{\eta(\varepsilon-1)}}=\left(\frac{\beta}{1-\beta}\right)^{\frac{\varepsilon}{\varepsilon-1} \frac{1}{\eta}} \frac{\tilde{f}}{\tilde{\varphi}^{\sigma-1}},
$$

where

$$
\tilde{f} \equiv f \times\left(z q_{D}\right)^{1 / \eta} \frac{1}{\eta \gamma(\sigma-1)} \frac{1}{\Theta} \times \frac{1}{P^{1 / \eta} \Gamma}
$$

where

$$
\begin{aligned}
\Theta & =\frac{1}{\sigma}\left(\frac{\sigma}{\sigma-1}\right)^{1-\sigma}\left(\left(\frac{1}{1-\gamma}\right)^{1-\gamma}\left(\frac{1}{\gamma}\left(\frac{1}{q_{D}}\right)\right)^{\gamma}\right)^{1-\sigma}, \\
\Gamma & =\frac{S}{P^{(1-\gamma)(1-\sigma)}}
\end{aligned}
$$

Similarly, (106) and the import status condition (86) imply that the firm is an importer as long as

$$
\left[s_{D}^{-\frac{\gamma(\sigma-1)}{\varepsilon-1}}-1\right] \tilde{\varphi}^{\sigma-1}-\left(\frac{1-s_{D}}{s_{D}}\right)^{\frac{1}{\eta(\varepsilon-1)}} \gamma(\sigma-1) \eta\left(\frac{\beta}{1-\beta}\right)^{\frac{\varepsilon}{\varepsilon-1} \frac{1}{\eta}} \tilde{f}-\tilde{f}_{I}>0
$$

where

$$
\tilde{f}_{I} \equiv \frac{1}{\Gamma} \frac{1}{\Theta} \times f_{I}
$$

(107) and (111) show that we can solve for firms' optimal domestic share and import status with 
knowledge of $\tilde{\varphi}^{\sigma-1}, \tilde{f}$ and $\tilde{f}_{I}$ only. Thus, we can work with the joint distribution of $(\varphi, \tilde{f})$ to match the moments of the joint distribution of domestic shares and value added. We can then back out the exogenous component of fixed costs $f_{I}$ and $f$ from $\tilde{f}_{I}$ and $\tilde{f}$ using the equilibrium variables $S$ and $P$ and (110).

To solve for $S$, we require the aggregate resource loss of fixed costs (see (103)). To do so, note that

$$
\begin{aligned}
l_{\Sigma_{i}}=l_{i}\left(s_{D i}\right) & =f_{i} \times\left(\frac{s_{D i}}{1-s_{D i}}\right)^{\frac{1}{\eta(1-\varepsilon)}}\left(\frac{1}{P}\right)^{1 / \eta}\left(q_{D} z\right)^{1 / \eta}\left(\frac{\beta_{i}}{1-\beta_{i}}\right)^{\frac{\varepsilon}{\varepsilon-1} \frac{1}{\eta}}+f_{I} \\
& =\Gamma \Theta\left\{\eta \gamma(\sigma-1) \times \tilde{f}_{i} \times\left(\frac{s_{D i}}{1-s_{D i}}\right)^{\frac{1}{\eta(1-\varepsilon)}}\left(\frac{\beta_{i}}{1-\beta_{i}}\right)^{\frac{\varepsilon}{\varepsilon-1} \frac{1}{\eta}}+\tilde{f}_{I}\right\} .
\end{aligned}
$$

Hence,

$$
\int_{i}^{N} l_{\Sigma_{i}} d i=\Gamma \Theta\left\{\eta \gamma(\sigma-1) \times \int_{i}^{N} \tilde{f}_{i}\left(\frac{s_{D i}}{1-s_{D i}}\right)^{\frac{1}{\eta(1-\varepsilon)}}\left(\frac{\beta_{i}}{1-\beta_{i}}\right)^{\frac{\varepsilon}{\varepsilon-1} \frac{1}{\eta}} d i+\int_{i}^{N} \tilde{f}_{I} 1\left[s_{D i}\right] d i\right\} .
$$

The key is now to argue that $\Gamma$ is known given the calibration. If so, we can calculate $\int_{i}^{N} l_{\Sigma_{i}} d i$ from (113) given the calibrated $\tilde{f}$ and $\tilde{f}_{I}$ and parameters, as

$$
\int_{i}^{N} l_{\Sigma_{i}} d i=\Gamma \times \Theta \times \Delta
$$

where

$$
\Delta \equiv \eta \gamma(\sigma-1) \times \int_{i}^{N} \tilde{f}_{i}\left(\frac{s_{D i}}{1-s_{D i}}\right)^{\frac{1}{\eta(1-\varepsilon)}}\left(\frac{\beta_{i}}{1-\beta_{i}}\right)^{\frac{\varepsilon}{\varepsilon-1} \frac{1}{\eta}} d i+\int_{i}^{N} \tilde{f}_{I} 1\left[s_{D i}\right] d i .
$$

Recall that (110) and (103) imply that

$$
\begin{aligned}
\Gamma & =\frac{S}{P^{(1-\gamma)(1-\sigma)}}=\frac{1}{P^{(1-\gamma)(1-\sigma)}} \frac{\sigma}{(1-\gamma)(\sigma-1)}\left(L-\left(\int_{i}^{N} l_{\Sigma_{i}} d i\right)\right) \\
& =\frac{1}{P^{(1-\gamma)(1-\sigma)}} \frac{\sigma}{(1-\gamma)(\sigma-1)} L-\frac{1}{P^{(1-\gamma)(1-\sigma)}} \frac{\sigma}{(1-\gamma)(\sigma-1)} \Gamma \Theta \Delta
\end{aligned}
$$

Solving for $\Gamma$ yields

$$
\Gamma=\frac{\frac{1}{P^{(1-\gamma)(1-\sigma)}} \frac{\sigma}{(1-\gamma)(\sigma-1)}}{1+\frac{1}{P^{(1-\gamma)(1-\sigma)}} \frac{\sigma}{(1-\gamma)(\sigma-1)} \Theta \Delta} L
$$

As $L$ is a normalization (see below), (115) shows that $\Gamma$ is fully determined as $P$ can be evaluated from the calibrated data on domestic shares (see (104) and (105)). Hence,

$$
\int_{i}^{N} l_{\Sigma_{i}} d i=\Gamma \Theta \Delta=\frac{\frac{1}{P^{(1-\gamma)(1-\sigma)}} \frac{\sigma}{(1-\gamma)(\sigma-1)} \Theta \Delta}{1+\frac{1}{P^{(1-\gamma)(1-\sigma)}} \frac{\sigma}{(1-\gamma)(\sigma-1)} \Theta \Delta} L
$$

This implies that

$$
\frac{L-\int_{i}^{N} l_{\Sigma_{i}} d i}{L}=\frac{1}{1+\frac{1}{P^{(1-\gamma)(1-\sigma)} \frac{\sigma}{(1-\gamma)(\sigma-1)} \Theta \Delta}}
$$


so that $L$ is indeed a normalization. Finally we only have to show that (116) does not depend on $q_{D}$, even though $\Theta$ does (see (109)). However, it can easily be shown that

$$
\Theta P^{(1-\gamma)(\sigma-1)}=\Upsilon^{\sigma-1} \frac{1}{\sigma}
$$

Hence, the quality of domestic varieties $q_{D}$ and the foreign price level $z$ can be normalized for the calibration.

The five models we consider fit in this framework as follows :

1. The aggregate model assumes that $\beta_{i}=\beta$ and $f_{i}=f_{I}=0$. Hence, $\int_{i}^{N} l_{\Sigma_{i}} d i=0$ and $s_{D i}=s_{D}$ can be solved from (106) using that $n=1$ (as all firms are importers and import from every country). The level of $\beta$ is chosen to match the aggregate domestic share. The dispersion in productivity $\sigma_{\varphi}$ is chosen to match the dispersion in value added.

2. The homogenous bias model assumes that $\beta_{i}=\beta$ and $f_{i}=0<f_{I}$. Hence, conditional on importing, we have that $s_{D i}=s_{D}$, which can be solved from (106) using that $n=1$. The required level $\tilde{f}_{I}$ in (111) is chosen to match the share of importers. Given a distribution of productivity $\left[\tilde{\varphi}_{i}\right]_{i}$ we can then calculate $\Delta$ from (114), $P$ from (104) and (105) and hence $\Gamma$ from (115). This is sufficient to calculate welfare using (116) and $P^{A u t} / P$.

3. The heterogeneous bias model assumes that $\beta_{i}$ varies across firms and $f_{i}=0<f_{I}$. As for the case with fixed costs, it is useful to consider a scaled version of the home-bias $\tilde{\beta}_{i}=\frac{\beta_{i}}{1-\beta_{i}}$. In particular, (106) shows that $s_{D}$ only depends on $\beta^{*}=(\tilde{\beta})^{\varepsilon}\left(\frac{1}{p}\right)^{\varepsilon-1}$ (again, we have $n=$ 1 as there are no fixed costs per country). Hence, we draw $\left(\tilde{\varphi}, \beta^{*}\right)$ from a joint log-normal distribution. Using (106), this generates a joint distribution of $\left(\tilde{\varphi}_{i}, s_{D i}\right)$. We can then calibrate $\tilde{f}_{I}$ from (111) to match the share of importers. Like for the case of the homogenous bias model, we can then use (114), $P$ and (115) to compute all equilibrium objects.

4. For the heterogenous fixed cost model, we draw $\left(\tilde{\varphi}_{i} \cdot \tilde{f}_{i}\right)$ from a joint log-normal distribution. Using the $(107)$, this implies a joint distribution of $\left(\tilde{\varphi}_{i}, s_{D i}\right)$. We can then calibrate $\tilde{f}_{I}$ from (111) to match the share of importers. As above, we can then use (114), $P$ and (115) to compute all equilibrium objects.

5. The homogenous fixed cost model, is a special case of the heterogenous fixed cost model where $\tilde{f}_{i}=\tilde{f}$. Hence, the procedure is exactly the same given a marginal distribution for $\tilde{\varphi}_{i}$. 


\section{Documents de Travail}

600. M. Mogliani and T. Ferrière, "Rationality of announcements, business cycle asymmetry, and predictability of revisions. The case of French GDP” September 2016

601. R. S.J. Koijen; F. Koulischer; B. Nguyen and M. Yogo, "Quantitative Easing in the Euro Area: The Dynamics of Risk Exposures and the Impact on Asset Prices" September 2016

602. O. de Bandt and M. Chahad, “A DGSE Model to Assess the Post-Crisis Regulation of Universal Banks” September 2016

603. C. Malgouyres, "The Impact of Chinese Import Competition on the Local Structure of Employment and Wages: Evidence from France" September 2016

604. G. Cette, J. Lopez and J. Mairesse, "Labour market regulations and capital labour substitution” October 2016

605. C. Hémet and C. Malgouyres, "Diversity and Employment Prospects: Neighbors Matter!” October 2016

606. M. Ben Salem and B. Castelletti-Font, "Which combination of fiscal and external imbalances to determine the longrun dynamics of sovereign bond yields?" November 2016

607. M. Joëts, V. Mignon and T. Razafindrabe, "Does the volatility of commodity prices reflect macroeconomic uncertainty?" November 2016

608. M. Bussière, G. Gaulier and W. Steingress, "Global Trade Flows: Revisiting the Exchange Rate Elasticities" November 2016

609. V.Coudert and J. Idier, “An Early Warning System for Macro-prudential Policy in France” November 2016

610. S. Guilloux-Nefussi, “Globalization, Market Structure and Inflation Dynamics” December 2016

611. S.Fries, J-S. Mésonnier, S. Mouabbi, and J-P. Renne, "National natural rates of interest and the single monetary policy in the Euro Area" December 2016

612. J. Blaum, C. Lelarge and M. Peters, “The Gains from Input Trade with Heterogeneous Importers” December 2016

Pour accéder à la liste complète des Documents de Travail publiés par la Banque de France veuillez consulter le site : www.banque-france.fr

For a complete list of Working Papers published by the Banque de France, please visit the website: www.banque-france.fr

Pour tous commentaires ou demandes sur les Documents de Travail, contacter la bibliothèque de la Direction Générale des Études et des Relations Internationales à l'adresse suivante :

For any comment or enquiries on the Working Papers, contact the library of the Directorate General Economics and International Relations at the following address :

BANQUE DE FRANCE

49- 1404 Labolog

75049 Paris Cedex 01

tél : $0033(0) 142977724$ ou 0142926340 ou 4890 ou 6981

email : 1404-ut@banque-france.fr 